Check for updates

Cite this: Chem. Soc. Rev., 2020, 49,6605

Received 28th April 2020

DOI: $10.1039 / \mathrm{d} 0 \mathrm{cs} 00458 \mathrm{~h}$

rsc.li/chem-soc-rev

\title{
A comparative perspective of electrochemical and photochemical approaches for catalytic $\mathrm{H}_{2} \mathrm{O}_{2}$ production
}

\begin{abstract}
Yanyan Sun, ${ }^{a}$ Lei Han ${ }^{\mathrm{b}}$ and Peter Strasser (D) *a
Hydrogen peroxide $\left(\mathrm{H}_{2} \mathrm{O}_{2}\right)$ has a wide range of important applications in various fields including chemical industry, environmental remediation, and sustainable energy conversion/storage. Nevertheless, the stark disconnect between today's huge market demand and the historical unsustainability of the currently-used industrial anthraquinone-based production process is promoting extensive research on the development of efficient, energy-saving and sustainable methods for $\mathrm{H}_{2} \mathrm{O}_{2}$ production. Among several sustainable strategies, $\mathrm{H}_{2} \mathrm{O}_{2}$ production via electrochemical and photochemical routes has shown particular appeal, because only water, $\mathrm{O}_{2}$, and solar energy/electricity are involved during the whole process. In the past few years, considerable efforts have been devoted to the development of advanced electrocatalysts and photocatalysts for efficient and scalable $\mathrm{H}_{2} \mathrm{O}_{2}$ production with high efficiency and stability. In this review, we compare and contrast the two distinct yet inherently closely linked catalytic processes, before we detail recent advances in the design, preparation, and applications of different $\mathrm{H}_{2} \mathrm{O}_{2}$ catalyst systems from the viewpoint of electrochemical and photochemical approaches. We close with a balanced perspective on remaining future scientific and technical challenges and opportunities.
\end{abstract}

\section{Introduction}

${ }^{a}$ Department of Chemistry, Technical University of Berlin, 10623 Berlin, Germany. E-mail: pstrasser@tu-berlin.de

${ }^{b}$ College of Materials Science and Engineering, Hunan University, 410082, Changsha, Hunan, China. E-mail: hanlei@hnu.edu.cn

Hydrogen peroxide $\left(\mathrm{H}_{2} \mathrm{O}_{2}\right)$ has been widely used as an ecofriendly oxidant in chemical industry and environmental treatment such as organic/inorganic chemical synthesis, pulp and paper

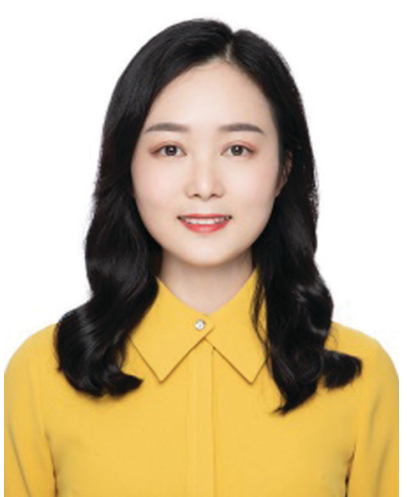

Yanyan Sun
Yanyan Sun received her PhD degree in Physical Chemistry and Electrochemistry from Technical University of Berlin (Germany) under the supervision of Prof. Peter Strasser in 2018. Currently, she is continuing her postdoctoral research with Prof. Peter Strasser. Her research focuses on the design and fabrication of carbon-based functional materials for the oxygen reduction reaction in fuel-cells and hydrogen peroxide production.

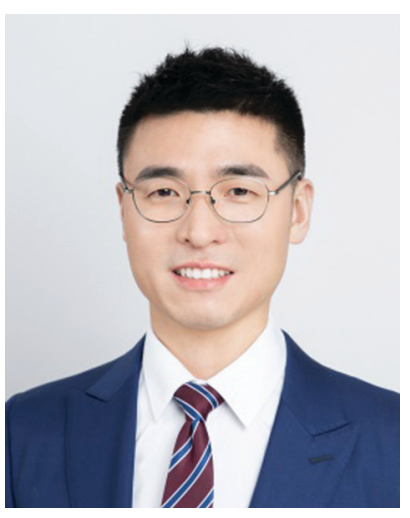

Lei Han
Lei Han is a professor at the School of Materials Science and Engineering, Hunan University, P. R. China. He received his $P h D$ degree from Changchun Institute of Applied Chemistry, Chinese Academy of Sciences, under the supervision of Prof. Shaojun Dong in 2015. After that, he did postdoctoral research at the Nanyang Technological University, University of Waterloo, and Free University of Berlin before joining Hunan University in 2018. His research interests include the design and application of nanostructured materials for solar energy conversion and storage systems including photocatalysis, photoelectrochemical devices and oxygen electrochemistry. 
bleaching, medical disinfection and wastewater treatment. ${ }^{1-5}$ Moreover, $\mathrm{H}_{2} \mathrm{O}_{2}$ could also be utilized as an ideal oxidant and sustainable energy carrier alternative to oxygen and hydrogen in fuel cells since it possesses the advantages of easy storage and safe operation, high oxidation potential, and only water as a by-product. ${ }^{6,7}$ Currently, the well-established industrial anthraquinone-based method for $\mathrm{H}_{2} \mathrm{O}_{2}$ production involves the hydrogenation and oxidation of the anthraquinone molecule, and extraction, purification and concentration of $\mathrm{H}_{2} \mathrm{O}_{2}$ solution. ${ }^{4}$ This method is very beneficial for the large-scale production of highly concentrated $\mathrm{H}_{2} \mathrm{O}_{2}$, but there are still some serious sustainability challenges to be solved. First, this method involves a sequential multi-step procedure including many purification steps, thus consuming a significant amount of energy and resources. Moreover, the use of a large amount of $\mathrm{H}_{2}$ during the hydrogenation step leads to difficulty in handling and storage. The by-products of anthraquinone/anthrahydroquinone require the use of a large amount of organic solvents during the process, which will become waste at the end. Furthermore, highly concentrated $\mathrm{H}_{2} \mathrm{O}_{2}$ is a hazardous chemical and requires great caution in transport, handling and storage, leading to an increase in cost and some safety issues. Alternatively, considerable efforts have been dedicated to developing the direct production of $\mathrm{H}_{2} \mathrm{O}_{2}$ from a mixture of $\mathrm{H}_{2}$ and $\mathrm{O}_{2}$ using chemical catalysts. ${ }^{8-11}$ However, to catalyze this reaction, noblemetal-based catalysts such as Pd, Au and their alloys are needed, which is a potential barrier in view of scale-up practical applications owing to their high cost and low abundance. Moreover, the activity and selectivity toward $\mathrm{H}_{2} \mathrm{O}_{2}$ production are also quite low, because water production is thermodynamically more favorable

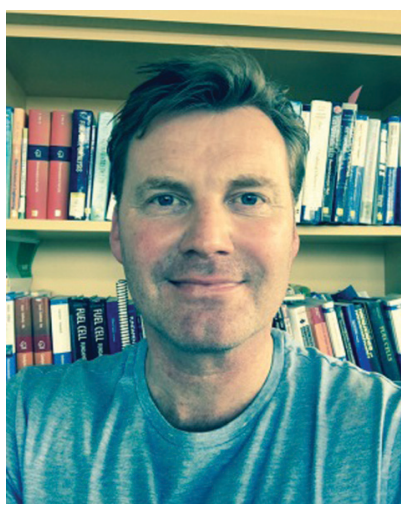

Peter Strasser is the chaired professor of "Electrochemistry and Electrocatalysis" in the Department of Chemistry at the Technical University of Berlin. Prior to his appointment, he was Assistant Professor at the Department of Chemical and Biomolecular Engineering at the University of Houston, after he served as Postdoctoral Scientist and later Senior Member of staff at Symyx Technologies, Inc., Santa Clara, USA. He earned his PhD in Physical Chemistry and Electrochemistry from the FritzHaber-Institute of the Max-Planck-Society in Berlin under the direction of Gerhard Ertl. He studied chemistry at Stanford University, the University of Tübingen, Germany, and the University of Pisa, Italy. He was awarded the ISE "Brian Conway Prize" in Physical Electrochemistry, the IAHE "Sir William Grove", award, the "Otto-Roelen" medal by the German Catalysis Society, the "Ertl Prize", as well as the "Otto-Hahn Research Medal" by the Max-Planck Society. than $\mathrm{H}_{2} \mathrm{O}_{2}$ production. Last but not least, the incoming feed of $\mathrm{H}_{2}$ and $\mathrm{O}_{2}$ constitutes an explosive and potentially hazardous mixture. To avoid this last issue, hydrogen-permeable membranes possessing catalytic activity have also been developed, ${ }^{12}$ which are generally made of thin Pd and Pd-Ag alloy membranes, Pd-coated V, Nb, or Mo metal membranes, and porous inorganic membranes. These bi-functional membranes enable the direct production of $\mathrm{H}_{2} \mathrm{O}_{2}$ without mixing $\mathrm{H}_{2}$ and $\mathrm{O}_{2}$. However, they lack sufficient stability and reproducibility, and have thus remained unattractive for industrial-scale production of $\mathrm{H}_{2} \mathrm{O}_{2}$ at the moment. Another important aspect that needs to be considered in the development of a future, sustainable synthetic $\mathrm{H}_{2} \mathrm{O}_{2}$ process is down-scalability of the process and product, that is, the direct production of dilute $\mathrm{H}_{2} \mathrm{O}_{2}$ from $\mathrm{O}_{2}$ or $\mathrm{H}_{2} \mathrm{O}$ locally and on smaller scales. Dilute $\mathrm{H}_{2} \mathrm{O}_{2}$ is more suitable for a wide range of applications, and also addresses the safety issue and largely decreases the cost mentioned above.

The electricity- and light-driven oxygen reduction reaction (ORR) and/or water oxidation reaction (WOR) through protoncoupled electron transfer (PCET) have been considered to be appealing processes for direct efficient and economic $\mathrm{H}_{2} \mathrm{O}_{2}$ production, chiefly because they merely require water, $\mathrm{O}_{2}$, and solar/electric energy, ${ }^{13-22}$ and enable scalable $\mathrm{H}_{2} \mathrm{O}_{2}$ production without $\mathrm{H}_{2} / \mathrm{O}_{2}$ gas explosion risks, thus dramatically decreasing the cost of transport, storage and handling of highly concentrated $\mathrm{H}_{2} \mathrm{O}_{2}$. The ORR process plays critical roles in various sustainable energy conversion/storage devices such as rechargeable fuel cells and rechargeable metal-air batteries. ${ }^{23-26}$ Generally, there are three kinds of reaction pathway during the ORR process (eqn (1)-(3)): (1) the four-electron ORR for water production; (2) the two-electron ORR for $\mathrm{H}_{2} \mathrm{O}_{2}$ production; and (3) the one-electron $\mathrm{ORR}$ to ${ }^{\bullet} \mathrm{OOH}$. It should be mentioned that all the reduction potentials in the present work are relative to the standard hydrogen electrode (SHE) without a special statement. Nevertheless, massive efforts have been made to develop highly advanced four-electron ORR catalysts for boosting this reaction and thus maximizing the energy conversion efficiency of devices, probably because $\mathrm{H}_{2} \mathrm{O}_{2}$ production could result in low energy conversion efficiency and cause instability issues such as catalyst corrosion and chemical degradation of the polymer electrolyte membrane in a proton-exchange membrane fuel cell (PEMFC) resulting from the self-decomposition of the produced $\mathrm{H}_{2} \mathrm{O}_{2} \cdot{ }^{27}$ Moreover, the four-electron ORR process $\left(+1.23 \mathrm{~V}_{\mathrm{SHE}}\right)$ is thermodynamically favored compared to the two-electron ORR process $\left(+0.68 \mathrm{~V}_{\mathrm{SHE}}\right)$ due to its more positive equilibrium potential. Recently, the direct electrochemical two-electron ORR for $\mathrm{H}_{2} \mathrm{O}_{2}$ production began to receive increasing attention from the perspective of chemical synthesis purposes. $\mathrm{H}_{2} \mathrm{O}_{2}$ production through the electrochemical two-electron ORR process can be performed in several types of electrochemical devices such as electrolytic cells, ${ }^{15}$ fuel cells, ${ }^{28,29}$ and microbial fuel cells. ${ }^{30,31}$ In an aqueous electrolytic device, $\mathrm{H}_{2} \mathrm{O}_{2}$ production can be achieved through the electrolysis of water and $\mathrm{O}_{2}$, where the anodic half-cell reaction proceeds by water oxidation and the cathodic half-cell reaction proceeds by the ORR. It should be here highlighted that on-site production of $\mathrm{H}_{2} \mathrm{O}_{2}$ has been achieved at the point of use 
through electrochemical generation devices by the HPNow company. ${ }^{32}$ Moreover, electrolyte-free $\mathrm{H}_{2} \mathrm{O}_{2}$ could also be obtained in the case of using a solid polymer electrolyte. ${ }^{1,15}$ Besides, in combination with intermittent renewable power sources like solar or wind, $\mathrm{H}_{2} \mathrm{O}_{2}$ could be produced in an ecofriendly fashion without additional energy input. What's more, electrochemical devices also enable in situ, on-demand $\mathrm{H}_{2} \mathrm{O}_{2}$ production for some practical applications, thus avoiding the cost of storage and transportation. In particular, if the twoelectron ORR process is carried out in fuel cells and microbial fuel cells, additional chemical electricity could be recovered along with $\mathrm{H}_{2} \mathrm{O}_{2}$ production. Meanwhile, in the fuel cell system, the potential for explosion could be avoided due to the separation of $\mathrm{O}_{2}$ and $\mathrm{H}_{2}$ by an ion-exchange membrane. Additionally, in the microbial fuel cell system, some organic compounds in wastewater could be directly oxidized by electrochemically active bacteria on the anode, thus achieving simultaneously wastewater treatment. In contrast, differently from the two-electron ORR process, the direct two-electron WOR has recently also attracted growing interest for electrochemical on-site production of $\mathrm{H}_{2} \mathrm{O}_{2}$ recently since it requires only the use of water as a raw material and enables the simultaneous production of valuable $\mathrm{H}_{2}$ at the cathode by a single water electrolysis device. Similarly, there are generally three reaction pathways during the WOR process (eqn (4)-(6), e.g. in acid electrolyte), ${ }^{33}$ including the one-electron pathway to form ${ }^{\circ} \mathrm{OH}$, the two-electron pathway for $\mathrm{H}_{2} \mathrm{O}_{2}$ production and the four-electron pathway for $\mathrm{O}_{2}$ evolution. Among these three water oxidation routes, currently, most research has mainly focused on the development of oxygen electrocatalysts for promoting the four-electron WOR (also called the oxygen evolution reaction, OER) since the OER is an important half-reaction in electrochemical water splitting and rechargeable metal-air batteries. ${ }^{34}$ So, improvement of the catalyst is necessary to achieve efficient energy conversion and storage. In contrast, two-electron water oxidation to $\mathrm{H}_{2} \mathrm{O}_{2}$ production has been long overlooked. This may be because the equilibrium potential of the two-electron WOR $\left(+1.77 \mathrm{~V}_{\mathrm{SHE}}\right)$ is thermodynamically higher than that of the four-electron WOR (+1.23 $\left.\mathrm{V}_{\mathrm{SHE}}\right)$. Therefore, the critical challenge for this route lies in the development of effective WOR catalysts capable of significantly promoting the two-electron pathway and suppressing the thermodynamically favorable four-electron pathway owing to its more negative potential.

$$
\begin{array}{cc}
\mathrm{O}_{2}+4 \mathrm{H}^{+}+4 \mathrm{e}^{-} \rightarrow 2 \mathrm{H}_{2} \mathrm{O} & E^{0}=+1.23 \mathrm{~V}_{\mathrm{SHE}} \\
\mathrm{O}_{2}+2 \mathrm{H}^{+}+2 \mathrm{e}^{-} \rightarrow \mathrm{H}_{2} \mathrm{O}_{2} & E^{0}=+0.68 \mathrm{~V}_{\mathrm{SHE}} \\
\mathrm{O}_{2}+\mathrm{H}^{+}+\mathrm{e}^{-} \rightarrow \cdot{ }^{\bullet} \mathrm{OOH} \quad E^{0}=-0.13 \mathrm{~V}_{\mathrm{SHE}} \\
\mathrm{H}_{2} \mathrm{O} \rightarrow \cdot \mathrm{OH}+\mathrm{H}^{+}+\mathrm{e}^{-} \quad E^{0}=+2.73 \mathrm{~V}_{\mathrm{SHE}} \\
2 \mathrm{H}_{2} \mathrm{O} \rightarrow \mathrm{H}_{2} \mathrm{O}_{2}+2 \mathrm{H}^{+}+2 \mathrm{e}^{-} \quad E^{0}=+1.77 \mathrm{~V}_{\mathrm{SHE}} \\
2 \mathrm{H}_{2} \mathrm{O} \rightarrow \mathrm{O}_{2}+4 \mathrm{H}^{+}+4 \mathrm{e}^{-} \quad E^{0}=+1.23 \mathrm{~V}_{\mathrm{SHE}}
\end{array}
$$

On the other hand, $\mathrm{H}_{2} \mathrm{O}_{2}$ production could also be achieved through the photocatalytic process in aqueous solution, ${ }^{5,20,21,35,36}$ which mainly involved light absorption, photo-generated carrier separation (also called electrons and holes), and interfacial carrier transfer to drive the corresponding reactions over the surface of semiconductor photocatalysts. During the process, the photogenerated holes from the valence band could oxidize water into $\mathrm{O}_{2}$, whereas the photo-generated electrons from the conduction band perform the two-electron ORR into $\mathrm{H}_{2} \mathrm{O}_{2} \cdot{ }^{37-39}$ Nevertheless, the key challenge for the achievement of solar-to- $\mathrm{H}_{2} \mathrm{O}_{2}$ conversion lies in the design and development of highly efficient, stable, lowcost photocatalysts with appropriate band structure capable of promoting both water oxidation and a selective two-electron ORR under moderate reaction conditions. Besides, the photoelectrochemical (PEC) two-electron WOR has also been developed as an efficient and sustainable route for $\mathrm{H}_{2} \mathrm{O}_{2}$ production, especially significantly improving the overall energy conversion efficiency of PEC devices by coupling with other cathodic reduction reactions like the hydrogen evolution reaction (HER) and two-electron ORR. ${ }^{5,40}$ In addition to this, careful observation demonstrates an interesting internal connection between the electrochemical and photochemical routes, that is, both routes involve a two-electron ORR process to achieve $\mathrm{H}_{2} \mathrm{O}_{2}$ production stimulated by external energy like solar energy/electricity. Therefore, it could be deduced that the incorporation of twoelectron ORR electrocatalysts into photocatalytic systems as co-catalysts will also be beneficial to improve the efficiency of $\mathrm{H}_{2} \mathrm{O}_{2}$ production by promoting the surface charge transfer on the surface of semiconductor photocatalysts.

Since the ORR is an inherently sluggish process involving proton-coupled multi-electron transfer and multiple reaction paths, ${ }^{1,18,24}$ a highly efficient and selective ORR for $\mathrm{H}_{2} \mathrm{O}_{2}$ production via the electrochemical and photochemical methods remains a significant challenge and faces many fundamental scientific and technical hurdles. ${ }^{1,13}$ The first study on electrochemical production of $\mathrm{H}_{2} \mathrm{O}_{2}$ came from Traube in 1887, who produced $\mathrm{H}_{2} \mathrm{O}_{2}$ from $\mathrm{O}_{2}$ at a $\mathrm{Hg}-\mathrm{Au}$ electrode. ${ }^{41}$ Subsequently, Berl et al. reported the electrochemical performances of a carbon electrode for $\mathrm{H}_{2} \mathrm{O}_{2}$ production in 1939. ${ }^{42}$ After that, there was a long time in which most research mainly focused on the investigation of experimental influencing parameters on the $\mathrm{H}_{2} \mathrm{O}_{2}$ production in electrochemical devices, such as high internal resistance and a low concentration of oxygen dissolved in the electrolyte. ${ }^{43,44}$ Some methods have also been developed to solve these issues above, including the usage of gas diffusion electrodes, ${ }^{43}$ an applied external voltage,${ }^{30}$ and buffered electrolytes, and reducing the distance between the anode and the cathode. ${ }^{45}$ In contrast, little attention was paid to the development of cost-effective advanced two-electron ORR catalysts with high catalytic activity, selectivity, and stability, which is actually also very important for $\mathrm{H}_{2} \mathrm{O}_{2}$ production. Recently, various ORR catalysts toward $\mathrm{H}_{2} \mathrm{O}_{2}$ production have sprung up including noble-metal-based materials, transition-metal-based materials, and metal-free carbon-based materials. Besides, some metal oxides such as $\mathrm{ZnO}, \mathrm{WO}_{3}, \mathrm{SnO}_{2}, \mathrm{BiVO}_{4}$, and $\mathrm{TiO}_{2}$ have been both theoretically estimated and experimentally investigated as potential catalyst candidates for $\mathrm{H}_{2} \mathrm{O}_{2}$ production from twoelectron water oxidation. On the other hand, the history of photocatalytic $\mathrm{H}_{2} \mathrm{O}_{2}$ production can be traced back to the 20th 
century. Baur and Neuweiler first observed the photo-driven ORR for $\mathrm{H}_{2} \mathrm{O}_{2}$ production over $\mathrm{ZnO}$ in the presence of glycerine and glucose under light illumination in $1927 .{ }^{46}$ In subsequent years, various photocatalysts were developed to catalyze $\mathrm{H}_{2} \mathrm{O}_{2}$ production through the two-electron ORR, including metal oxides, metal-organic frameworks or coordination polymers, and metal-free graphitic carbon nitride $\left(\mathrm{g}-\mathrm{C}_{3} \mathrm{~N}_{4}\right)$. Meanwhile, some photoelectrochemical systems based on electrocatalysts and photocatalysts have been designed and developed for $\mathrm{H}_{2} \mathrm{O}_{2}$ production. In the past few years, considerable research efforts were reported with a focus on the electrocatalytic and photocatalytic production of $\mathrm{H}_{2} \mathrm{O}_{2}$, and many exciting results have been achieved that merit a careful review to establish the conceptual links between the recent advances in materials and methodologies.

This review begins with a brief introduction of the fundamentals principles and some important parameters for evaluating the catalytic performances of electricity/photo-driven ORR and WOR catalysts designed for $\mathrm{H}_{2} \mathrm{O}_{2}$ production. Thereafter, we summarize recent progress in the design, preparation, and applications of different catalysts for $\mathrm{H}_{2} \mathrm{O}_{2}$ production from the perspective of electrochemical and photochemical routes. Finally, the critical challenges and opportunities for future development in this field are also presented. We hope that this review could provide guidance for the design and preparation of novel electricity/photo-driven ORR and WOR catalysts with high performance, and promote their practical applications in energy conversion/storage systems.

\section{Fundamentals of electrocatalytic and photocatalytic $\mathrm{H}_{2} \mathrm{O}_{2}$ production}

Electrocatalytic and photocatalytic $\mathrm{H}_{2} \mathrm{O}_{2}$ production through the ORR and WOR processes are both thermodynamically uphill reactions. What complicates the $\mathrm{H}_{2} \mathrm{O}_{2}$ production chemistry further is the fact that there are several competing reduction products (e.g. $\mathrm{H}_{2} \mathrm{O}, \mathrm{H}_{2} \mathrm{O}_{2}$, and ${ }^{\bullet} \mathrm{O}_{2}{ }^{-}$) formed via distinct reaction pathways of the ORR and WOR processes with one-, two- and four-electron transfer. The dominant reaction pathway is mainly determined by the nature of the electrocatalysts and photocatalysts as well as the experimental conditions. ${ }^{47-49}$ As a result of these competing reaction pathways, electrocatalytic and photocatalytic $\mathrm{H}_{2} \mathrm{O}_{2}$ production face severe challenges in terms of low energy efficiency and limited Faradaic efficiency (chemical selectivity).

\subsection{Fundamentals of electrocatalytic $\mathrm{H}_{2} \mathrm{O}_{2}$ production}

The mechanism of the ORR process has been widely investigated. Following a popular 4-step proton-coupled electron transfer mechanism from the early $2000 \mathrm{~s}$, the process involves three reaction intermediates $\left(\mathrm{HOO}^{*}, \mathrm{O}^{*}\right.$, and $\left.\mathrm{HO}^{*}\right)$ and proceeds as follows in acid medium: ${ }^{50}$

$$
\begin{gathered}
\mathrm{O}_{2}+\mathrm{H}^{+}+\mathrm{e}^{-}+* \rightarrow \mathrm{HOO}^{*} \\
\mathrm{HOO}^{*}+\mathrm{H}^{+}+\mathrm{e}^{-} \rightarrow \mathrm{O}^{*}+\mathrm{H}_{2} \mathrm{O}
\end{gathered}
$$

$$
\begin{gathered}
\mathrm{O}^{*}+\mathrm{H}^{+}+\mathrm{e}^{-} \rightarrow \mathrm{HO}^{*}+\mathrm{H}_{2} \mathrm{O} \\
\mathrm{HO}^{*}+\mathrm{H}^{+}+\mathrm{e}^{-} \rightarrow^{*}+\mathrm{H}_{2} \mathrm{O}
\end{gathered}
$$

By contrast, only one reaction intermediate $\left(\mathrm{HOO}^{*}\right)$ is involved in the two-electron process as the following steps in acid medium: ${ }^{50}$

$$
\begin{gathered}
\mathrm{O}_{2}+\mathrm{H}^{+}+\mathrm{e}^{-}+{ }^{*} \rightarrow \mathrm{HOO}^{*} \\
\mathrm{HOO}^{*}+\mathrm{H}^{+}+\mathrm{e}^{-} \rightarrow{ }^{*}+\mathrm{H}_{2} \mathrm{O}_{2}
\end{gathered}
$$

where ${ }^{*}$ denotes a bare surface active site. It can be seen that the two kinds of ORR reaction pathway both involve the reaction intermediate $\mathrm{HOO}^{*}$, so balanced binding of $\mathrm{HOO}^{*}$ on the surface of catalysts is very necessary to produce $\mathrm{H}_{2} \mathrm{O}_{2}$ through preventing the breakage of the $\mathrm{O}-\mathrm{O}$ bond during the ORR process. ${ }^{2,51}$ In practice, there are some important parameters to be measured and/or calculated for the evaluation and comparison of the catalytic performances of new ORR catalysts, including the catalytic activity and selectivity of the desired $\mathrm{H}_{2} \mathrm{O}_{2}$ production reaction, the competing catalytic activity toward the $\mathrm{H}_{2} \mathrm{O}_{2}$ reduction reaction, the $\mathrm{H}_{2} \mathrm{O}_{2}$ productivity and Faradaic efficiency, and finally the catalyst stability.

The catalytic activity and selectivity toward $\mathrm{H}_{2} \mathrm{O}_{2}$ production can be evaluated using the Rotating Ring-Disk Electrode (RRDE) technique. For the RRDE technique, linear sweep voltammetry (LSV) was generally performed on the disk electrode with a constant applied potential on the ring electrode (e.g. $+1.2 \mathrm{~V}_{\mathrm{RHE}}$ ) for detecting the $\mathrm{H}_{2} \mathrm{O}_{2}$ produced on the disk electrode. So, the current assigned to the production of $\mathrm{H}_{2} \mathrm{O}_{2}$ $\left(I_{\mathrm{H} 2 \mathrm{O} 2}\right.$, in units of $\left.\mathrm{mA}\right)$ can be calculated from the ring current ( $I_{\text {ring }}$, in units of $\mathrm{mA}$ ) and the electrode geometry-dependent collection efficiency $(N)$ of the ring electrode as follows:

$$
I_{\mathrm{H}_{2} \mathrm{O}_{2}}=\frac{I_{\text {ring }}}{N} .
$$

Whereas, the disk current $\left(I_{\text {disk }}\right.$, in units of $\left.\mathrm{mA}\right)$ is the sum of the two-electron $I_{\mathrm{H} 2 \mathrm{O} 2}$ and the four-electron $I_{\mathrm{H} 2 \mathrm{O}}$ (the current attributed to the production of $\mathrm{H}_{2} \mathrm{O}$ ), that is,

$$
I_{\text {disk }}=I_{\mathrm{H} 2 \mathrm{O} 2}+I_{\mathrm{H} 2 \mathrm{O}}
$$

The $\mathrm{H}_{2} \mathrm{O}_{2}$ selectivity with respect to the conversion of molecular oxygen, assuming negligible electroreduction of $\mathrm{H}_{2} \mathrm{O}_{2}$ to $\mathrm{H}_{2} \mathrm{O}$, can be calculated from the molar flux rates of $\mathrm{O}_{2}$ according to the following equations: ${ }^{18,52}$

$$
\begin{gathered}
n_{\mathrm{H}_{2} \mathrm{O}_{2}}=\frac{I_{\mathrm{H}_{2} \mathrm{O}_{2}}}{2 F} . \\
n_{\mathrm{H}_{2} \mathrm{O}}=\frac{I_{\mathrm{H}_{2} \mathrm{O}}}{4 F} . \\
\mathrm{H}_{2} \mathrm{O}_{2} \%=\frac{n_{\mathrm{H}_{2} \mathrm{O}_{2}}}{n_{\mathrm{H}_{2} \mathrm{O}_{2}}+n_{\mathrm{H}_{2} \mathrm{O}}}=\frac{2 \times I_{\text {ring }}}{N \times\left|I_{\text {disk }}\right|+I_{\text {ring }}} .
\end{gathered}
$$

Under certain assumptions, the accurate number of transferred electrons $(n)$ during the ORR process can be calculated 
according to the Koutechy-Levich equation: ${ }^{52,53}$

$$
\frac{1}{j}=\frac{1}{j_{\mathrm{k}}}+\frac{1}{\left(0.62 n F C_{0}\left(D_{0}\right)^{2 / 3} \nu^{-1 / 6} \omega^{1 / 2}\right)} .
$$

Here $j$ is the measured current density $\left(\mathrm{mA} \mathrm{cm}{ }^{-2}\right), j_{\mathrm{k}}$ is the kinetic current density $\left(\mathrm{mA} \mathrm{cm}^{-2}\right), n$ is the number of electrons transferred, $F$ is the Faraday constant (96485 $\mathrm{C} \mathrm{mol}^{-1}$ ), $D_{0}$ is the diffusion coefficient of oxygen in the electrolyte $\left(\mathrm{cm}^{2} \mathrm{~s}^{-1}\right), C_{0}$ is the bulk concentration of oxygen in the electrolyte $\left(\mathrm{mol} \mathrm{cm}{ }^{-3}\right)$, $\nu$ is the kinetic viscosity of the electrolyte $\left(\mathrm{cm}^{2} \mathrm{~s}^{-1}\right)$, and $\omega$ is the angular velocity of the disk $(\omega=2 \pi N, N$ is the linear rotation speed (rpm)).

The produced $\mathrm{H}_{2} \mathrm{O}_{2}$ may be further catalytically reduced to $\mathrm{H}_{2} \mathrm{O}$ by the ORR catalyst, which is detrimental for overall $\mathrm{H}_{2} \mathrm{O}_{2}$ production. Starting from this point, the catalytic activity toward the $\mathrm{H}_{2} \mathrm{O}_{2}$ reduction reaction $\left(\mathrm{H}_{2} \mathrm{O}_{2} \mathrm{RR}\right)$ also needs to be investigated for accurately evaluating the actual $\mathrm{H}_{2} \mathrm{O}_{2}$ production capacity. Typically, the evaluation of the $\mathrm{H}_{2} \mathrm{O}_{2} \mathrm{RR}$ was performed under the same conditions as the ORR measurement except the addition of $\mathrm{H}_{2} \mathrm{O}_{2}$ in the nitrogen-saturated electrolyte. $^{18}$

The evaluation of the $\mathrm{H}_{2} \mathrm{O}_{2}$ productivity in various reaction media has been typically performed in membrane-separated two-compartment $\mathrm{H}$-cells, $\mathrm{H}_{2} / \mathrm{O}_{2}$ fuel cells or electrolysis cells by measuring the concentration of the produced $\mathrm{H}_{2} \mathrm{O}_{2}$ at the cathode within defined time intervals. During this process, one of the biggest problems facing ORR routes to $\mathrm{H}_{2} \mathrm{O}_{2}$ production is the low solubility of $\mathrm{O}_{2}$ in various electrolytes, such as the bulk concentration of $\mathrm{O}_{2}$ up to $1.2 \mathrm{mM}$ in $0.1 \mathrm{M} \mathrm{KOH}$ and $1.1 \mathrm{mM}$ in $0.5 \mathrm{M} \mathrm{H}_{2} \mathrm{SO}_{4} \cdot{ }^{54}$ Moreover, the solubility of $\mathrm{O}_{2}$ decreases with increasing the temperature and the concentration of the electrolyte but increases as the pressure increases. In order to solve this issue efficiently, gas diffusion layers (GDLs) modified with ORR catalysts (then referred to as gas diffusion electrodes, GDEs) have been recently deployed to promote the mass transport of $\mathrm{O}_{2}$. Enhanced mass transport and larger local $\mathrm{O}_{2}$ concentrations at the catalyst surface prolonged the contact time of $\mathrm{O}_{2}$ with the catalyst surface at a 3-phase interface (solid catalyst, liquid solvent/electrolyte, and gaseous oxygen), further supported by unique porous and hydrophobic structures, ultimately resulting in enhanced space time yields of $\mathrm{H}_{2} \mathrm{O}_{2}$ by the ORR. ${ }^{18,43}$ To date, most of the investigated ORR catalysts as cathodes in these systems were commercial carbon-based materials (e.g. active carbon and vapor-grown-carbon-fiber) ${ }^{55}$ and metal complexes (e.g. iron and cobalt-phthalocyanine). ${ }^{56,57}$ Moreover, some researchers demonstrated that electrolyte-free neutral $\mathrm{H}_{2} \mathrm{O}_{2}$ solution can also be obtained through the use of a solid polymer electrolyte (SPE), which is more useful and flexible for practical applications. ${ }^{29,58}$ Besides, continuous electrolytic flow reactors, also called flow-through electrolyzer cells, overcame the above issues of mass transport by continuously circulating the reactants and products to and away from the electrodes, and inhibit the subsequent decomposition of $\mathrm{H}_{2} \mathrm{O}_{2}$ due to the accumulation of $\mathrm{H}_{2} \mathrm{O}_{2}$, thus resulting in an increased amount of produced $\mathrm{H}_{2} \mathrm{O}_{2} \cdot{ }^{18,43,59}$

The $\mathrm{H}_{2} \mathrm{O}_{2}$ concentration within certain time intervals can be determined by the UV-vis spectrophotometric method, and chemical titration of potassium permanganate or iodometry solution, ${ }^{60,61}$ as well as by the chemiluminescence method based on the catalytic oxidation of luminol by hydrogen peroxide. ${ }^{14}$ Among these methods, the UV-vis spectrophotometric method has been well developed and only requires the use of a spectrophotometer with easy operation and low-cost. Moreover, several indicators have been proposed for the measurement of the $\mathrm{H}_{2} \mathrm{O}_{2}$ concentration including ammonium molybdate/KI solution, ${ }^{62}$ potassium titanium(Iv) oxalate, ${ }^{30}$ TiOSO $_{4}{ }^{18}$ and a commercial hydrogen peroxide test. ${ }^{63}$ Nevertheless, this method is only suitable for the determination of low-concentration hydrogen peroxide, so in order to ensure accuracy, further dilution is generally necessary prior to measurement. Besides, standard solutions of $\mathrm{H}_{2} \mathrm{O}_{2}$ also need to be prepared and measured to obtain the calibration curve. In contrast, the operation of chemical titration is relatively simple without the need for a calibration curve and suitable for high-concentration hydrogen peroxide, whereas the accuracy may be inferior to the spectrophotometric method. Differently, additional flow-injection is needed during the measurement for the chemiluminescence method, which makes the overall operation complex.

The $\mathrm{H}_{2} \mathrm{O}_{2}$ production Faradaic efficiency $\left(\mathrm{H}_{2} \mathrm{O}_{2} \mathrm{FE}\right)$ can then be calculated by dividing the charge transferred to the produced $\mathrm{H}_{2} \mathrm{O}_{2}$ by the total charge passed through the circuit as the following equation: ${ }^{63}$

$$
\mathrm{H}_{2} \mathrm{O}_{2} \mathrm{FE}(\%)=\frac{2 \times C \times V \times F}{Q} .
$$

Here $C$ is the $\mathrm{H}_{2} \mathrm{O}_{2}$ concentration $\left(\mathrm{mol} \mathrm{L}^{-1}\right), V$ is the volume of electrolyte (L), $F$ is the Faraday constant (96485 $\mathrm{C} \mathrm{mol}^{-1}$ ), and $Q$ is the amount of charge passed (C).

In addition to the catalytic activity and selectivity above, long-term stability is also of importance for any $\mathrm{H}_{2} \mathrm{O}_{2}$ production catalysts in practical applications. In this regard, there are two reported methods for the evaluation of the catalytic stability of catalysts including chronoamperometry (CA) or chronopotentiometry (CP), and accelerated durability tests (ADTs).

Similar to the ORR process, the WOR process also involves three oxygenated reaction intermediates on the surface of catalysts including $\mathrm{O}^{*}, \mathrm{HO}^{*}$, and $\mathrm{HOO}^{*}{ }^{33,64}$ The activity and selectivity of the WOR process are related to the adsorption free energies of these relevant intermediates $\left(\Delta G_{\mathrm{O}^{*}}, \Delta G_{\mathrm{HO}^{*}}\right.$, and $\left.\Delta G_{\mathrm{HOO}^{*}}\right)$, and theoretical results demonstrated that the proper range of $\Delta G_{\mathrm{HO}^{*}}$ from $1.6 \mathrm{eV}$ to $2.4 \mathrm{eV}$ is beneficial for $\mathrm{H}_{2} \mathrm{O}_{2}$ production, especially with zero theoretical over-potential under the condition of $\Delta G_{\mathrm{HO}^{*}} \approx 1.76 \mathrm{eV}$. Generally, there are also some parameters for evaluating the performances of WOR catalysts toward $\mathrm{H}_{2} \mathrm{O}_{2}$ production, including the onset potential, selectivity or Faradaic efficiency, and stability. For the onset potential, there are two kinds of different definition, that is, the experimental potential at a current density of 
$0.2 \mathrm{~mA} \mathrm{~cm} \mathrm{~cm}^{-2}$ and the experimental potential for the $\mathrm{H}_{2} \mathrm{O}_{2}$ concentration to go up to $1 \mathrm{ppm}$ after testing for $10 \mathrm{~min}$, respectively. ${ }^{64}$ The Faradaic efficiency for $\mathrm{H}_{2} \mathrm{O}_{2}$ production via the WOR process could be calculated in a similar manner to the ORR process, that is, the ratio between the amount of experimentally produced $\mathrm{H}_{2} \mathrm{O}_{2}$ and the theoretically calculated $\mathrm{H}_{2} \mathrm{O}_{2}$ according to the current density. ${ }^{65}$ Also, the stability could be evaluated by the CA or CP method.

\subsection{Fundamentals of photocatalytic $\mathrm{H}_{2} \mathrm{O}_{2}$ production}

Typically, there are five continuous steps over a semiconductor photocatalyst during the photocatalytic $\mathrm{H}_{2} \mathrm{O}_{2}$ production process, including light harvesting, photo-generated carrier separation, $\mathrm{O}_{2}$ adsorption, surface redox reactions and $\mathrm{H}_{2} \mathrm{O}_{2}$ desorption. Electrons and holes are firstly generated from the valence band and conduction band within the semiconductor photocatalyst under illumination with incident photons with energy identical to its band gap. In order to better utilize solar energy, it is thus very necessary to develop visible-light-driven semiconductor photocatalysts since about $40 \%$ of the solar spectrum is located in the visible light region. Besides, the use of UV light also induces the decomposition of the produced $\mathrm{H}_{2} \mathrm{O}_{2}$ on the surface of the semiconductor photocatalyst. ${ }^{66}$ Prior to participation in the subsequent redox reactions, photo-generated electrons and holes first need to be separated with the minority carrier being transferred to the surface of the semiconductor photocatalyst. Charge recombination is a competing detrimental process, which is influenced by several factors such as the crystallinity, morphology, and surface properties of the photocatalyst. ${ }^{36,39}$ The proper modification of material structures is the most effective way to improve the overall photocatalytic efficiency by means of regulating the separation and recombination processes of photo-generated carriers. After transferring to the surface, photo-generated electrons and holes can drive the ORR to either $\mathrm{H}_{2} \mathrm{O}_{2}$ or the superoxide radical $\left({ }^{\bullet} \mathrm{OOH}\right)$, while catalyzing water oxidation to molecular oxygen, respectively. ${ }^{37,67}$ Conduction band edge positions located between the redox potential of oxygen reduction to $\mathrm{H}_{2} \mathrm{O}_{2}\left(+0.68 \mathrm{~V}_{\mathrm{SHE}}\right)$ and ${ }^{\bullet} \mathrm{OOH}$ $\left(-0.13 \mathrm{~V}_{\mathrm{SHE}}\right)$ are most favorable for $\mathrm{H}_{2} \mathrm{O}_{2}$ production. ${ }^{37,68}$ At the same time, regardless of $\mathrm{H}_{2} \mathrm{O}_{2}$ and ${ }^{\circ} \mathrm{OOH}$ production, the valence band edge position should be more positive than the redox potential of water oxidation $\left(+1.23 \mathrm{~V}_{\mathrm{SHE}}\right)$, which is energetically favorable for water oxidation. In practice, kinetic over-potentials are inevitable during these electrochemical processes. In this regard, considerable efforts have been devoted to engineering the band structure of semiconductor photocatalysts by means of heteroatom-doping, surface modification, and the formation of hetero-junctions, aiming at meeting the ideal requirements. Especially, the incorporation of two-electron ORR or water oxidation catalysts as co-catalysts could significantly accelerate the kinetic process of the interfacial redox reaction, and thus facilitate charge transfer and separation, clearly demonstrating the close connection between electrocatalysis and photocatalysis.

Photocatalytic $\mathrm{H}_{2} \mathrm{O}_{2}$ production is usually performed with the photocatalyst suspended in a mixture of water and an electron donor such as ethanol, methanol, formic acid, and 2-propanol under illumination. It should be noted that the use of electron donors leads to difficulties in the subsequent separation of $\mathrm{H}_{2} \mathrm{O}_{2}$, which is why it is highly desirable to develop a photocatalytic system without the need for an electron donor. In addition, semiconductor photocatalysts have also been used to fabricate photoelectrodes for photoelectrochemical production of $\mathrm{H}_{2} \mathrm{O}_{2}$ via the two-electron ORR or twoelectron WOR. The catalytic performance of the photocatalyst is usually expressed using the $\mathrm{H}_{2} \mathrm{O}_{2}$ production rate in terms of $\mu \mathrm{mol} \mathrm{h}^{-1}$ or $\mu \mathrm{mol} \mathrm{L}^{-1} \mathrm{~h}^{-1}$ under given conditions including temperature and light intensity. The concentration of the produced $\mathrm{H}_{2} \mathrm{O}_{2}$ can be determined by potassium permanganate $\left(\mathrm{KMnO}_{4}\right)$ and iodometric titration or HPLC in conjunction with an electrochemical analyzer. ${ }^{37}$ The $\mathrm{H}_{2} \mathrm{O}_{2}$ selectivity over semiconductor photocatalysts can also be evaluated by the RDE technique according to Koutecky-Levich plots. ${ }^{37}$ In addition, from the viewpoint of practical application, the behavior of $\mathrm{H}_{2} \mathrm{O}_{2}$ decomposition over the semiconductor photocatalyst also needs to be investigated by dispersing the semiconductor photocatalyst into nitrogen-saturated $\mathrm{H}_{2} \mathrm{O}_{2}$ solution under illumination. ${ }^{37}$ Besides, there are two additional important parameters for evaluating the photocatalytic performances of photocatalysts including the apparent quantum yield (AQY) and solar-to-chemical conversion (SCC) efficiency. In the reported literature, the $\mathrm{AQY}$ is defined as the ratio of the number of electrons transferred toward $\mathrm{H}_{2} \mathrm{O}_{2}$ production relative to the incident photons at a given wavelength, and thus could be calculated according to the following equations: ${ }^{37,69}$

$$
\begin{gathered}
\phi_{\mathrm{AQY}}(\%)=\frac{2 \times n_{\mathrm{H}_{2} \mathrm{O}_{2}}}{N_{\mathrm{aph}}} \times 100 \% . \\
N_{\mathrm{aph}}=\frac{E \times A_{\mathrm{d}}}{U_{\lambda}} . \\
U_{\lambda}=\frac{h \times c \times N_{\mathrm{A}}}{\lambda} .
\end{gathered}
$$

Here $n_{\mathrm{H} 2 \mathrm{O} 2}$ is the molar amount of produced $\mathrm{H}_{2} \mathrm{O}_{2}, N_{\text {aph }}$ is the number of incident photons entering the reaction vessel, $E$ is the measured difference in the light intensity transmitted before and after being absorbed by the photocatalyst $\left(\mathrm{mW} \mathrm{cm}^{-2}\right)$, $A_{\mathrm{d}}$ is the area of the light collector part of the radiometer $\left(\mathrm{cm}^{2}\right)$, $U_{\lambda}$ is the mole photon energy of the given wavelength $\lambda$ $\left(\mathrm{J} \mathrm{mol}_{\text {photon }}{ }^{-1}\right), h$ is the Planck constant $\left(6.626 \times 10^{-34} \mathrm{~J} \mathrm{~s}\right)$, $c$ is the speed of light in a vacuum $\left(3 \times 10^{8} \mathrm{~m} \mathrm{~s}^{-1}\right), N_{\mathrm{A}}$ is the Avogadro number $\left(6.022 \times 10^{23} \mathrm{~mol}^{-1}\right)$, and $\lambda$ is the given wavelength of incident photons (nm). AQY measurements are generally carried out in a borosilicate glass bottle using an air mass (AM) 1.5 solar simulator combined with wavelengthdependent band-pass filters. ${ }^{37}$ Similarly, the SCC efficiency is measured under similar conditions to those of AQY measurements except for the use of a $\lambda>420 \mathrm{~nm}$ cutoff filter, ${ }^{70}$ which is used to suppress the subsequent decomposition of the produced $\mathrm{H}_{2} \mathrm{O}_{2}$ by UV light. The SCC efficiency was calculated 
based on the following equation: ${ }^{70}$

$$
\text { SCC efficiency }(\%)=\frac{\Delta G \times n_{\mathrm{H}_{2} \mathrm{O}_{2}}}{P \times t} \times 100 \% \text {. }
$$

Here $\Delta G$ is the free energy for $\mathrm{H}_{2} \mathrm{O}_{2}$ generation $\left(117 \mathrm{~kJ} \mathrm{~mol}^{-1}\right)$, $P$ is the power of the incident photons (W), and $t$ is the illumination time (s). The number of incident photons and average intensity of irradiation can be measured by a radiometer.

\section{Electrocatalytic materials for $\mathrm{H}_{2} \mathrm{O}_{2}$ production}

ORR electrocatalysts are considered to be one of the most important components in electrochemical devices for $\mathrm{H}_{2} \mathrm{O}_{2}$ production. To date, the developed ORR electrocatalysts can be categorized into noble-metal-based materials, transitionmetal-based materials, and metal-free carbon-based materials. All these developed ORR electrocatalysts will be discussed in detail below.

\subsection{Noble-metal-based materials}

Platinum-based catalysts are considered to be the state-ofthe-art ORR electrocatalysts, and have also been widely used in commercialized PEMFCs due to their high catalytic activity, selectivity, and durability in acidic environments. ${ }^{24}$ Generally, the ORR process over platinum-based catalysts mainly proceeds by a four-electron reaction pathway for selective production of water, which is also highly desirable from the perspective of the achievement of highly efficient energy conversion. Besides, during the ORR process, the reaction pathway is usually considered to be strongly dependent on the ability of the catalyst for the dissociation of the $\mathrm{O}-\mathrm{O}$ bond, whereas the cleavage of the $\mathrm{O}-\mathrm{O}$ bond is undesirable for $\mathrm{H}_{2} \mathrm{O}_{2}$ production. In this regard, two configurations have been proposed for $\mathrm{O}_{2}$ adsorption on the surface of these platinum-based catalysts, including a "side-on" adsorption configuration and an "end-on" adsorption configuration (Fig. 1a and b). ${ }^{71}$ For the "side-on" adsorption configuration, the four-electron ORR reaction pathway is dominant because the adjacent noble metal atoms favor the dissociative adsorption of $\mathrm{O}_{2}$ and the continual reduction of $\mathrm{H}_{2} \mathrm{O}_{2}$ through providing separate binding sites for the two oxygen atoms in $\mathrm{O}_{2}$ and $\mathrm{H}_{2} \mathrm{O}_{2}$, which was also called ensemble effects. By contrast, the elimination of accessible ensembles of noble metal active sites (site isolation strategy) could induce the "end-on" adsorption configuration of $\mathrm{O}_{2}$ on the surface of the catalyst, thus making the ORR process occur through both four-electron and two-electron reaction pathways, which was beneficial for the selective production of $\mathrm{H}_{2} \mathrm{O}_{2}$. On the basis of these considerations above, Choi's group coated amorphous carbon layers on the surface of a commercial $\mathrm{Pt} / \mathrm{C}$ catalyst (Johnson-Matthey, $60 \mathrm{wt} \% \mathrm{Pt}$ ) through chemical vapor deposition (CVD) in order to eliminate accessible Pt ensemble sites, thus resulting in the increased selective production of $\mathrm{H}_{2} \mathrm{O}_{2}$ during the ORR process. Furthermore, the amorphous carbon layers also efficiently suppressed the consecutive chemical decomposition of $\mathrm{H}_{2} \mathrm{O}_{2}$ by a disproportionation reaction or electrochemical reduction reaction, and also made the catalyst possess excellent stability.

Theoretically, according to Sabatier's principle, the binding of the reaction intermediates on the surface of the catalyst should be neither too strong nor too weak for the ideal catalyst, that is, a moderate interaction between the catalyst surface and the reaction intermediates. ${ }^{2,51}$ Therefore, as the sole reaction intermediate during the $\mathrm{H}_{2} \mathrm{O}_{2}$ production process, $\mathrm{HOO}^{*}$ should be bound on the surface of the catalyst within a moderate range, which is thus conducive to the preservation of the $\mathrm{O}-\mathrm{O}$ bond. Nevertheless, for conventional Pt-based catalysts, the $\mathrm{HOO}^{*}$ dissociation to $\mathrm{O}^{*}$ and $\mathrm{HO}^{*}$ (the fourelectron ORR intermediates) is generally preferred over the $\mathrm{HOO}^{*}$ hydrogenation to $\mathrm{H}_{2} \mathrm{O}_{2}$ due to their strong binding of HOO $^{*}$ on their surface. Rossmeisl and Stephens recently reported the tunable binding of the reaction intermediates through regulating the composition of the catalysts, and screened a series of oxygen electrocatalysts based on noble metal alloys for $\mathrm{H}_{2} \mathrm{O}_{2}$ production using density functional theory (DFT) calculations (Fig. 1c-f). ${ }^{51}$ In their work, the binding of $\mathrm{HOO}^{*}$ could be optimized by the modification of reactive noble metals including $\mathrm{Pt}, \mathrm{Pd}$, and $\mathrm{Ag}$ with inactive metals such as $\mathrm{Au}$ and $\mathrm{Hg}$, in order to regulate the catalytic activity and selectivity toward $\mathrm{H}_{2} \mathrm{O}_{2}$ production. Electrochemical results demonstrated that the resultant $\mathrm{Pt}-\mathrm{Hg}, \mathrm{Ag}-\mathrm{Hg}$, and $\mathrm{Pd}-\mathrm{Hg}$ exhibited high selectivity toward $\mathrm{H}_{2} \mathrm{O}_{2}$ production owing to the elimination of the accessible active metal ensemble sites through the isolation of active sites using $\mathrm{Hg}$. Besides, starting from the viewpoint of both composition and morphology optimization, Mahata et al. also studied three cuboctahedral core-shell nanoclusters of $\mathrm{Au}_{19} @ \mathrm{Pt}_{60}, \mathrm{Co}_{19} @ \mathrm{Pt}_{60}$ and $\mathrm{Au}_{10} \mathrm{Co}_{9} @ \mathrm{Pt}_{60}$ by performing DFT calculations to get better understanding of the influence of the core metal (Co and $\mathrm{Au}$ ) on improving the selectivity and efficiency of $\mathrm{H}_{2} \mathrm{O}_{2}$ production. ${ }^{72}$ The optimal binding of $\mathrm{HOO}^{*}$ can be achieved by the formation of a mixed alloy consisting of $\mathrm{Co}$ and $\mathrm{Au}$ due to the synergetic effect of $\mathrm{Co}$ and $\mathrm{Au}$ with different oxygen binding energies. Among them, the $\mathrm{Au}_{10} \mathrm{Co}_{9} @ \mathrm{Pt}_{60} \mathrm{NCs}$ showed the lowest over-potential and highest selectivity for $\mathrm{H}_{2} \mathrm{O}_{2}$ production.

The particle size of nanostructured materials has been reported to show significant influences on the catalytic performances including the catalytic activity and reaction pathway. For instance, Anderson's group prepared different size $\mathrm{Pt}_{n}$ clusters supported on indium tin oxide (ITO) films in an ultrahigh vacuum, and found size-dependent catalytic activity and selectivity toward $\mathrm{H}_{2} \mathrm{O}_{2}$ production, ${ }^{73}$ where the smallest $\mathrm{Pt}_{n}$ clusters were most beneficial for $\mathrm{H}_{2} \mathrm{O}_{2}$ production. Other typical examples of the size effect are single-atom catalysts (SACs) with the advantages of minimal noble metal usage and unique catalytic properties. Extensive efforts have been devoted to the preparation of Pt SACs dispersed on various substrates such as $\mathrm{MgO}, \mathrm{FeO}_{x}$, zeolites, $\mathrm{TiO}_{2}$, and $\mathrm{MoS}_{2}$, showing high catalytic activity for different catalytic applications such as propane combustion, ${ }^{74} \mathrm{CO}$ oxidation, ${ }^{75}$ nitroarene hydrogenation, ${ }^{76}$ 


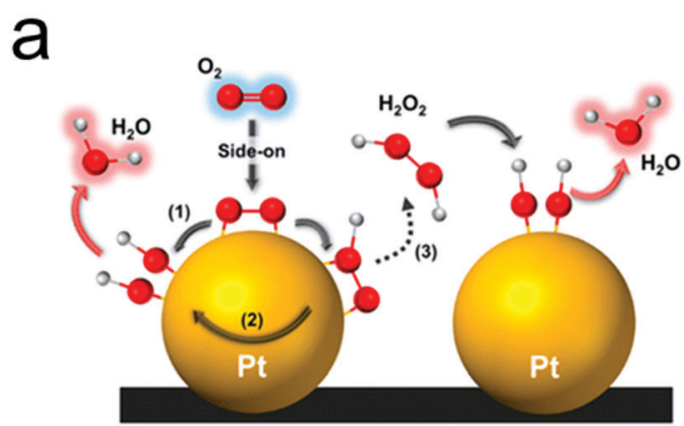

b

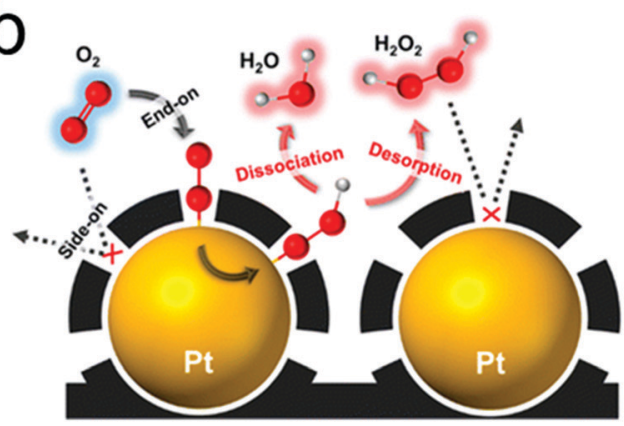

C
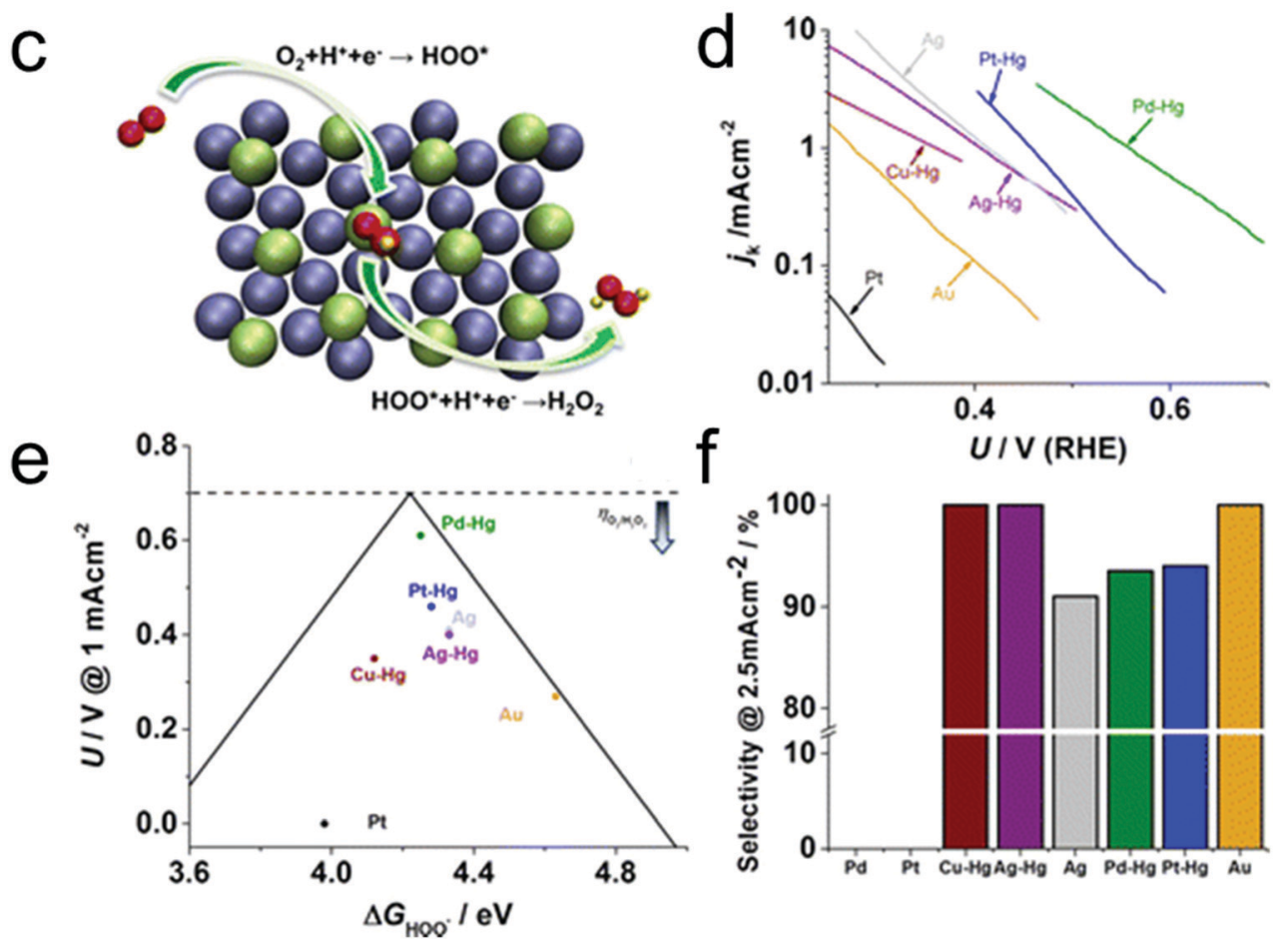

Fig. 1 ( $a$ and b) ORR pathways on Pt surfaces: (a) on the pristine Pt/C, molecular $\mathrm{O}_{2}$ prefers to adsorb on the Pt surface as a side-on configuration and then reduces to $\mathrm{H}_{2} \mathrm{O}$ through (1) dissociative, (2) associative, and (3) non-dissociative mechanisms; (b) on the carbon-coated Pt, molecular $\mathrm{O}_{2}$ absorbs on the Pt surface as an end-on configuration and then produces $\mathrm{H}_{2} \mathrm{O}$ and $\mathrm{H}_{2} \mathrm{O}_{2}$ via competitive dissociation and desorption steps, respectively. The produced $\mathrm{H}_{2} \mathrm{O}_{2}$ is not further reduced on the Pt surface due to hindrance by the carbon layer. (c-f) Trends in activity and selectivity for $\mathrm{H}_{2} \mathrm{O}_{2}$ production: (c) Schematic representation of oxygen reduction to $\mathrm{H}_{2} \mathrm{O}_{2}$ on a model $\mathrm{Pd}_{2} \mathrm{Hg}_{5}(001)$ surface. Palladium atoms are represented in green, mercury in blue, oxygen in red, and hydrogen in yellow. (d) Partial kinetic current density to $\mathrm{H}_{2} \mathrm{O}_{2}$ as a function of the applied potential, corrected for mass transport losses. (e) Potential required to reach $1 \mathrm{~mA} \mathrm{~cm}^{-2}$ kinetic current density to $\mathrm{H}_{2} \mathrm{O}_{2}$ on polycrystalline catalysts as a function of the calculated $\mathrm{HOO}^{*}$ binding energy. The solid lines represent the theoretical Sabatier volcano. The dotted line represents the thermodynamic potential for oxygen reduction to $\mathrm{H}_{2} \mathrm{O}_{2}$. (f) $\mathrm{H}_{2} \mathrm{O}_{2}$ selectivity for different catalysts at $2.5 \mathrm{~mA} \mathrm{~cm}{ }^{-2}$ total current density. All electrochemical experiments were performed at $50 \mathrm{mV} \mathrm{s}{ }^{-1}$ and $1600 \mathrm{rpm}$ in $\mathrm{O}_{2}$-saturated $0.1 \mathrm{M} \mathrm{HClO}_{4}$ at room temperature with corrections for ohmic drop. The surface area was normalized to the geometrical value. (a and b) Reprinted with permission. ${ }^{71}$ Copyright 2014, American Chemical Society. (c-f) Reprinted with permission. ${ }^{51}$ Copyright 2014 , American Chemical Society.

and photocatalytic hydrogen production. ${ }^{77,78}$ Besides, the elimination of Pt ensemble sites in these Pt SACs also induced the pathway change of some chemical reactions such as formic acid oxidation. ${ }^{79}$ Generally, formic acid oxidation proceeds by the indirect dehydration pathway over conventional Pt nanoparticles. However, Pt SACs can catalyze formic acid oxidation through the direct dehydration pathway. Recently, Pt SACs have also been employed as ORR electrocatalysts for selective $\mathrm{H}_{2} \mathrm{O}_{2}$ production.
For instance, Lee's group demonstrated high mass activity and selectivity toward $\mathrm{H}_{2} \mathrm{O}_{2}$ production over single-atom Pt supported on TiN nanoparticles because of the absence of Pt ensemble active sites, ${ }^{79}$ and also observed the support effect on the catalytic performances of Pt SACs toward the electrochemical ORR, indicating that the substrate was not only used as anchoring sites to stabilize the single metal atoms, but also may participate in the surface catalytic reaction. ${ }^{80}$ Meanwhile, the composition 
and structure of the substrate have significant effects on the loading of atomically dispersed Pt. A high loading of atomically dispersed Pt up to $5 \mathrm{wt} \%$ can be achieved using sulfur-doped zeolite-templated carbon as a support with a high sulfur content of $17 \mathrm{wt} \%$ and highly curved three dimensional networks of graphene nanoribbons, which was attributed to the abundant S-functionalities and unique carbon structure. ${ }^{81}$ Very recently, the loading of single atom Pt sites was further improved to $24.8 \%$ by atomically dispersing platinum on the surface of an amorphous $\mathrm{CuS}_{x}$ hollow nanosphere support due to the strong Pt-S interaction (Fig. 2), ${ }^{82}$ which exhibited a high $\mathrm{H}_{2} \mathrm{O}_{2}$ selectivity of 92-96\% over a wide potential range as well as excellent stability even after 10000 cyclic voltammetry cycles within a potential range from +0.1 to $+0.8 \mathrm{~V}_{\mathrm{RHE}}$ in $\mathrm{HClO}_{4}$ electrolyte. In addition, the loading amount of the Pt-based catalyst on the electrode showed a significant influence on the $\mathrm{H}_{2} \mathrm{O}_{2}$ production during the ORR process, and showed an inverse correlation with the $\mathrm{H}_{2} \mathrm{O}_{2}$ selectivity. ${ }^{49}$ A similar phenomenon was also observed for some non-Pt-based ORR electrocatalysts like $\mathrm{Fe}-\mathrm{N}-\mathrm{C}$ and $\mathrm{Se} / \mathrm{Ru} / \mathrm{C}$ catalysts. ${ }^{83,84}$
$\mathrm{Au}$ has been demonstrated to be a promising ORR electrocatalyst for $\mathrm{H}_{2} \mathrm{O}_{2}$ production, and its selectivity is strongly influenced by the crystallographic orientation and experimental conditions. ${ }^{82}$ However, the weak binding of $\mathrm{HOO}^{*}$ on its surface resulted in a low coverage of $\mathrm{O}_{2}$ and thus limited the catalytic activity. ${ }^{82}$ Recently, rational design of alloying with other metals, such as $\mathrm{Pd}, \mathrm{Pt}$, and $\mathrm{Rh}$, has been proposed to optimize the catalytic properties of Au. The typical example reported is the $\mathrm{Au}-\mathrm{Pd}$ alloy system, ${ }^{17}$ which has been investigated as a heterogeneous catalyst for direct catalytic production of $\mathrm{H}_{2} \mathrm{O}_{2}$ from $\mathrm{H}_{2}$ and $\mathrm{O}_{2} \cdot{ }^{85}$ For instance, the $\mathrm{Au}-\mathrm{Pd}$ alloy with variable $\mathrm{Pd}$ content has also been investigated as an ORR electrocatalyst for $\mathrm{H}_{2} \mathrm{O}_{2}$ production, and increased $\mathrm{H}_{2} \mathrm{O}_{2}$ selectivity was observed at the optimal content of Pd owing to the ensemble effect arising from the presence of finely dispersed $\mathrm{Pd}$ within $\mathrm{Au}$. In contrast, excess content of $\mathrm{Pd}$ resulted in a decrease of $\mathrm{H}_{2} \mathrm{O}_{2}$ selectivity due to the strong binding of $\mathrm{HOO}^{*}$ on the surface of Pd. In addition to Pd, some DFT calculation results demonstrated that the combination of $\mathrm{Ni}$ with $\mathrm{Au}$ resulted in increased coverage of $\mathrm{O}_{2}$, maintaining simultaneously weak
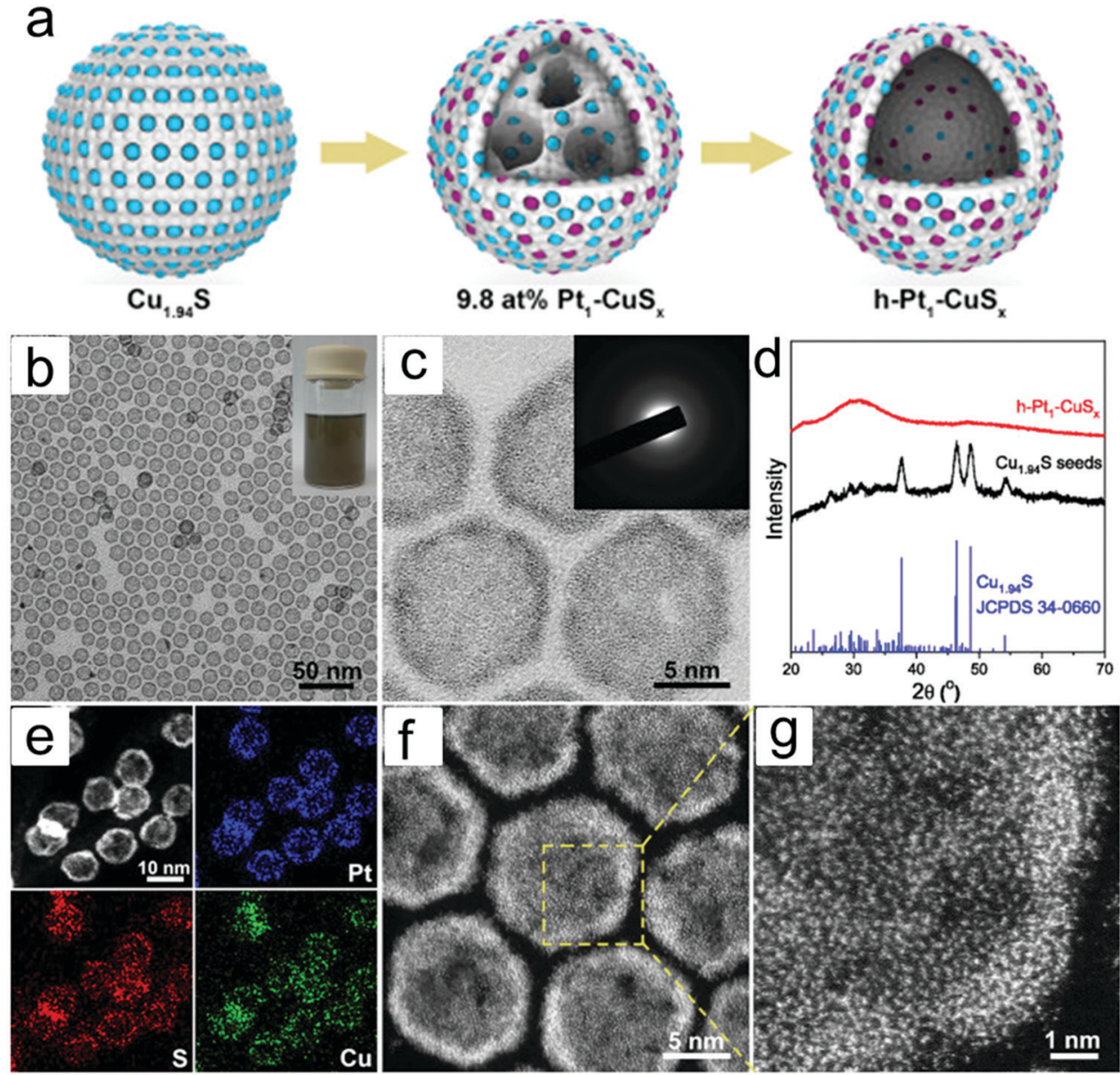

Fig. 2 (a) Schematic illustration of the structure evolution of $\mathrm{h}-\mathrm{Pt}_{1}-\mathrm{CuS}_{x}$ (blue, purple and white balls represent $\mathrm{Cu}$, $\mathrm{Pt}$, and $\mathrm{S}$ atoms, respectively); and $(b-g)$ characterization of $\mathrm{h}-\mathrm{Pt}_{1}-\mathrm{CuS}_{x}$ nanoparticles: (b) TEM image of $\mathrm{h}-\mathrm{Pt}_{1}-\mathrm{CuS}_{x}$ (the inset is the photograph of the nanoparticles dispersed in

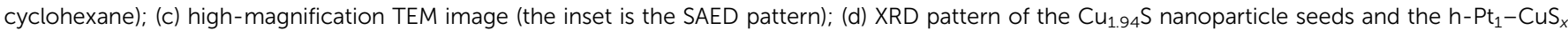
nanoparticles; (e) EDS elemental mapping of $\mathrm{Pt}, \mathrm{S}$, and $\mathrm{Cu}$; and ( $\mathrm{f}$ and g) AC-HAADF-STEM images of h-Pt ${ }_{1}-\mathrm{CuS}_{\mathrm{x}}$. Reprinted with permission. ${ }^{61}$ Copyright 2019, Elsevier Inc. 
dissociation of the $\mathrm{O}-\mathrm{O}$ bond. Inspired by this point, Amal's group reported the designed synthesis of $\mathrm{Au}-\mathrm{Ni}$ core-shell nanorods though the epitaxial growth method, ${ }^{82}$ which exhibited improved catalytic activity and selectivity toward $\mathrm{H}_{2} \mathrm{O}_{2}$ production. The enhanced results could be attributed to the following aspects: (1) the decreased tendency for the dissociation of the $\mathrm{O}-\mathrm{O}$ bond resulting from $\mathrm{Au}-\mathrm{Ni}$; and (2) the complex electron interaction and the lattice strain effect resulting from the epitaxial growth process. What's more, a Pt layer was also further introduced to improve the catalytic activity and selectivity toward $\mathrm{H}_{2} \mathrm{O}_{2}$ production by tuning the electrical properties of the Ni shell and the degree of lattice strain caused by the high work function of Pt. Similarly, the substrate has a significant influence on selective $\mathrm{H}_{2} \mathrm{O}_{2}$ production over Au-based ORR electrocatalysts. Camargo's group reported the synthesis of hybrid materials consisting of $\mathrm{Au}$ and $\mathrm{TiO}_{2}$ with different morphologies including spheres and wires. ${ }^{86}$ Interestingly, the $\mathrm{TiO}_{2}$ spheres had a positive effect on the selectivity for $\mathrm{H}_{2} \mathrm{O}_{2}$ production whereas the $\mathrm{H}_{2} \mathrm{O}_{2}$ selectivity decreased for the $\mathrm{TiO}_{2}$ wires.

\subsection{Transition-metal-based materials}

Transition-metal-based materials, mainly including transitionmetal complexes, metal-N-C materials, metal/C materials, and metal oxides, showed good catalytic activity and selectivity toward the ORR to $\mathrm{H}_{2} \mathrm{O}_{2}$ via the two-electron reaction pathway. The most popular examples of transition-metal complex ORR electrocatalysts for $\mathrm{H}_{2} \mathrm{O}_{2}$ production are cobalt-based porphyrins and iron-based phthalocyanines. ${ }^{56,57}$ Their unique geometric configuration, consisting of reactive metal atoms surrounded by supporting and coordinating atoms such as $\mathrm{N}$ and $\mathrm{C}$, could efficiently restrain the dissociation of the $\mathrm{O}-\mathrm{O}$ bond, thus realizing high selectivity toward two-electron $\mathrm{H}_{2} \mathrm{O}_{2}$ production. Besides, DFT calculation results revealed that the neither too strong nor too weak binding of the reaction intermediate $\mathrm{HOO}^{*}$ on the surface of these catalysts proved most beneficial for $\mathrm{H}_{2} \mathrm{O}_{2}$ production. ${ }^{87}$ However, the high cost and unsatisfactory durability of these catalysts largely prohibited their practical applications. Nevertheless, some research studies also reported the significant improvement of their catalytic activity and durability through heat treatment. Inspired by this, extensive efforts have been made for the synthesis of Co-N-C catalysts from various nitrogen-containing precursors, carbon supports, and Co salts. Research demonstrated that the catalytic activity and selectivity of these Co-N-C catalysts were largely related to the nature of the carbon supports and nitrogen-containing precursors. For instance, bidentate $\mathrm{N}$-ligands were found to be optimal nitrogen-containing carbon precursors because of the favorable formation of such structures with Co-coordinated $\mathrm{Co}-\mathrm{N}_{2}-\mathrm{C}$ sites during the heat treatment process, which were found to be active sites for the selective ORR for $\mathrm{H}_{2} \mathrm{O}_{2}$ production. ${ }^{88}$ In addition to the formation of $\mathrm{Co}-\mathrm{N}_{2}-\mathrm{C}$ sites, metal Co nanoparticles coated with Co oxides were also generally produced during the heat treatment process, where the produced $\mathrm{H}_{2} \mathrm{O}_{2}$ was further electrochemically reduced to $\mathrm{H}_{2} \mathrm{O}$. Besides, there have also been conflicting opinions on the roles of Co- $\mathrm{N}_{x}-\mathrm{C}$ sites ( $x$ represents the coordination number), that is,
Co- $\mathrm{N}_{4}-\mathrm{C}$ sites are considered to be active sites for $\mathrm{H}_{2} \mathrm{O}_{2}$ production through the two-electron ORR, whereas $\mathrm{Co}-\mathrm{N}_{2}-\mathrm{C}$ sites promote the four-electron ORR for $\mathrm{H}_{2} \mathrm{O}$ production. ${ }^{90}$ Recently, our group observed the activity-selectivity trends for electrochemical $\mathrm{H}_{2} \mathrm{O}_{2}$ production over single-site metal- $\mathrm{N}-\mathrm{C}$ (metal = $\mathrm{Mn}, \mathrm{Fe}, \mathrm{Co}, \mathrm{Ni}$, and $\mathrm{Cu}$ ) by the combination of computational calculations and experimental results. The as-prepared $\mathrm{Co}-\mathrm{N}-\mathrm{C}$ catalyst was found to possess the most optimal binding energy of the $\mathrm{HO}^{*}$ intermediate near the top of the volcano of the twoelectron ORR, which well explained its outstanding $\mathrm{H}_{2} \mathrm{O}_{2}$ productivity with high ORR activity, highest $\mathrm{H}_{2} \mathrm{O}_{2}$ selectivity, and lowest $\mathrm{H}_{2} \mathrm{O}_{2}$ reduction reaction activity (Fig. 3a-e). ${ }^{18}$ Moreover, industrial $\mathrm{H}_{2} \mathrm{O}_{2}$ productivity over the prepared Co-N-C catalyst in a micro flow cell was achieved with a production rate of more than $4 \mathrm{~mol}$ peroxide $\mathrm{g}_{\text {catalyst }}{ }^{-1} \mathrm{~h}^{-1}$ at a current density of $50 \mathrm{~mA} \mathrm{~cm}{ }^{-2}$. Later, the introduction of oxygen functional groups (OFGs) into carbon-based materials possessing $\mathrm{Co}-\mathrm{N}_{x}-\mathrm{C}$ active sites could further improve the catalytic activity and selectivity toward electrochemical $\mathrm{H}_{2} \mathrm{O}_{2}$ production, where $\mathrm{Co}-\mathrm{N}_{x}-\mathrm{C}$ sites mainly contributed to the catalytic ORR reactivity, whereas the $\mathrm{H}_{2} \mathrm{O}_{2}$ selectivity was attributed to OFGs (Fig. $3 \mathrm{f}$ and $\mathrm{g}$ ). ${ }^{89}$ Very recently, Hyeon's group also observed nearly the same phenomenon, that is, Co- $\mathrm{N}_{4}$ moieties surrounded by oxygen species $(\mathrm{C}-\mathrm{O}-\mathrm{C}$ epoxides) as an ideal system for highly active $\mathrm{H}_{2} \mathrm{O}_{2}$ production from both electrochemical results and DFT calculations. ${ }^{91}$ Besides, Wang's group also reported $\mathrm{Fe}-\mathrm{O}-\mathrm{C}$ as an efficient ORR catalyst for $\mathrm{H}_{2} \mathrm{O}_{2}$ production with a relative positive onset potential of $+0.822 \mathrm{~V}_{\mathrm{RHE}}$ and high selectivity of more than $95 \%$ in both alkaline and neutral medium, ${ }^{92}$ which was completely different from the previously reported $\mathrm{Fe}-\mathrm{N}-\mathrm{C}$ ORR catalysts. Therefore, the fundamental understanding of the nature of the active sites of these $\mathrm{M}-\mathrm{N}-\mathrm{C}$ catalysts toward the ORR remains important yet challenging, and more work is still needed.

\subsection{Metal-free carbon-based materials}

In the past few decades, metal-free carbon-based materials have been widely used as supports in many energy-related applications due to their advantages of earth-abundance, low-cost, facile preparation, large specific surface area, excellent electrical conductivity, chemical resistance, and mechanical stability. ${ }^{23,25,93}$ Recently, metal-free carbon-based materials, such as activated carbon fibers and graphite, have also shown great promise as alternative catalysts to noble metal materials for electrochemical production of $\mathrm{H}_{2} \mathrm{O}_{2}$ through the two-electron ORR process in alkaline solution. ${ }^{14-16,42,94,95}$ It has been well accepted that the electrochemical performances of metal-free carbon-based materials are strongly determined by their geometric and electronic structures. Starting from these two aspects, considerable efforts have been made for the synthesis of advanced metal-free carbon-based materials with high activity, selectivity, and stability for electrochemical $\mathrm{H}_{2} \mathrm{O}_{2}$ production.

One of the most promising geometric structures for $\mathrm{H}_{2} \mathrm{O}_{2}$ production is reported to be porous structures since such structures with large surface area and high pore volume are beneficial for mass transfer and also help in exposing more catalytically active sites. Metal-organic frameworks (MOFs) as a 

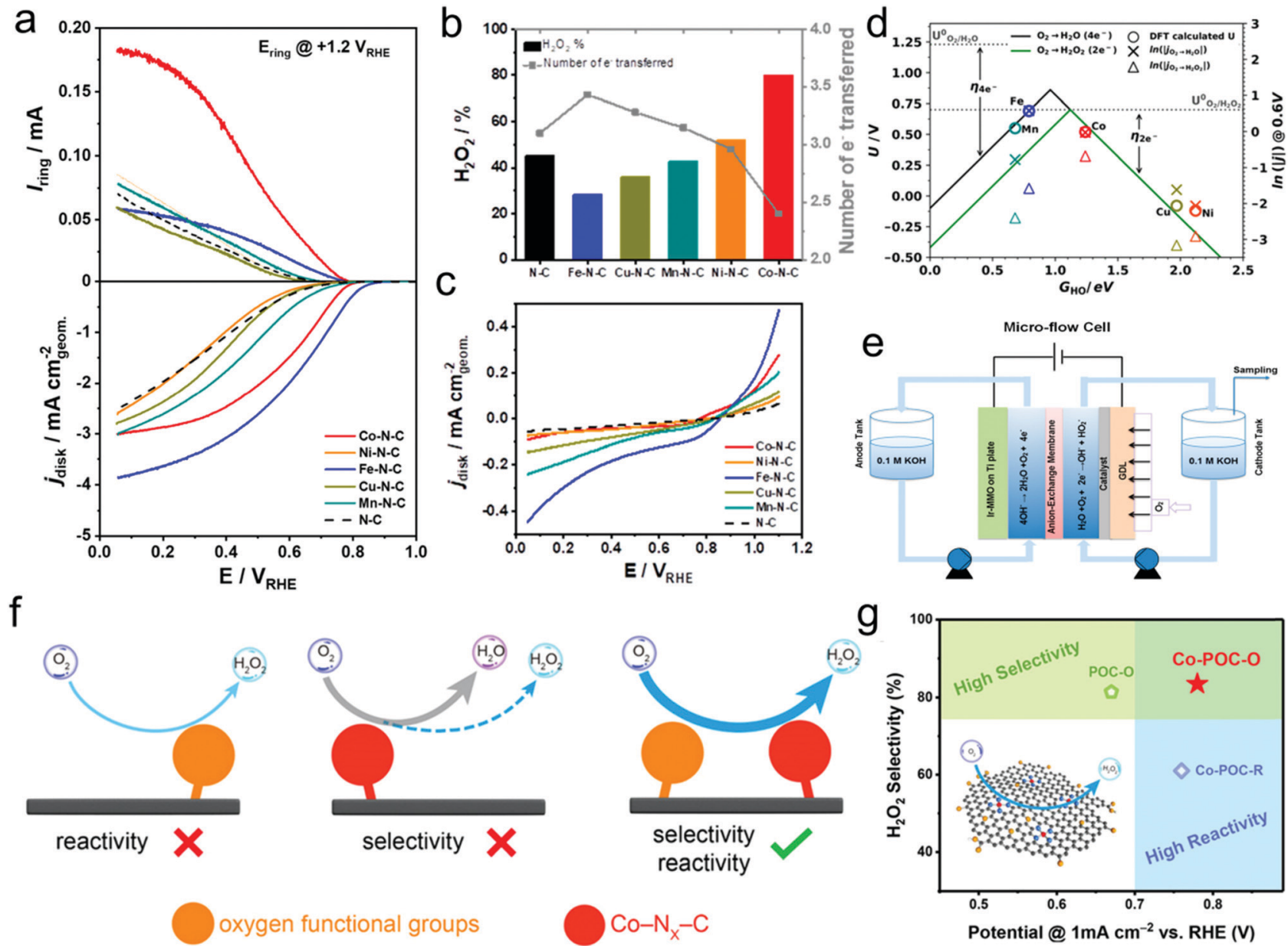

oxygen functional groups

Co- $-N_{x}-C$

Potential @ 1mA cm ${ }^{-2}$ vs. RHE (V)

Fig. 3 (a) Linear sweep voltammetry (LSV) in a rotating ring-disk electrode (RRDE) setup with the Pt ring held at $+1.2 \mathrm{~V}_{\mathrm{RHE}}$. (b) $\mathrm{H}_{2} \mathrm{O}_{2}$ selectivity $\left(\mathrm{H}_{2} \mathrm{O}_{2} \%\right.$ ) and the number of electrons ( $n$ ) at $+0.1 \mathrm{~V}_{\mathrm{RHE}}$ derived from RRDE data. (c) Background-corrected $\mathrm{H}_{2} \mathrm{O}_{2} \mathrm{RR}$ performance in $\mathrm{N}_{2}$-saturated $0.5 \mathrm{M} \mathrm{H}_{2} \mathrm{SO}_{4}$ electrolyte containing $1 \mathrm{mM} \mathrm{H}_{2} \mathrm{O}_{2}$. (d) Thermodynamic relations (volcano) lines for the two- (green solid line) and four-electron ORR (black solid line). The DFT calculated ORR onset potential values (circles) are on the left $y$-axis, while the experimental current densities (crosses and triangles), reported as $\ln (|j|)$, are on the right $y$-axis. Both are shown as functions of the chosen reaction descriptor, the DFT calculated $\mathrm{HO}^{*}$ binding free energy $\left(G_{\mathrm{HO}}\right)$. (e) Scheme of the micro-flow cell setup. (f) Schematic of the synergistic strategy of atomic Co- $\mathrm{N}_{x}-\mathrm{C}$ sites and OFGs for $\mathrm{H}_{2} \mathrm{O}_{2}$ electrosynthesis on noblemetal-free electrocatalysts. (g) Performance comparison in regard to reactivity and selectivity for $\mathrm{H}_{2} \mathrm{O}_{2}$ electrosynthesis on Co-POC-O, Co-POC-R, and POC-O electrocatalysts. The inset in (g) shows the mechanism scheme for synergistic $\mathrm{H}_{2} \mathrm{O}_{2}$ electrosynthesis. The carbon, nitrogen, oxygen, and cobalt atoms are marked with black, blue, yellow, and red, respectively. (a-e) Reprinted with permission. ${ }^{18}$ Copyright 2019, American Chemical Society. (f and g) Reprinted with permission. ${ }^{89}$ Copyright 2019, Wiley-VCH.

typical porous multi-functional material have received increasing attention due to their high surface area and uniform porosity, and have been proposed as promising precursors for the fabrication of porous carbon materials. For instance, hierarchically porous carbon (HPC) was fabricated under an atmosphere of $\mathrm{H}_{2}$ through the direct pyrolysis of MOF-5, which was synthesized using zinc nitrate and terephthalic acid. ${ }^{14}$ The resultant porous carbon exhibited high catalytic activity and selectivity for electrochemical reduction of $\mathrm{O}_{2}$ to $\mathrm{H}_{2} \mathrm{O}_{2}$ production in a wide range of $\mathrm{pH}$ from 1 to 7 . These outstanding performances can be attributed to the high amount of $\mathrm{sp}^{3}-\mathrm{C}$ and defects, high surface area, and favorable mass transfer. In addition, the pore size also showed a significant influence on the catalytic properties of porous carbon materials. Two kinds of porous carbon materials with mesoporedominant porous carbon (Meso-C) and micropore-dominant porous carbon (Micro-C) have been investigated for electrochemical production of $\mathrm{H}_{2} \mathrm{O}_{2}$, where Meso-C exhibited superior ORR performance for $\mathrm{H}_{2} \mathrm{O}_{2}$ production compared to MicroC. ${ }^{94,96}$ This result may be explained by the fact that the favorable mass transport within the mesoporous structure resulted in the fast release of the produced $\mathrm{H}_{2} \mathrm{O}_{2}$ from the surface of the catalyst, thus avoiding the subsequent reduction of $\mathrm{H}_{2} \mathrm{O}_{2}$.

Heteroatom doping, such as with oxygen, nitrogen, sulphur, and fluorine, has been reported as another promising strategy to regulate the catalytic activity and selectivity of metal-free carbon materials through tailoring their electronic structures. ${ }^{16,94,97}$ Santos's group compared the electrochemical performance of Vulcan XC-72R and Printex carbon supports for $\mathrm{H}_{2} \mathrm{O}_{2}$ production. ${ }^{98}$ They found that there are more oxygenated 
functional groups on the surface of Printex L6 compared to Vulcan XC-72R, resulting in improved $\mathrm{H}_{2} \mathrm{O}_{2}$ selectivity. Moreover, the same group also further investigated the influence of different surface modification on the selectivity of these two carbon supports toward $\mathrm{H}_{2} \mathrm{O}_{2}$ production through pretreatment with nitric acid and ammonia. ${ }^{99}$ A similar phenomenon was also observed that acid-treated Printex L6 exhibited the highest selectivity toward $\mathrm{H}_{2} \mathrm{O}_{2}$ production due to the largest concentration of oxygenated functional groups. Very recently, Cui and co-workers also reported the increased activity and selectivity of carbon materials toward $\mathrm{H}_{2} \mathrm{O}_{2}$ production through surface oxidation treatment. ${ }^{3}$ Moreover, a linear correlation of the catalytic activity and selectivity with the oxygen content was observed, and DFT results demonstrated that the existence of the $-\mathrm{COOH}$ functional group in the armchair edge and the $\mathrm{C}-\mathrm{O}-\mathrm{C}$ functional group in the basal plane of graphene resulted in the high activity and selectivity toward $\mathrm{H}_{2} \mathrm{O}_{2}$ production. These results implied that the introduction of oxygenated functional groups plays an important role in regulating the chemical selectivity.

In addition to oxygen functionalization, nitrogen doping has also been reported to be an efficient means for improving the ORR performances of metal-free carbon materials since the incorporation of nitrogen with higher electronegativity could induce the charge redistribution of the $\pi$ conjugated system of the carbon frameworks and thus tailor the adsorption properties of carbon materials for ORR reactive intermediates. ${ }^{100}$ Nevertheless, most of the reported nitrogen-doped carbon materials led to the four-electron ORR to $\mathrm{H}_{2} \mathrm{O}$, and only a few samples were reported to exhibit high selectivity toward $\mathrm{H}_{2} \mathrm{O}_{2}$ production. ${ }^{63,97,101-104}$ For example, Anderson's group investigated the ORR performance of nitrogen-doped Ketjenblack for $\mathrm{H}_{2} \mathrm{O}_{2}$ production from both experimental and theoretical calculation viewpoints. ${ }^{105}$ Experimental results demonstrated that the nitrogen-doped Ketjenblack showed a lower onset potential and mainly followed the two-electron ORR process for $\mathrm{H}_{2} \mathrm{O}_{2}$ production. Meanwhile, DFT results also indicated that the formed carbon radical sites neighboring substitutional $\mathrm{N}$ in graphite were active for the electrochemical ORR to $\mathrm{H}_{2} \mathrm{O}_{2}$. In addition, Iglesias et al. also reported the synthesis of nitrogen-doped graphitized single wall carbon nanohorns (CNHs) by coating polydopamine (PDA) followed by annealing, ${ }^{106}$ which also exhibited high catalytic activity with a very positive onset potential, high Faradaic efficiency, and excellent stability in a wide $\mathrm{pH}$ range from 1.0 to 13.0. In their work, the outstanding performances were assigned to their specific $\mathrm{N}_{\text {pyridinic }} / \mathrm{N}_{\text {pyrrolic }}$ ratios and microporosity. Besides, our group also reported improved ORR activity and $\mathrm{H}_{2} \mathrm{O}_{2}$ selectivity induced by nitrogen doping and observed the different roles of nitrogen doping species during the ORR process by means of ex situ XPS, where pyridinic-N contributed to the catalytic ORR process in acid medium while graphitic-N groups appeared to be catalytically active moieties in neutral and alkaline conditions. ${ }^{63,107}$ Further, our group investigated the effect of graphene precursors with different in-plane carbon lattice defect density on the subsequent nitrogen doping and the catalytic performances of their derived nitrogen-doped graphene.
The resultant nitrogen-doped graphene derived from oxo-G with lower carbon lattice defect density exhibited the highest $\mathrm{H}_{2} \mathrm{O}_{2}$ selectivity. Similar to nitrogen, fluorine doping can also create active sites through inducing the polarization of adjacent carbon, which is beneficial for improving the ORR performances. Moreover, the fluorine doping content and different fluorine species were also found to influence the catalytic activity and selectivity toward $\mathrm{H}_{2} \mathrm{O}_{2}$ production. For instance, Zhao et al. reported the synthesis of fluorine-doped hierarchically porous carbon (FPC) from an aluminum-based MOF. ${ }^{108}$ Electrochemical measurements and DFT calculations demonstrated that the incorporation of $\mathrm{CF}_{2,3}$ atoms into carbon frameworks could facilitate the adsorption of $\mathrm{O}_{2}$ and desorption of reactive intermediate $\mathrm{HOO}^{*}$, thus resulting in significantly increased activity and selectivity toward $\mathrm{H}_{2} \mathrm{O}_{2}$ production.

In addition to the two-electron ORR process, the twoelectron WOR process has also been widely investigated theoretically and experimentally for $\mathrm{H}_{2} \mathrm{O}_{2}$ production recently. ${ }^{111}$ For instance, Nørskov's group presented a thermodynamic picture of the adsorption free energies of the intermediates $\left(\mathrm{HO}^{*}\right)$ on the surface of different catalysts for the three different reaction pathways using thermodynamic analysis based on DFT calculations, and $\mathrm{SnO}_{2}$ and $\mathrm{TiO}_{2}$ were identified as promising candidate materials with good selectivity for $\mathrm{H}_{2} \mathrm{O}_{2}$ production. $^{33,112}$ Subsequently, they further adopted DFT calculations to investigate the trends in activity of four different oxides including $\mathrm{WO}_{3}, \mathrm{SnO}_{2}, \mathrm{TiO}_{2}$ and $\mathrm{BiVO}_{4}$ for water oxidation toward $\mathrm{H}_{2} \mathrm{O}_{2}$ production. ${ }^{109} \mathrm{BiVO}_{4}$ was identified theoretically and experimentally as the best catalyst for $\mathrm{H}_{2} \mathrm{O}_{2}$ production with a high FE of $70 \%$ in the dark and $98 \%$ under 1 sun illumination under the condition of the optimal bias range (Fig. 4a). Nevertheless, there also exist some limitations of the $\mathrm{BiVO}_{4}$ catalyst, including high over-potential and poor stability from $\mathrm{VO}_{4}{ }^{3-}$ dissolution. Recently, Zheng's group developed an efficient method to improve the activity and stability of $\mathrm{BiVO}_{4}$ for $\mathrm{H}_{2} \mathrm{O}_{2}$ production by doping rare earth element gadolinium (Gd). ${ }^{65}$ Theoretical calculation results demonstrated that Gd doping not only makes several facets of $\mathrm{BiVO}_{4}$ more active for $\mathrm{H}_{2} \mathrm{O}_{2}$ production, but also results in the increase of the energy barrier of $\mathrm{VO}_{4}{ }^{3-}$ dissolution. Experimentally, the Gd-doped $\mathrm{BiVO}_{4}$ exhibited a significant decrease of the onset potential for $\mathrm{H}_{2} \mathrm{O}_{2}$ production by around $110 \mathrm{mV}$ with a high $\mathrm{FE}$ of around $99.5 \%$ and a substantially prolonged catalytic lifetime under illumination. Meanwhile, the same group also employed DFT calculations to identify another two efficient and selective WOR catalysts for $\mathrm{H}_{2} \mathrm{O}_{2}$ production, including $\mathrm{CaSnO}_{3}$ and $\mathrm{ZnO}$, which were also verified experimentally (Fig. $4 \mathrm{~b}-\mathrm{d}$ ). ${ }^{64,110}$

\section{Photocatalytic materials for $\mathrm{H}_{2} \mathrm{O}_{2}$ production}

Semiconductor photocatalysts have been widely applied in the field of various solar energy storage and conversion systems including dye-sensitized solar cells (DSSCs), photocatalytic water splitting and $\mathrm{CO}_{2}$ reduction since Fujishima and Honda first demonstrated the photocatalytic application of $\mathrm{TiO}_{2}$ in 1972. ${ }^{113-115}$ 

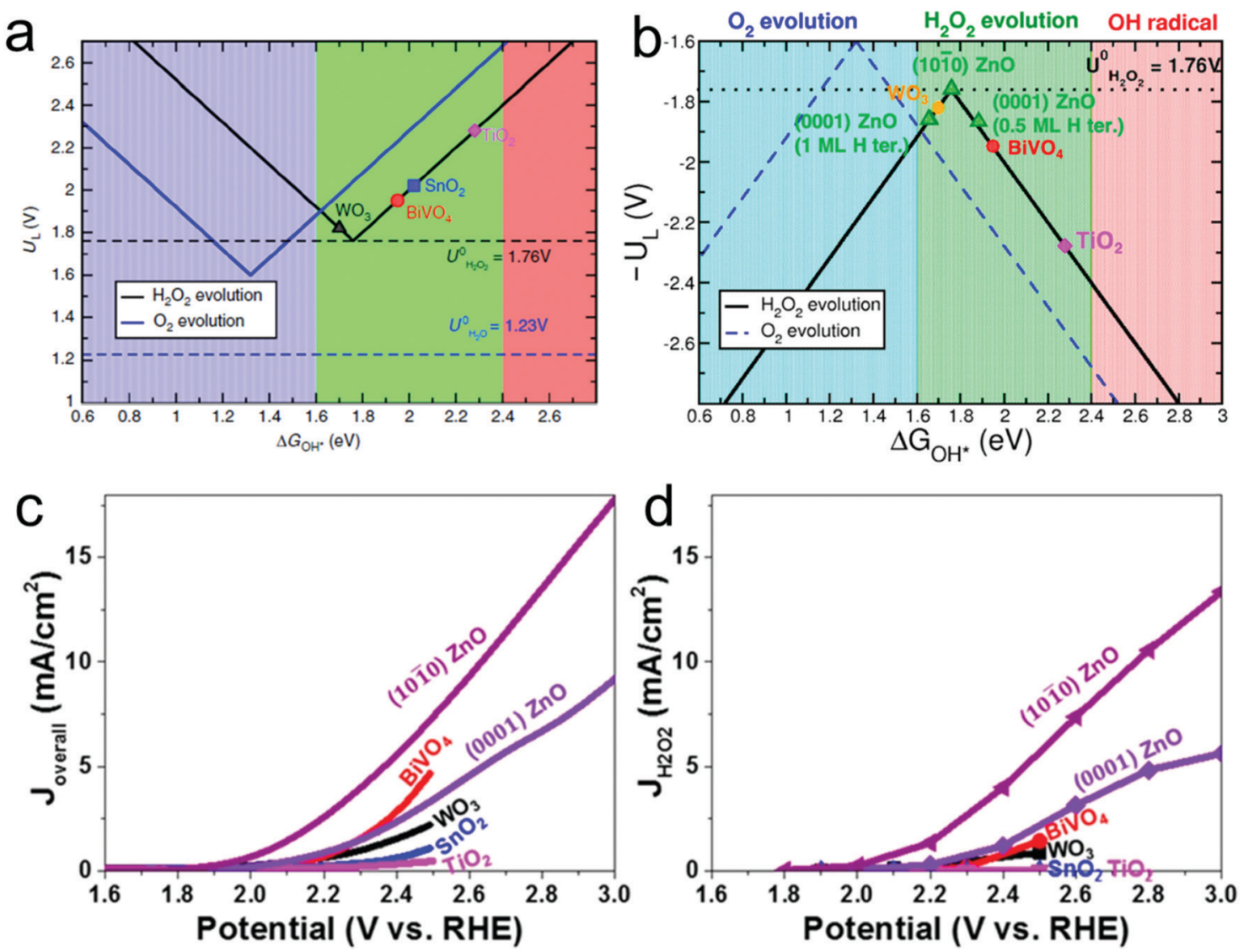

Fig. 4 (a) Activity volcano plots based on calculated limiting potentials as a function of calculated adsorption energies of $H O *$ ( $\Delta G_{H O}$ ) for two-electron oxidation of water to hydrogen peroxide evolution (black) and four-electron oxidation to oxygen evolution (blue). The corresponding equilibrium potentials for each reaction are shown as dashed lines. (b) Volcano plots showing the calculated limiting potential UL for four-electron $\mathrm{H}_{2} \mathrm{O}$ oxidation to $\mathrm{O}_{2}$ (blue dashed line) and two-electron $\mathrm{H}_{2} \mathrm{O}$ oxidation to $\mathrm{H}_{2} \mathrm{O}_{2}$ (black solid line) as a function of $\Delta G_{\mathrm{HO}}$. The convention is such that a low value of $\mathrm{UL}$ (a high value of $-\mathrm{UL}$ ) corresponds to a low overpotential and thus a high rate. The full lines correspond to the trend model described in the text, and DFT calculated values for different catalyst materials are included. The 0.5 and $1 \mathrm{ML} \mathrm{H}$ ter. of (0001) $\mathrm{ZnO}$ indicate two different terminations at the bottom of the slabs. (c) Overall current density $J-V$ curves for (1010) $\mathrm{ZnO}$, (0001) $\mathrm{ZnO}$, and several reported metal oxides. (d) Corresponding $\mathrm{J}_{\mathrm{H}_{2} \mathrm{O}_{2}}-V$ curves for the current density toward $\mathrm{H}_{2} \mathrm{O}_{2}$ formation, for which $\mathrm{J}_{\mathrm{H}_{2}} \mathrm{O}_{2}$ was calculated by multiplying the overall current $J_{\text {overall }}$ by the Faraday efficiency at each potential. (a) Reprinted with permission. ${ }^{109}$ Copyright 2017, Nature publishing group. (b-d) Reprinted with permission. ${ }^{110}$ Copyright 2019 , American Chemical Society.

Recent studies also began to focus on the design and development of advanced semiconductor photocatalysts with novel compositions and structures for photocatalytic $\mathrm{H}_{2} \mathrm{O}_{2}$ production. To date, the reported semiconductor photocatalysts mainly include metal oxides, metal-organic complexes, and metal-free graphitic carbon nitride (Table 1). Subsequently, recent progress on these photocatalysts will be discussed in detail below.

\subsection{Metal oxides}

Metal oxide semiconductors have been proposed as promising catalysts for photocatalytic $\mathrm{H}_{2} \mathrm{O}_{2}$ production because of their general superior stability to liquid electrolytes and facile preparation. ${ }^{60,116}$ Among the various metal oxide semiconductors, $\mathrm{TiO}_{2}$ is the most widely investigated but usually showed unsatisfactory efficiency for $\mathrm{H}_{2} \mathrm{O}_{2}$ production within the micro molar range. This is largely a consequence of the intrinsic properties of $\mathrm{TiO}_{2}$ related to its band gap width and band gap structure, coupled with the sluggish intrinsic surface reaction kinetics of water oxidation, low selectivity toward the two-electron ORR for $\mathrm{H}_{2} \mathrm{O}_{2}$ production, and the decomposition of the produced $\mathrm{H}_{2} \mathrm{O}_{2}$ by the absorbed UV light and photo-generated electrons/holes, thus significantly hampering the overall photocatalytic performances. ${ }^{37}$ In order to mitigate the problems above, various strategies have been explored to improve the photocatalytic performances for $\mathrm{H}_{2} \mathrm{O}_{2}$ production over $\mathrm{TiO}_{2}$-based photocatalysts, including the incorporation of noble metal ${ }^{60,66,117}$ and carbon materials, ${ }^{48,118}$ and reaction medium optimization. ${ }^{47,119}$

The introduction of noble metals is one powerful route for the design and preparation of advanced $\mathrm{TiO}_{2}$-based photocatalysts for $\mathrm{H}_{2} \mathrm{O}_{2}$ production. The most commonly used noble metals include $\mathrm{Au},{ }^{60}$ the $\mathrm{Au}-\mathrm{Ag}$ bimetallic alloy, ${ }^{66}$ and $\mathrm{Pd} .{ }^{120}$ For instance, Tada's group demonstrated a significant improvement in $\mathrm{H}_{2} \mathrm{O}_{2}$ production through loading Au nanoparticles on the surface of $\mathrm{TiO}_{2} \cdot{ }^{60}$ On one hand, the formation of a junction between $\mathrm{Au}$ and $\mathrm{TiO}_{2}$ was beneficial for efficient photo-induced 
Table 1 Summary of the reported photocatalysts for $\mathrm{H}_{2} \mathrm{O}_{2}$ production

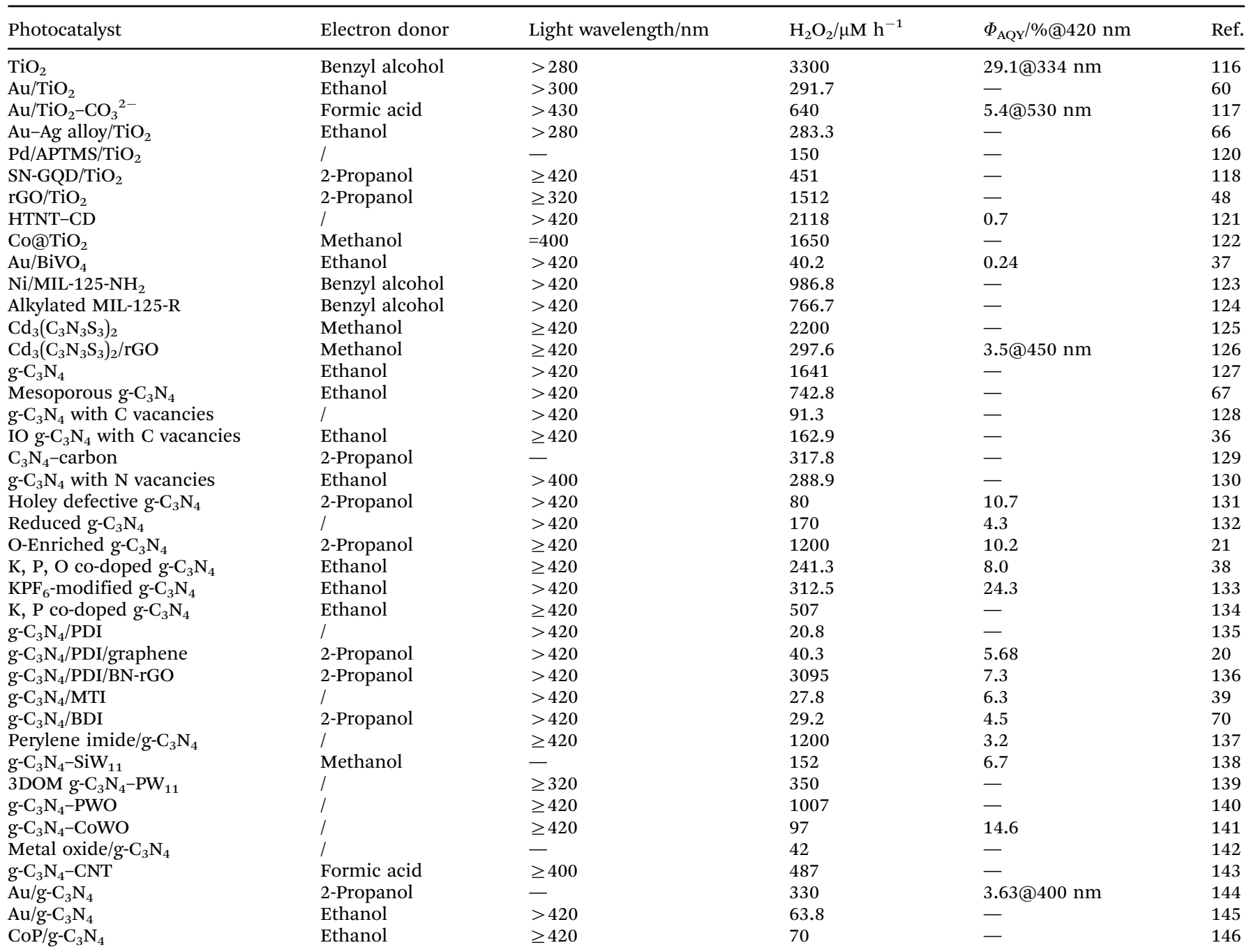

Note: APTMS is aminopropyltrimethoxysilane. HTNT-CD is proton-form titania nanotubes with carbon dots. IO g- $\mathrm{C}_{3} \mathrm{~N}_{4}$ means inverse opal g-C $\mathrm{C}_{3} \mathrm{~N}_{4}$. "/" means without the use of an electron donor.

interfacial electron transfer from $\mathrm{TiO}_{2}$ to $\mathrm{Au}$. On the other hand, these transferred electrons were favorable to selectively follow the two-electron ORR process toward $\mathrm{H}_{2} \mathrm{O}_{2}$ production over the Au nanoparticles. These two effects both resulted in efficient $\mathrm{H}_{2} \mathrm{O}_{2}$ production. Nevertheless, Au particles were also found to promote the decomposition of $\mathrm{H}_{2} \mathrm{O}_{2}$ by reduction with the transferred electrons due to their strong adsorption for $\mathrm{H}_{2} \mathrm{O}_{2}$ molecules. ${ }^{66}$ In this regard, the introduction of $\mathrm{Au}-\mathrm{Ag}$ bimetallic alloy particles as a substitute for Au was reported to address this dilemma and showed improved efficiency for $\mathrm{H}_{2} \mathrm{O}_{2}$ production by means of the decreased adsorption of $\mathrm{H}_{2} \mathrm{O}_{2}$ onto the $\mathrm{Au}$ atoms (Fig. 5a and b). ${ }^{66}$ Recently, Kim's group reported the synthesis of electronically tuned Pd nanoparticles loaded on a $\mathrm{TiO}_{2}$ substrate by coordinating organic ligands on the surface of Pd. ${ }^{120}$ The increased negative charge on the surface of Pd nanoparticles induced by electron donation from amine groups of the coordinated ligands was found to facilitate enhanced catalytic activity and selectivity for the two-electron
ORR for $\mathrm{H}_{2} \mathrm{O}_{2}$ production (Fig. 5c-e). In short, the introduction of noble metals plays several different vital roles in enhancing the photocatalytic performances: (1) promoting the separation of photo-generated electron-hole pairs through the formation of a hetero-junction between the metal and metal oxide semiconductor; (2) reducing the decomposition of the produced $\mathrm{H}_{2} \mathrm{O}_{2}$ through suppressing the adsorption of $\mathrm{H}_{2} \mathrm{O}_{2}$ on the surface of photocatalysts; and (3) improving the $\mathrm{H}_{2} \mathrm{O}_{2}$ selectivity by promoting the desired two-electron ORR. Nevertheless, despite improved $\mathrm{H}_{2} \mathrm{O}_{2}$ efficiencies, there still exist other challenges that need viable solutions, such as the low quantum efficiency resulting from UV illumination and wide band gap semiconductors, and the continuous need for a suitable electron donor molecule in the liquid phase.

In addition to noble metals, carbon materials were considered as promising candidates for the fabrication of high performance metal-oxide-based photocatalysts due to low cost, large surface area, and high conductivity. ${ }^{48,118}$ In particular, 

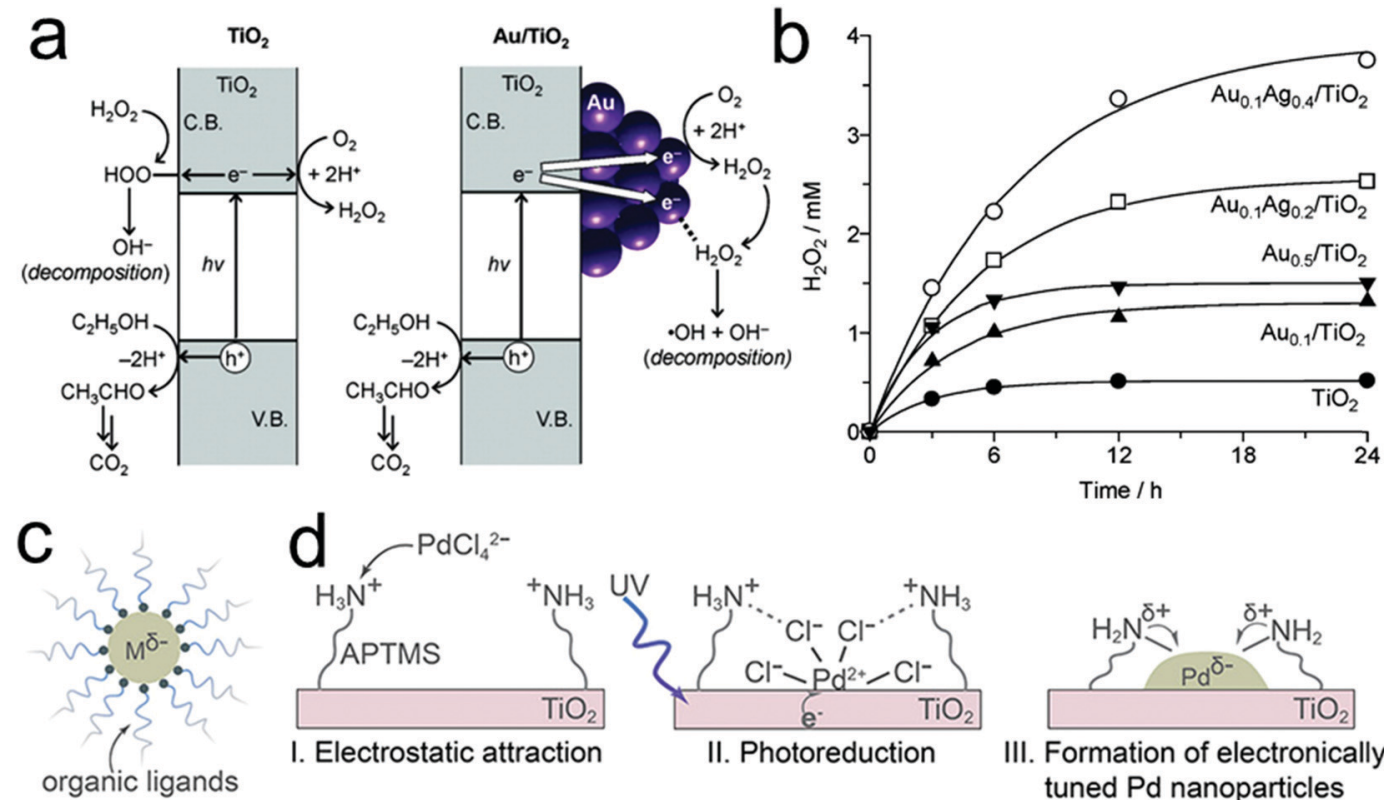

I. Electrostatic attraction

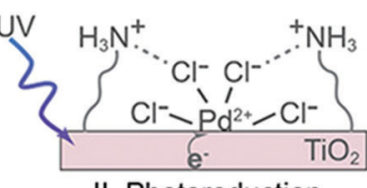

II. Photoreduction

III. Formation of electronically tuned Pd nanoparticles

e

Pathway 1 (four-electron ORR for $\mathrm{H}_{2} \mathrm{O}$ generation)

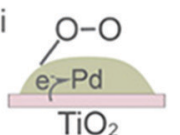
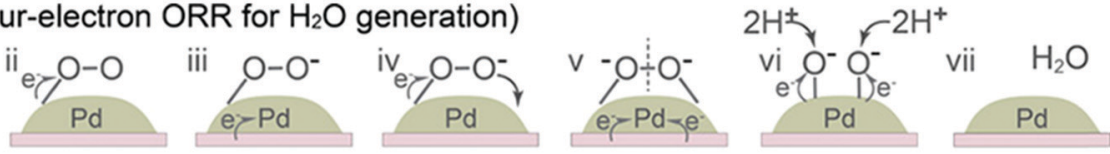

Pathway 2 (two-electron $\mathrm{ORR}$ for $\mathrm{H}_{2} \mathrm{O}_{2}$ generation)
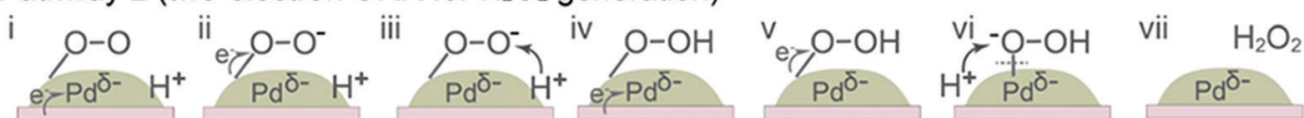

Fig. 5 (a) Photocatalytic formation and decomposition of $\mathrm{H}_{2} \mathrm{O}_{2}$ on $\mathrm{TiO}_{2}$ and $\mathrm{Au} / \mathrm{TiO}_{2}$ catalysts; (b) time-dependent change in $\mathrm{H}_{2} \mathrm{O}_{2}$ concentration during the photoreaction with the respective catalysts; (c) solvent-dispersed metal nanoparticles that are electronically tuned by coordinating with dissolved organic ligands; (d) preparation of electronically tuned $\mathrm{Pd}$ nanoparticles on $\mathrm{TiO}_{2}$ by coordinating with immobilized organic ligands; and (e) mechanisms of oxygen reduction on the surface of Pd nanoparticles. (a and b) Reprinted with permission. ${ }^{66}$ Copyright 2012 , American Chemical Society. (c-e) Reprinted with permission. ${ }^{120}$ Copyright 2018, American Chemical Society.

carbon quantum dots (CQDs), a kind of amorphous carbon along with $\mathrm{sp}^{2}$ hybridized graphitic carbon, have received considerable attention in the fields of bio-imaging, biosensors, and other opto-electrical devices due to their unique features such as fluorescence properties with excitation wavelengthdependent multi-color emission. ${ }^{147}$ This fascinating feature made CQDs a promising concept in order to expand the absorption capability of photocatalysts into smaller band gaps, thereby harvesting photons in the range of the UV-visible spectral region. Recently, Xiao's group reported a hybrid photocatalyst of protonated $\mathrm{TiO}_{2}$ nanotubes and CQDs (PTNT-CQD) with an $\mathrm{H}_{2} \mathrm{O}_{2}$ productivity of $3.42 \mathrm{mmol} \mathrm{g}_{\text {cat }}{ }^{-1} \mathrm{~h}^{-1}$, a solar-to$\mathrm{H}_{2} \mathrm{O}_{2}$ efficiency of $5.2 \%$, and good continuous cyclic stability under visible-light illumination. ${ }^{121}$ The protons on PTNT-CQD were found to play critical roles in boosting the two-electron ORR for $\mathrm{H}_{2} \mathrm{O}_{2}$ production and suppressing the decomposition of the produced $\mathrm{H}_{2} \mathrm{O}_{2}$. Long's group also utilized highly luminescent sulfur and nitrogen co-doped graphene quantum dots (SN-GQDs) that were loaded on the surface of $\mathrm{TiO}_{2}$ in order to extend the light absorption into the visible light region and promote the migration of photo-generated electrons. ${ }^{118}$ Moreover, the introduction of SN-GQDs resulted in a promoted twoelectron ORR accompanied by the suppressed decomposition of $\mathrm{H}_{2} \mathrm{O}_{2}$, thus achieving photocatalytic performances with an $\mathrm{H}_{2} \mathrm{O}_{2}$ productivity of $451 \mu \mathrm{mol} \mathrm{L}{ }^{-1}$. Besides, a similar role of graphene was also observed in the photocatalytic systems of $\mathrm{WO}_{3}$ and $\mathrm{TiO}_{2} / \mathrm{WO}_{3}$ composites for enhanced performances for photocatalytic $\mathrm{H}_{2} \mathrm{O}_{2}$ production. ${ }^{148,149}$

The photocatalytic performance of a semiconductor photocatalyst is usually dependent on the bulk (e.g. light absorption, separation and recombination of photo-generated electron and hole pairs, and band edge position) and surface (e.g. structural defects and reconstruction, and surface charge) properties. ${ }^{119}$ However, the optimization of the entire catalytic solid-liquid interface is of the essence to arrive at a viable photocatalytic reaction system. For instance, a recent study examined the role of the reaction medium in the regulation of the surface properties of semiconductor photocatalysts for $\mathrm{H}_{2} \mathrm{O}_{2}$ production. More specifically, the study focused on the electrolyte's $\mathrm{pH}$, the addition of inorganic anions and cations, and the nature of 
the sacrificial electron donor. The authors highlighted how surface passivation through complexation with metal cations or non-metal anions leads to blocking of the trapping sites ( $\equiv \mathrm{Ti}-\mathrm{OH}$ ) on the surface of $\mathrm{TiO}_{2}$ for photo-generated electrons and holes, and thereby suppresses the formation of $\equiv \mathrm{Ti}-\mathrm{OOH}$ complexes for the decreased decomposition of $\mathrm{H}_{2} \mathrm{O}_{2}$. For instance, the introduction of $\mathrm{Cu}$ ions and $\mathrm{Zn}$ ions into the photocatalytic system resulted in an increased $\mathrm{H}_{2} \mathrm{O}_{2}$ yield over the $\mathrm{TiO}_{2}$ photocatalyst and the surface coverage of $\mathrm{Zn}$ ions was also observed to be strongly dependent on the electrolyte's pH. ${ }^{119,150}$ In addition, the introduction of $\mathrm{F}^{-}$also achieved enhanced efficiency for photocatalytic $\mathrm{H}_{2} \mathrm{O}_{2}$ production through surface fluorination to prohibit the surface complexation of superoxide/peroxide species and the decomposition of the produced $\mathrm{H}_{2} \mathrm{O}_{2} \cdot{ }^{47}$ These results demonstrated the important roles of surface speciation during the photocatalytic process and also provided insights on improving the photocatalytic $\mathrm{H}_{2} \mathrm{O}_{2}$ production efficiency by the combined effect of $\mathrm{pH}$ and surface passivation. On the other hand, ethanol is usually used as an electron and proton donor in photocatalytic systems for $\mathrm{H}_{2} \mathrm{O}_{2}$ production in order to promote the separation of photo-generated electrons and holes by replacing water oxidation with sluggish kinetics. Recently, the use of benzylic alcohols as a substitute for ethanol was found to further improve the $\mathrm{H}_{2} \mathrm{O}_{2}$ yield up to ca. $40 \mathrm{mM}$, which was attributed to the efficient formation of side-on coordinated peroxo species on the surface of the $\mathrm{TiO}_{2}$ photocatalyst through the reaction between benzylic alcohol and $\mathrm{O}_{2}{ }^{116}$ The formed peroxo species can be easily converted into $\mathrm{H}_{2} \mathrm{O}_{2}$, thus facilitating highly efficient $\mathrm{H}_{2} \mathrm{O}_{2}$ production.

Direct production of $\mathrm{H}_{2} \mathrm{O}_{2}$ without the need for sacrificial organic electron donors in the photocatalytic system is desirable from the viewpoint of green chemistry and sustainability. To that effect, Choi's group reported enhanced $\mathrm{H}_{2} \mathrm{O}_{2}$ production up to a milli molar level over reduced graphene oxide (rGO)/ $/ \mathrm{TiO}_{2}$ composites in the presence of phosphate and cobalt ions in the absence of organic electron donors. ${ }^{48}$ On the one hand, the improvements were attributed to the synergistic effect of RGO, phosphate and cobalt ions. The introduced RGO can be used as an electron mediator to facilitate the separation of photo-generated electron-hole pairs thanks to the lower Fermi level compared to the conduction band edge of $\mathrm{TiO}_{2}$. Furthermore, RGO can also be used as a co-catalyst to promote the two-electron ORR for $\mathrm{H}_{2} \mathrm{O}_{2}$ production. On the other hand, two different roles of phosphate were observed in their work: (1) phosphate can be used as a surface passivation agent to retard the adsorption and decomposition of the produced $\mathrm{H}_{2} \mathrm{O}_{2}$ within a wide range of $\mathrm{pH}$; and (2) phosphate reacts with cobalt ions for in situ formation of cobalt phosphate complexes on the surface of the $\mathrm{RGO} / \mathrm{TiO}_{2}$ composite as a water oxidation co-catalyst to promote water oxidation.

Given that visible light is dominant in the solar spectrum and UV light induces the decomposition of the produced $\mathrm{H}_{2} \mathrm{O}_{2}$, the development of visible-light-driven photocatalysts is highly desirable for efficient and sustainable $\mathrm{H}_{2} \mathrm{O}_{2}$ production. In this regard, Shiraishi's group reported the design and synthesis of an advanced inorganic photocatalyst consisting of $\mathrm{Au}$ nanoparticles loaded on $\mathrm{BiVO}_{4}$ for highly efficient $\mathrm{H}_{2} \mathrm{O}_{2}$ production from water and $\mathrm{O}_{2}$ under visible light illumination (Fig. 6). ${ }^{37}$ In their work, $\mathrm{BiVO}_{4}$ possesses not only a narrow band gap for a visible-light response, but also a proper position of the $\mathrm{CB}$ edge $\left(+0.02 \mathrm{~V}_{\mathrm{SHE}}\right)$ between the one-electron ORR potential $\left(-0.13 \mathrm{~V}_{\mathrm{SHE}}\right)$ and the two-electron ORR potential $\left(+0.68 \mathrm{~V}_{\text {SHE }}\right)$, thus facilitating selective $\mathrm{H}_{2} \mathrm{O}_{2}$ production. Besides, the formation of a junction between $\mathrm{Au}$ and $\mathrm{BiVO}_{4}$ was also favorable for the separation of photo-generated electron-hole pairs and the two-electron ORR for $\mathrm{H}_{2} \mathrm{O}_{2}$ production.

\subsection{Metal-organic-frameworks or metal-coordination polymers}

Metal-organic-frameworks (MOFs), a family of coordination materials consisting of secondary building units interconnected by organic linkers, have been widely investigated in various fields of gas storage/separation, drug delivery, sensors, and catalysis due to their significant advantages of facile preparation, high surface area, and adjustable composition and structure. ${ }^{151-155}$ Recently, MOFs with amine-functionalization of terephthalic acid as an organic linker have been demonstrated to catalyze various photocatalytic reactions such as water splitting, $\mathrm{CO}_{2}$ reduction and oxidation of organic compounds. ${ }^{156-159}$ For instance, Yamashita's group reported photocatalytic $\mathrm{H}_{2} \mathrm{O}_{2}$ production over a MOF photocatalyst consisting of $\mathrm{Ti}_{8} \mathrm{O}_{8}(\mathrm{OH})_{4}$ clusters and 2-aminoterephthalic acid linkers (MIL-125- $\mathrm{NH}_{2}$ ) in the presence of triethanolamine (TEOA) and benzyl alcohol under visible-light illumination. ${ }^{123}$ In this case, Ti(Iv) within the $\mathrm{Ti}_{8} \mathrm{O}_{8}(\mathrm{OH})_{4}$ clusters was first reduced to $\mathrm{Ti}(\mathrm{III})$ by ligand-tocluster electron transfer (LCET), which can be used to further reduce $\mathrm{O}_{2}$ to produce the ${ }^{\bullet} \mathrm{O}_{2}{ }^{-}$intermediate with subsequent fast disproportionation for $\mathrm{H}_{2} \mathrm{O}_{2}$ production, whereas benzyl alcohol was oxidized to benzaldehyde by photo-generated holes. Nevertheless, the resultant mixture of $\mathrm{H}_{2} \mathrm{O}_{2}$ and benzaldehyde dissolved in acetonitrile brought difficulty in the separation process and thus resulted in high energy consumption. Later, they applied a two-phase system consisting of benzyl alcohol and water to achieve efficient separation between $\mathrm{H}_{2} \mathrm{O}_{2}$ and benzaldehyde accompanied by enhanced photocatalytic $\mathrm{H}_{2} \mathrm{O}_{2}$ production, which mainly benefited from the hydrophobization of the MOF by the modification of alkyl chains (Fig. 7). ${ }^{124}$ Moreover, the concentration of the obtained $\mathrm{H}_{2} \mathrm{O}_{2}$ solution can be easily tuned by the volume of the aqueous phase.

In addition, metal coordination polymers have also been investigated as robust photocatalysts for $\mathrm{H}_{2} \mathrm{O}_{2}$ production, which was mainly inspired by the structure of superoxide dismutases (SODs) in nature systems consisting essentially of late transition metal ions as central atoms and proteins as organic ligands. ${ }^{160}$ Long's group developed an octahedral $\mathrm{Cd}_{3}\left(\mathrm{C}_{3} \mathrm{~N}_{3} \mathrm{~S}_{3}\right)_{2}$ coordination polymer as a kind of novel noblemetal-free photocatalyst for photocatalytic $\mathrm{H}_{2} \mathrm{O}_{2}$ production in a mixture of methanol and water solution, where high $\mathrm{H}_{2} \mathrm{O}_{2}$ productivity of $c a .110 .0 \mathrm{mmol} \mathrm{L}^{-1} \mathrm{~g}^{-1}$ at $\mathrm{pH}=2.8$ could be achieved under visible-light illumination. ${ }^{125}$ In order to further improve the $\mathrm{H}_{2} \mathrm{O}_{2}$ production efficiency, they introduced RGO as a $2 \mathrm{D}$ support to modulate the growth and formation of 

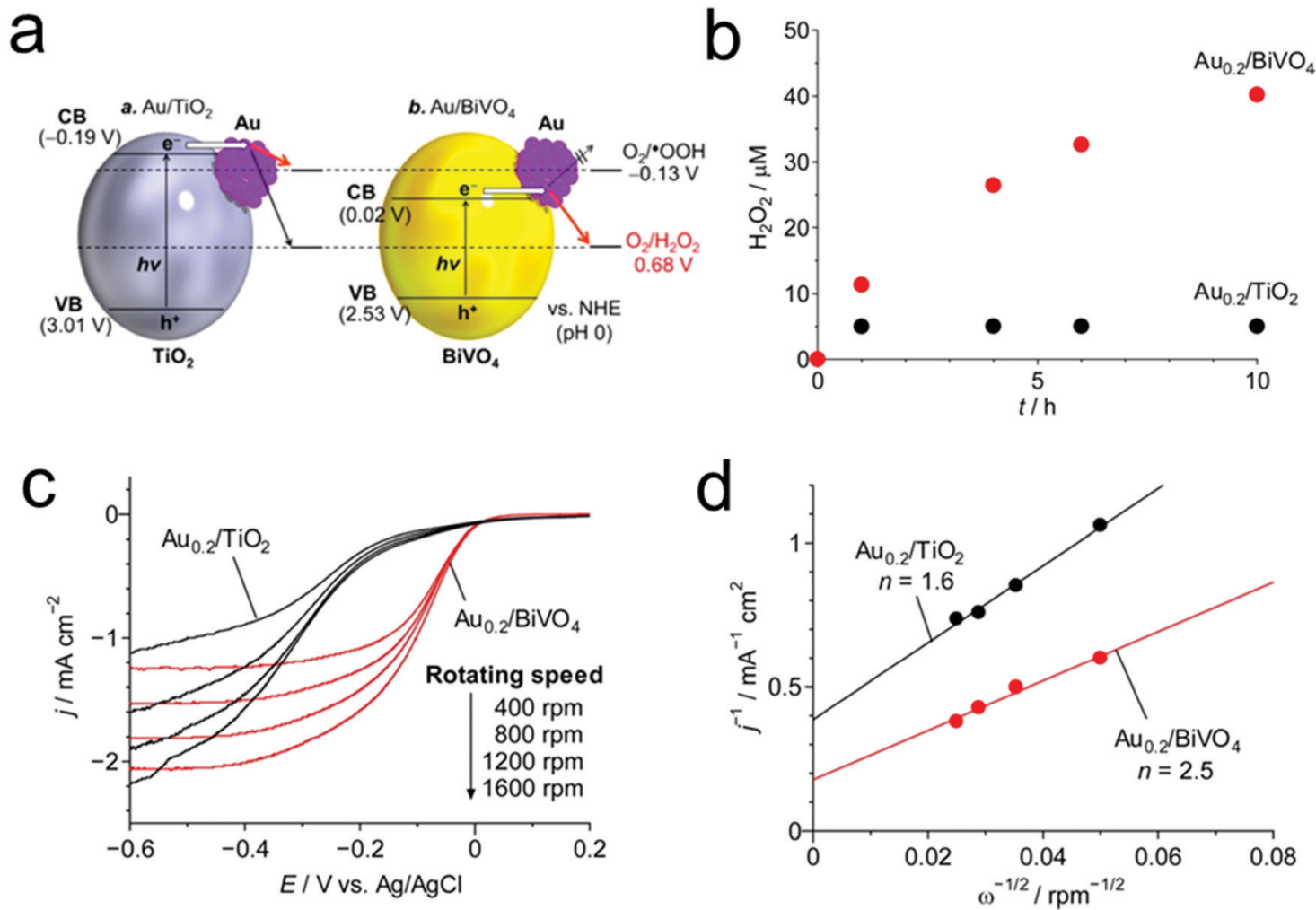

Fig. 6 (a) Energy diagrams for $\mathrm{Au} / \mathrm{TiO}_{2}$ and $\mathrm{Au} / \mathrm{BiVO}_{4}$ and the reduction potential of $\mathrm{O}_{2}$; (b) time-dependent changes in the $\mathrm{H}_{2} \mathrm{O}_{2}$ concentrations during the photoreaction on $\mathrm{Au}_{0.2} / \mathrm{TiO}_{2}(\lambda>300 \mathrm{~nm})$ and $\mathrm{Au}_{0.2} / \mathrm{BiVO}_{4}$ prepared by calcination at $673 \mathrm{~K}(\lambda>420 \mathrm{~nm})$; (c) linear-sweep voltammograms of $\mathrm{Au}_{0.2} / \mathrm{TiO}_{2}$ and $\mathrm{Au}_{0.2} / \mathrm{BiVO}_{4}$ prepared by calcination at $673 \mathrm{~K}$, measured on a rotating-disk electrode at different rotating speeds and (d) Koutecky-Levich plots of the data obtained at a constant potential $\left(-0.3\right.$ V). Reprinted with permission. ${ }^{37}$ Copyright 2016 American Chemical Society.
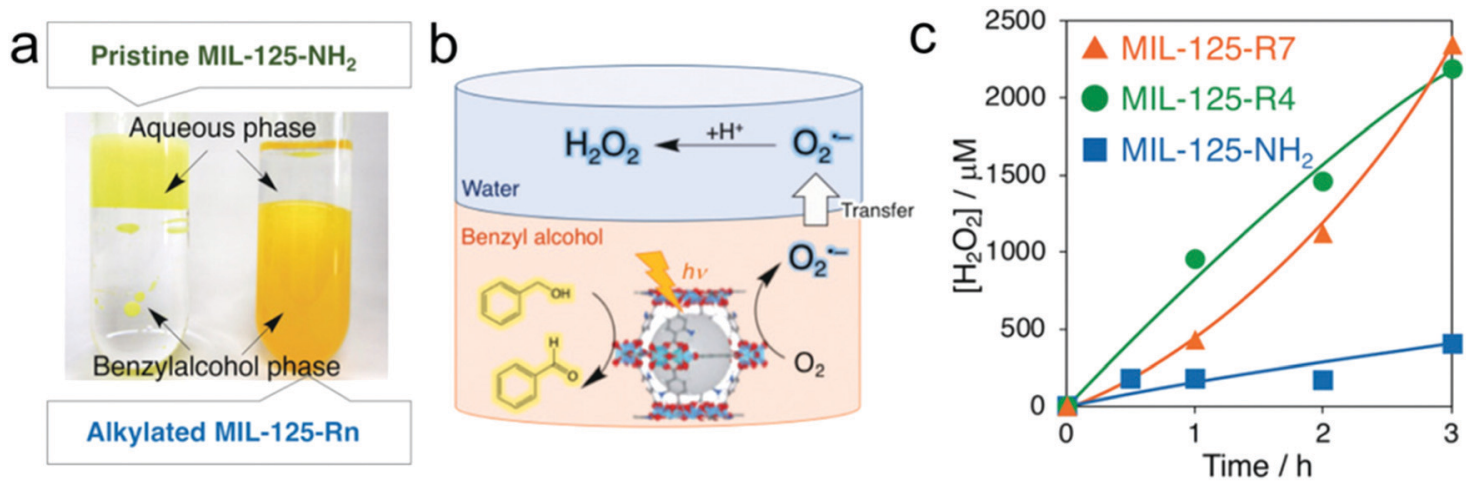

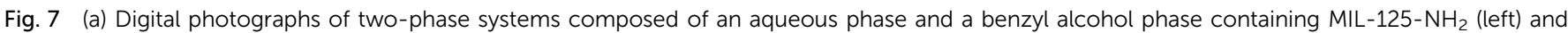
MIL-125-Rn (right); (b) photocatalytic $\mathrm{H}_{2} \mathrm{O}_{2}$ production utilizing the two-phase system; and (c) time courses of $\mathrm{H}_{2} \mathrm{O}_{2}$ production under photoirradiation $(\lambda>420 \mathrm{~nm})$ of the two-phase system composed of benzyl alcohol $(5.0 \mathrm{~mL})$ and water $(2.0 \mathrm{~mL})$ catalyzed by $5.0 \mathrm{mg}$ of MIL-125-NH $(\mathrm{blue}), \mathrm{MIL}-125-\mathrm{R} 4$ (green), and MIL-125-R7 (orange). Reprinted with permission. ${ }^{124}$ Copyright 2019 Wiley-VCH.

$\mathrm{Cd}_{3}\left(\mathrm{C}_{3} \mathrm{~N}_{3} \mathrm{~S}_{3}\right)_{2}$, leading to accelerated photo-generated charge transfer and thus achieving 2.5 -fold enhancement. ${ }^{126}$

\subsection{Metal-free graphitic carbon nitride}

Graphitic carbon nitride $\left(\mathrm{g}-\mathrm{C}_{3} \mathrm{~N}_{4}\right)$ possesses a graphitic stacking structure of $\mathrm{C}_{3} \mathrm{~N}_{4}$ layers comprising tri-s-triazine units connected through planar amino groups. ${ }^{67,127,135,161}$ To date, $\mathrm{g}-\mathrm{C}_{3} \mathrm{~N}_{4}$-based materials as metal-free organic polymeric semiconductor photocatalysts have received wide attention in the fields of water splitting, ${ }^{162-164}$ the $\mathrm{ORR},{ }^{165} \mathrm{CO}_{2}$ reduction, ${ }^{166,167}$ organic photosynthesis, ${ }^{168}$ and organic pollutant degradation, ${ }^{169}$ due to their facile preparation, environmentally friendly nature, low-cost, reliable thermal and chemical stability and, more importantly, appropriate band gap structure for a visible light response and target reactions, ${ }^{165}$ since the first report about the excellent performances in photocatalytic hydrogen production by Antonietti's group in 2009. ${ }^{161}$ Recently, Shiraishi's group extended the application of the g- $\mathrm{C}_{3} \mathrm{~N}_{4}$ 
photocatalyst into photocatalytic $\mathrm{H}_{2} \mathrm{O}_{2}$ production. ${ }^{127}$ They pointed out that the efficient formation of 1,4-endoperoxide species on the surface of $\mathrm{g}-\mathrm{C}_{3} \mathrm{~N}_{4}$ could suppress the oneelectron ORR to produce $\cdot \mathrm{OOH}$ and promote the selective two-electron ORR to produce $\mathrm{H}_{2} \mathrm{O}_{2}$, thus resulting in high $\mathrm{H}_{2} \mathrm{O}_{2}$ selectivity. Nevertheless, the overall photo-conversion efficiency is still low because of the limited absorption and utilization in the visible-light region, the poor separation efficiency of photo-generated electrons and holes, and the sluggish kinetics for water oxidation, and thus needs to be further improved prior to practical applications. In this regard, various strategies have been actively developed in order to improve the photocatalytic performances of g- $\mathrm{C}_{3} \mathrm{~N}_{4}$ for $\mathrm{H}_{2} \mathrm{O}_{2}$ production such as self-modification, chemical modification, and hybridization with other materials including noble metals and metal phosphides.

In recent years, self-modification of g- $\mathrm{C}_{3} \mathrm{~N}_{4}$ could be achieved by the introduction of carbon vacancies, nitrogen vacancies, and heteroatom doping. Wang's group demonstrated improved photocatalytic $\mathrm{H}_{2} \mathrm{O}_{2}$ production efficiency over g- $\mathrm{C}_{3} \mathrm{~N}_{4}$ through the incorporation of carbon vacancies. ${ }^{128}$ Two important roles of carbon vacancies were proposed: (1) reducing the symmetry and band gap of $\mathrm{C}_{3} \mathrm{~N}_{4}$ facilitated the extension of the visible-light absorption and the increase of photo-generated electrons; and (2) increasing the catalytic sites enhanced the adsorption and activation of $\mathrm{O}_{2}$ molecules and induced the transformation of the $\mathrm{H}_{2} \mathrm{O}_{2}$ production pathway from the two-step one-electron ORR to the one-step two-electron ORR. An inverse opal (IO) structure was also introduced into $\mathrm{g}-\mathrm{C}_{3} \mathrm{~N}_{4}$ with carbon vacancies to further improve the efficiency for $\mathrm{H}_{2} \mathrm{O}_{2}$ production through the enhanced absorption and utilization of visible light, and increased surface area, which benefited from the unique structural advantages of the IO structure such as the slow photon effect, Bragg diffraction and scattering. ${ }^{36}$ Besides, a series of $\mathrm{g}^{-} \mathrm{C}_{3} \mathrm{~N}_{4}$ with tunable doping of foreign carbon was also prepared by a facile hydrothermal reaction of glucose with subsequent thermal treatment. ${ }^{129}$ The energy levels of the resultant carbon-doped g- $\mathrm{C}_{3} \mathrm{~N}_{4}$ were found to vary with the doping content of carbon, accompanied by the positive shift of the conduction and valence band, which was favorable for a selective two-electron ORR and achieved two-fold enhancement of $\mathrm{H}_{2} \mathrm{O}_{2}$ production.

In addition to carbon vacancies, nitrogen vacancies have also been developed to modify the intrinsic electronic structure to narrow the band gap and create more catalytically active sites for photocatalytic reactions. For instance, Zhang's group developed the thermal reduction treatment of $\mathrm{g}^{-} \mathrm{C}_{3} \mathrm{~N}_{4}$ in the presence of $\mathrm{NaBH}_{4}$ to introduce nitrogen vacancies through the formation of $\mathrm{C} \equiv \mathrm{N}$ functional groups. ${ }^{132}$ This structural change resulted in the narrowing of the band gap and the positive shift of the band edge, thus extending the light absorption within the visible-light region, and facilitating water oxidation and a selective two-electron ORR for $\mathrm{H}_{2} \mathrm{O}_{2}$ production. The optimal reduced g- $\mathrm{C}_{3} \mathrm{~N}_{4}$ photocatalyst exhibited an $\mathrm{H}_{2} \mathrm{O}_{2}$ productivity of $170 \mu \mathrm{mol} \mathrm{L}{ }^{-1} \mathrm{~h}^{-1}$ with a solar-to- $\mathrm{H}_{2} \mathrm{O}_{2}$ chemical conversion efficiency of $0.26 \%$ and AQY of $4.3 \%$ under visible-light illumination without organic electron donors. Besides, nitrogen vacancies have been successfully in situ embedded into g- $\mathrm{C}_{3} \mathrm{~N}_{4}$ moieties through dielectric barrier discharge (DBD) plasma under an $\mathrm{H}_{2}$ atmosphere. ${ }^{130}$ Compared with the direct annealing treatment under an $\mathrm{H}_{2}$ atmosphere, $\mathrm{H}_{2}$ plasma treatment can achieve more nitrogen vacancies embedded in $\mathrm{g}-\mathrm{C}_{3} \mathrm{~N}_{4}$ moieties, which facilitated the adsorption of $\mathrm{O}_{2}$ molecules and the transfer of photo-generated electrons for the subsequent two-electron ORR. Nevertheless, these methods have inherent shortcomings such as high energy consumption and explosive potential. In this case, Ye's group reported a novel photo-assisted thermal reduction route for the preparation of holey defective g- $\mathrm{C}_{3} \mathrm{~N}_{4}$ photocatalysts (Fig. 8). ${ }^{131}$ The developed method could achieve the introduction of abundant nitrogen vacancies and holey structure within the $\mathrm{g}-\mathrm{C}_{3} \mathrm{~N}_{4}$ photocatalyst simultaneously, thus facilitating the increase of the visible-light absorption range, the separation of photogenerated electrons and holes, and the accessibility of reactants to the surface active sites. The optimal holey defective g- $\mathrm{C}_{3} \mathrm{~N}_{4}$ (DCN) photocatalysts show ten-fold enhanced photocatalytic activity for $\mathrm{H}_{2} \mathrm{O}_{2}$ production compared to pristine bulk g- $\mathrm{C}_{3} \mathrm{~N}_{4}(\mathrm{BCN})$.

Recent research demonstrated that the introduction of oxygen function groups (- $\mathrm{COOH}$ and $\mathrm{C}-\mathrm{O}-\mathrm{C})$ and other heteroatom doping into carbon frameworks can significantly improve the selective electrochemical two-electron ORR for $\mathrm{H}_{2} \mathrm{O}_{2}$ production. ${ }^{3}$ Similarly, the doping of earth-abundant heteroatoms (potassium, phosphorus, oxygen, and fluorine) into the $\mathrm{C}_{3} \mathrm{~N}_{4}$ framework was reported to improve the efficiency of photocatalytic $\mathrm{H}_{2} \mathrm{O}_{2}$ production through the formation of photo-generated charge trapping sites on the surface of the $\mathrm{g}-\mathrm{C}_{3} \mathrm{~N}_{4}$ photocatalyst. Zhu's group prepared oxygen-enriched $\mathrm{g}-\mathrm{C}_{3} \mathrm{~N}_{4}$ (OCN) using ammonium para-tungstate and dicyandiamide, ${ }^{21}$ which exhibited a 3.5-fold higher AQY for $\mathrm{H}_{2} \mathrm{O}_{2}$ production of $10.2 \%$ at $420 \mathrm{~nm}$ compared to pristine bulk $\mathrm{g}^{-} \mathrm{C}_{3} \mathrm{~N}_{4}$ due to the relatively easy formation of 1,4-endoperoxide species and the highly selective ORR to $\mathrm{H}_{2} \mathrm{O}_{2}$. Potassium-, phosphorus-, and oxygen-doped g- $\mathrm{C}_{3} \mathrm{~N}_{4}$ can also be successfully prepared through the one-pot thermal polymerization of urea or melamine in the presence of phosphates. ${ }^{38}$ The incorporation of these heteroatoms resulted in the narrowing of the band gap, the increase of the generation, transfer, and lifetime of photogenerated electrons and holes, and the inhibition of the decomposition of the produced $\mathrm{H}_{2} \mathrm{O}_{2}$, thus achieving high AQY for $\mathrm{H}_{2} \mathrm{O}_{2}$ production.

Chemical modification with electron-deficient or $\pi$-conjugated organic monomers was another efficient way to improve the photocatalytic performances of g- $\mathrm{C}_{3} \mathrm{~N}_{4}$ for $\mathrm{H}_{2} \mathrm{O}_{2}$ production. For instance, the incorporation of pyromellitic diimide (PDI) with high electron affinity into the lattice network of $\mathrm{g}-\mathrm{C}_{3} \mathrm{~N}_{4}$, which was achieved by a facile thermal condensation of melem and pyromellitic dianhydride (PMDA), resulted in the simultaneous positive shift of the valence and conduction band edge, thus promoting water oxidation and maintaining a highly selective two-electron ORR for $\mathrm{H}_{2} \mathrm{O}_{2}$ production. ${ }^{135}$ Subsequently, graphene with high charge carrier mobility was also introduced into the $\mathrm{g}-\mathrm{C}_{3} \mathrm{~N}_{4} / \mathrm{PDI}$ moiety by a hydrothermalcalcination process (Fig. 9a-c) ${ }^{20}$ The introduction of graphene facilitated the transfer of photo-generated electrons from 

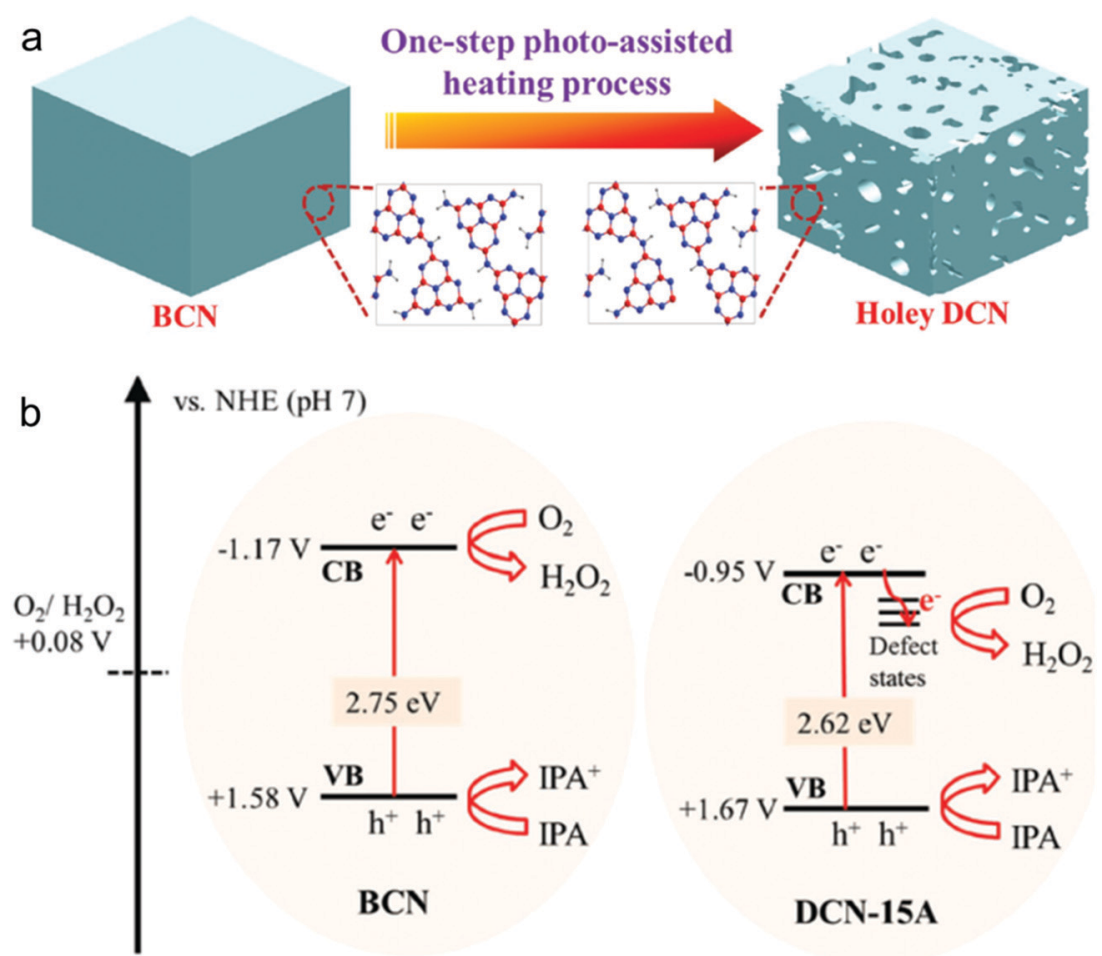

Fig. 8 (a) Illustration of the preparation process of holey DCN, and the insets are the simulated structure $(\mathrm{H}, \mathrm{C}$, and $\mathrm{N}$ atoms are represented by the gray, red, and blue balls) and (b) schematic of mechanisms underlying the photoexcited dynamics involved in photocatalytic $\mathrm{H}_{2} \mathrm{O}_{2}$ evolution over $\mathrm{BCN}$ and DCN-15A. Reprinted with permission. ${ }^{131}$ Copyright 2018 Wiley-VCH.

$\mathrm{g}^{-} \mathrm{C}_{3} \mathrm{~N}_{4} / \mathrm{PDI}$ to graphene and then promoted the selective twoelectron ORR for $\mathrm{H}_{2} \mathrm{O}_{2}$ production on the graphene moiety. In order to further improve the photocatalytic activity for $\mathrm{H}_{2} \mathrm{O}_{2}$ production, layered boron nitride (BN) was also introduced into the above hybrid catalyst of $g-\mathrm{C}_{3} \mathrm{~N}_{4} / \mathrm{PDI} /$ graphene to promote the transfer of photo-generated electrons and holes to graphene and $\mathrm{BN}$, thus promoting the two-electron ORR for $\mathrm{H}_{2} \mathrm{O}_{2}$ production on the surface of graphene and water oxidation on the surface of $\mathrm{BN}$, respectively. ${ }^{136}$ Meanwhile, they also utilized three-directional mellitic triimide (MTI) and biphenyl diimide (BDI) units as a substitute for PDI to incorporate into the $\mathrm{g}-\mathrm{C}_{3} \mathrm{~N}_{4}$ moiety to promote $\mathrm{H}_{2} \mathrm{O}_{2}$ production from the viewpoint of enhanced electrical conductivity and charge separation. ${ }^{39,70}$

Polyoxometalates (POMs), consisting of cations and polyanion clusters, were reported to produce a hole center $\left(\mathrm{O}^{-}\right)$and trapped electron center $\left(\mathrm{M}^{(n-1)+}\right)$ pair as electron acceptors and donors through the charge transfer between $\mathrm{O}^{2-}$ and $\mathrm{M}^{n+}(n=5,6)$ under light illumination, making them promising guest molecules for chemical modification of the $\mathrm{g}-\mathrm{C}_{3} \mathrm{~N}_{4}$ host. Based on this point, Zhu's group demonstrated the covalent combination of a POM cluster of $\left[\mathrm{PW}_{11} \mathrm{O}_{39}\right]^{7-}\left(\mathrm{PW}_{11}\right)$ with three dimensionally ordered macroporous (3DOM) g- $\mathrm{C}_{3} \mathrm{~N}_{4}$ through the reaction between the amine groups of the $\mathrm{g}-\mathrm{C}_{3} \mathrm{~N}_{4}$ framework and (triethoxysilyl)-propyl isocyanate (Fig. 9d). ${ }^{139}$ The resultant $3 \mathrm{DOM}$ g- $\mathrm{C}_{3} \mathrm{~N}_{4} / \mathrm{PW}_{11}$ hybrid photocatalyst exhibited efficient photocatalytic $\mathrm{H}_{2} \mathrm{O}_{2}$ production without the use of organic electron donors, which was attributed to the suppressed one-electron $\mathrm{ORR}$ to ${ }^{\bullet} \mathrm{OOH}$ and the promoted charge separation and two-electron ORR to $\mathrm{H}_{2} \mathrm{O}_{2}$. Later, they applied a similar organic linker strategy to fabricate the hybrid catalyst of a POM cluster of $\left[\mathrm{SiW}_{11} \mathrm{O}_{39}\right]^{8-}\left(\mathrm{SiW}_{11}\right)$ possessing a more negative $\mathrm{CB}$ edge and $\mathrm{g}-\mathrm{C}_{3} \mathrm{~N}_{4}$ containing more amine groups obtained by thermal decomposition of urea. ${ }^{138}$ Recently, Zhao's group reported the incorporation of POM-derived metal oxides into the $\mathrm{g}-\mathrm{C}_{3} \mathrm{~N}_{4}$ framework by the thermal treatment of the $\mathrm{g}-\mathrm{C}_{3} \mathrm{~N}_{4}$ precursor and the POM precursor. ${ }^{140,141}$ The incorporation of POM-derived metal oxides resulted in the negative shift of the CB edge of $\mathrm{g}-\mathrm{C}_{3} \mathrm{~N}_{4}$ and thus promoted the one-electron ORR to - $\mathrm{OOH}$, whereas it is also thermodynamically favored to oxidize - OOH by photo-generated holes to singlet oxygen $\left({ }^{1} \mathrm{O}_{2}\right)$, both of which can promote photocatalytic $\mathrm{H}_{2} \mathrm{O}_{2}$ production. A similar effect was also achieved through the covalent combination of carbon nanotubes (CNTs) with $\mathrm{g}-\mathrm{C}_{3} \mathrm{~N}_{4}$ because of their unique $\pi$-conjugated structure capable of accepting, transporting and storing electrons. ${ }^{143}$

The hybridization of $\mathrm{g}-\mathrm{C}_{3} \mathrm{~N}_{4}$ with catalytically active metal nanoparticles (NPs) as a co-catalyst has also been used to improve the photocatalytic performances for $\mathrm{H}_{2} \mathrm{O}_{2}$ production by promoting the separation efficiency of photo-generated electrons and holes. For instance, loading $\mathrm{Au}$ nanoparticles on the surface of $\mathrm{g}-\mathrm{C}_{3} \mathrm{~N}_{4}$ resulted in highly efficient and stable $\mathrm{H}_{2} \mathrm{O}_{2}$ production because of the favorable two-electron ORR and the inert nature for catalyzing the decomposition of the produced $\mathrm{H}_{2} \mathrm{O}_{2}$ over the hybrid catalyst. ${ }^{144,145}$ As a noble-metalfree co-catalyst, CoP has also been loaded on the surface of 

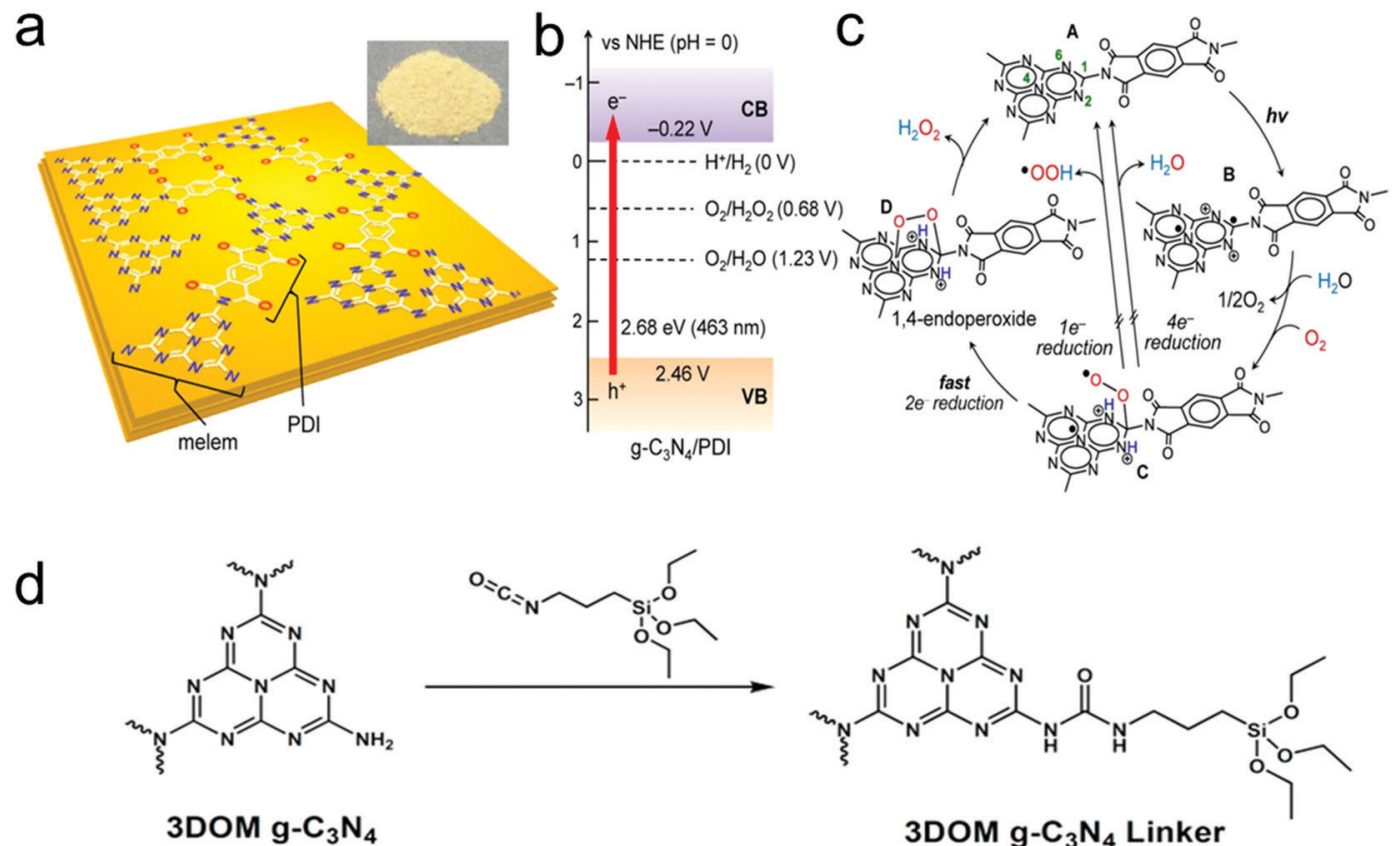

$3 \mathrm{DOM} \mathrm{g-C} \mathrm{N}_{4}$

3DOM g- $\mathrm{C}_{3} \mathrm{~N}_{4}$ Linker
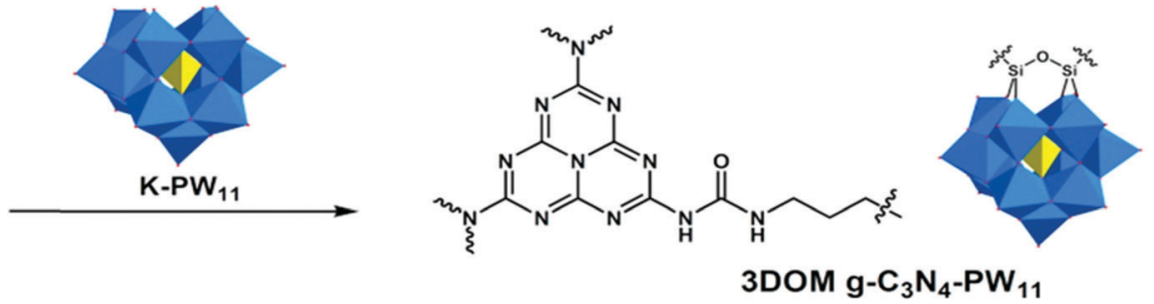

Fig. 9 (a-c) g- $\mathrm{C}_{3} \mathrm{~N}_{4} / \mathrm{PDI}$ structures and mechanism for photocatalytic $\mathrm{H}_{2} \mathrm{O}_{2}$ production: (a) three-dimensional structure, (b) electronic band structure of g- $\mathrm{C}_{3} \mathrm{~N}_{4} / \mathrm{PDI}$ (containing $51 \% \mathrm{PDI}$ units), and (c) mechanism of photocatalytic $\mathrm{H}_{2} \mathrm{O}_{2}$ production. (d) Preparation process of $3 D O M$ g- $\mathrm{C}_{3} \mathrm{~N}_{4}-\mathrm{PW} \mathrm{W}_{11}$. (a-c) Reprinted with permission. ${ }^{20}$ Copyright 2016 American Chemical Society. (d) Reprinted with permission. ${ }^{139}$ Copyright 2017 Elsevier Ltd.

g- $\mathrm{C}_{3} \mathrm{~N}_{4}$ to improve the photocatalytic $\mathrm{H}_{2} \mathrm{O}_{2}$ production efficiency under visible-light illumination by extending the light absorption range and promoting charge separation and electron transfer. ${ }^{146}$

Last but not least, a new type of photoelectrochemical (PEC) system without an external bias has also been developed to simultaneously achieve the generation of $\mathrm{H}_{2} \mathrm{O}_{2}$ and electricity in recent years. ${ }^{174,175}$ Generally, the PEC configuration for $\mathrm{H}_{2} \mathrm{O}_{2}$ production can be divided into three categories based on where $\mathrm{H}_{2} \mathrm{O}_{2}$ was produced, at the cathode, anode, or both. Early research demonstrated the indirect ORR for $\mathrm{H}_{2} \mathrm{O}_{2}$ production through the photoelectrochemical reduction of anthraquinone derivative molecules followed by reaction with $\mathrm{O}_{2}$ (Fig. 10a). ${ }^{170,176,177}$ Nevertheless, for this kind of configuration, the use of organic solvents is unavoidable and the energy conversion efficiency is low, arising from sluggish electrode kinetics, which hinders wide application from the viewpoint of sustainability. Recently, the direct ORR to $\mathrm{H}_{2} \mathrm{O}_{2}$ has also been achieved with high Faradaic efficiency and decent photocurrent on a dye-sensitized $\mathrm{NiO}$ photocathode in aqueous electrolyte, ${ }^{171,178}$ where photo-generated electron-hole pairs from the excited dye upon illumination performed fast hole injection into $\mathrm{NiO}$ and one-electron transfer to $\mathrm{O}_{2}$ for the formation of ${ }^{\bullet} \mathrm{OOH}$, followed by reaction with a proton and disproportionation into hydrogen peroxide in protic electrolytes (Fig. 10b). It should be highlighted here that the design of dye molecules has a significant effect on the energy conversion efficiency and electrode stability. Currently, the investigated dye molecules mainly include porphyrin, coumarin, and ruthenium dyes, and $\mathrm{BH} 4$ dye (a kind of hydrophobic donor-double-acceptor dye). In addition, some organic polymeric semiconductors, like polyterthiophene (pTTh), ${ }^{179}$ polymeric metal salen-type complexes, ${ }^{180}$ poly-tetrakis-5,10,15,20-(4-aminophenyl)porphyrin (pTAPP) and its cobalt derivative (pCoTAPP), ${ }^{173}$ have been directly explored as efficient photocathodes without dye sensitization for $\mathrm{H}_{2} \mathrm{O}_{2}$ production via the two-electron ORR (Fig. 10c and d). In order to further optimize the performances, an organic hetero-junction photocathode comprising phthalocyanine and tetracarboxylic perylenediimide has been developed, which exhibited continuous generation of high concentrations of peroxide with the Faradaic efficiency remaining at around $70 \% .{ }^{174}$ Besides, cathodic $\mathrm{H}_{2} \mathrm{O}_{2}$ production has also been performed in such a PEC configuration, where semiconductor photocatalysts were used as photoanodes to drive water oxidation, and electrocatalysts as cathodes to promote the selective twoelectron ORR for $\mathrm{H}_{2} \mathrm{O}_{2}$ production. ${ }^{5,172,181,182}$ For instance, Fukuzumi's group systematically investigated $\mathrm{WO}_{3}$ and $\mathrm{BiVO}_{4}$ 
a
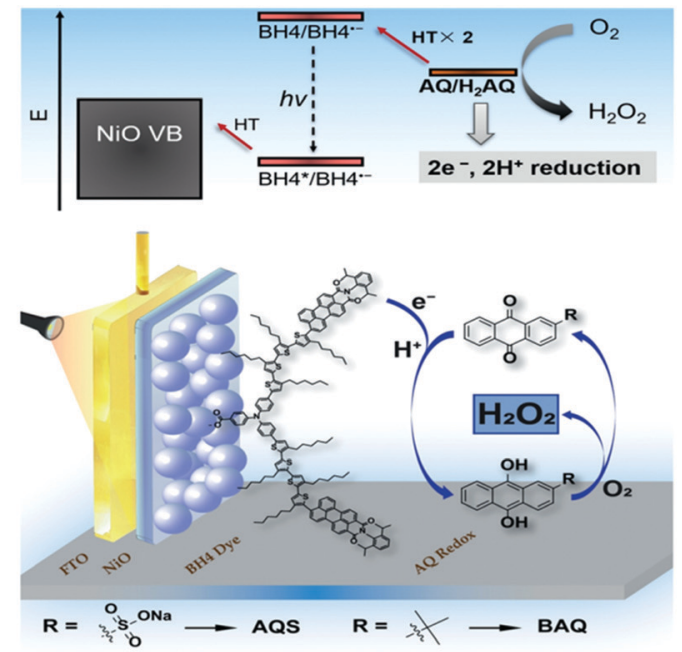

C

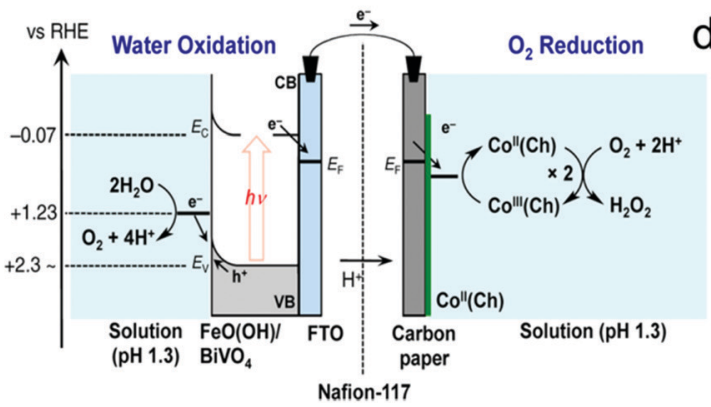

b
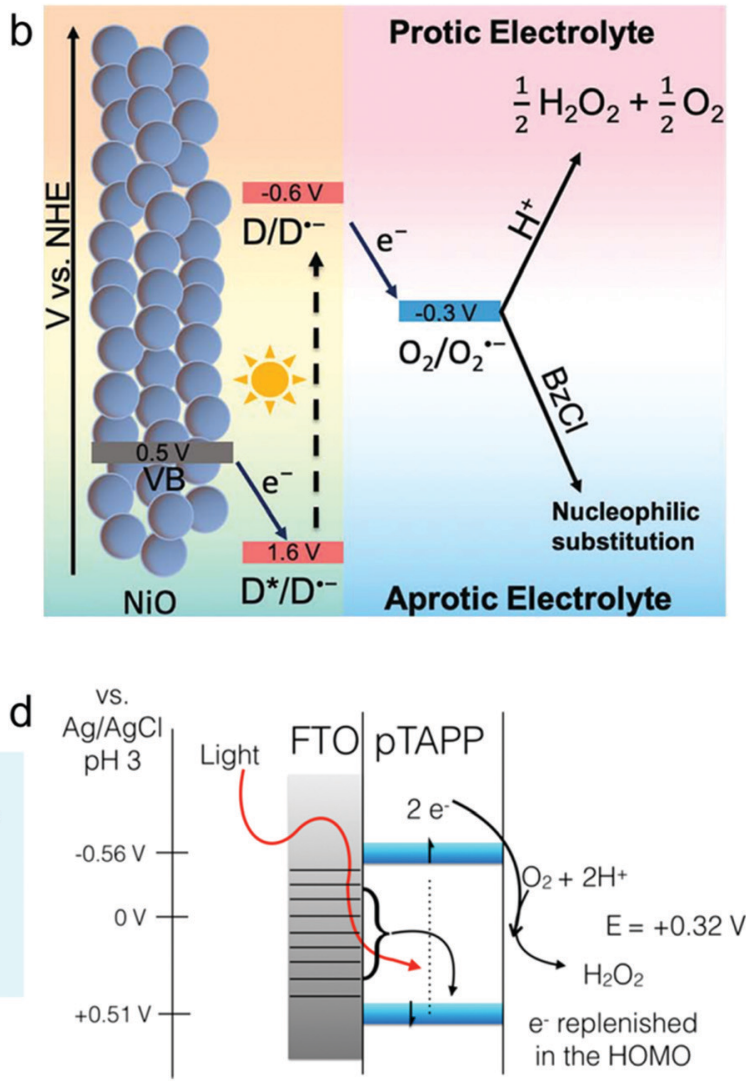

Fig. 10 (a) Illustration of the working principle of dye sensitized photo-electrochemical cells (DSPECs) for $\mathrm{H}_{2} \mathrm{O}_{2}$ production by using $A Q$ redox mediators (a, top), and the corresponding schematic representation (a, bottom). (b) Schematic representation of the DSPECs for $\mathrm{H}_{2} \mathrm{O}_{2}$ production in protic electrolyte and nucleophilic substitution in aprotic electrolyte. (c) Schematic reaction diagram of a photoelectrochemical cell for hydrogen peroxide production. (d) Band gap diagram showing photoresponse behaviors in the photosynthetic reduction of oxygen by pTAPP. (a) Reprinted with permission. ${ }^{170}$ Copyright 2020 Wiley-VCH. (b) Reprinted from Chemical Science, ${ }^{171}$ published by The Royal Society of Chemistry. (c) Reprinted with permission. ${ }^{172}$ Copyright 2016 American Chemical Society. (d) Reprinted with permission. ${ }^{173}$ Copyright 2017 American Chemical Society.

as a durable photoanode with a cobalt chlorine complex supported on a glassy carbon substrate as a cathode to construct a two-compartment PEC cell separated by a Nafion membrane for efficient $\mathrm{H}_{2} \mathrm{O}_{2}$ production from water and $\mathrm{O}_{2}$ under solar illumination. ${ }^{5,172}$ Especially, when iron(III) oxide(hydroxide) $(\mathrm{FeO}(\mathrm{OH}))$ was modified as a water oxidation catalyst on the surface of $\mathrm{BiVO}_{4}$, the produced $\mathrm{H}_{2} \mathrm{O}_{2}$ with a high concentration up to $61 \mathrm{mM}$ can be used directly as a fuel to generate electricity in an $\mathrm{H}_{2} \mathrm{O}_{2}$ fuel cell. ${ }^{172}$

On the other hand, $\mathrm{H}_{2} \mathrm{O}_{2}$ production has also been reported through two-electron water oxidation over semiconductor photoanodes. $^{40,185-189}$ For instance, Sayama's group reported the production and accumulation of $\mathrm{H}_{2} \mathrm{O}_{2}$ through two-electron water oxidation using a $\mathrm{WO}_{3} / \mathrm{BiVO}_{4}$ photoanode with simultaneous $\mathrm{H}_{2}$ production on a Pt cathode in an aqueous solution of $\mathrm{KHCO}_{3}$ at an applied voltage far lower than the theoretical electrolysis voltage under simulated solar light. ${ }^{40}$ Particularly, $\mathrm{H}_{2} \mathrm{O}_{2}$ formation was proposed through the hydrolysis of percarbonate intermediates $\left(\mathrm{HCO}_{4}{ }^{-}\right.$and $\left.\mathrm{C}_{2} \mathrm{O}_{6}{ }^{2-}\right)$ from the oxidation of $\mathrm{HCO}_{3}{ }^{-}$by the photo-generated holes within $\mathrm{BiVO}_{4}$. Moreover, highly concentrated $\mathrm{HCO}_{3}{ }^{-}$could effectively suppress the oxidation degradation of the produced $\mathrm{H}_{2} \mathrm{O}_{2}$. In order to further improve the selective $\mathrm{H}_{2} \mathrm{O}_{2}$ production by two-electron water oxidation, the surface modification of the $\mathrm{WO}_{3} / \mathrm{BiVO}_{4}$ photoanode with an $\mathrm{Al}_{2} \mathrm{O}_{3}$ layer has also been developed by the metal-organic decomposition method and chemical vapor deposition method to suppress the oxidative decomposition of the produced $\mathrm{H}_{2} \mathrm{O}_{2}$, thus leading to high Faradaic efficiency for $\mathrm{H}_{2} \mathrm{O}_{2}$ production. ${ }^{68,185}$ Further, the introduction of Au-supported fluorine-doped tin oxide (FTO) glass or ordered mesoporous carbon as a substitute for the Pt cathode into the above system successfully achieved the simultaneous production of $\mathrm{H}_{2} \mathrm{O}_{2}$ and electricity without the need for an external bias from both sides of the PEC cell through the two-electron ORR and two-electron water oxidation (Fig. 11), respectively. ${ }^{183,184}$

\section{Conclusions and perspectives}

$\mathrm{H}_{2} \mathrm{O}_{2}$ plays an essential role in the fields of chemical industry, environmental treatment, and sustainable energy conversion/ storage. Therefore, the development of efficient, energy-saving and sustainable methods for $\mathrm{H}_{2} \mathrm{O}_{2}$ production is of great significance and urgency to address the contradiction between 

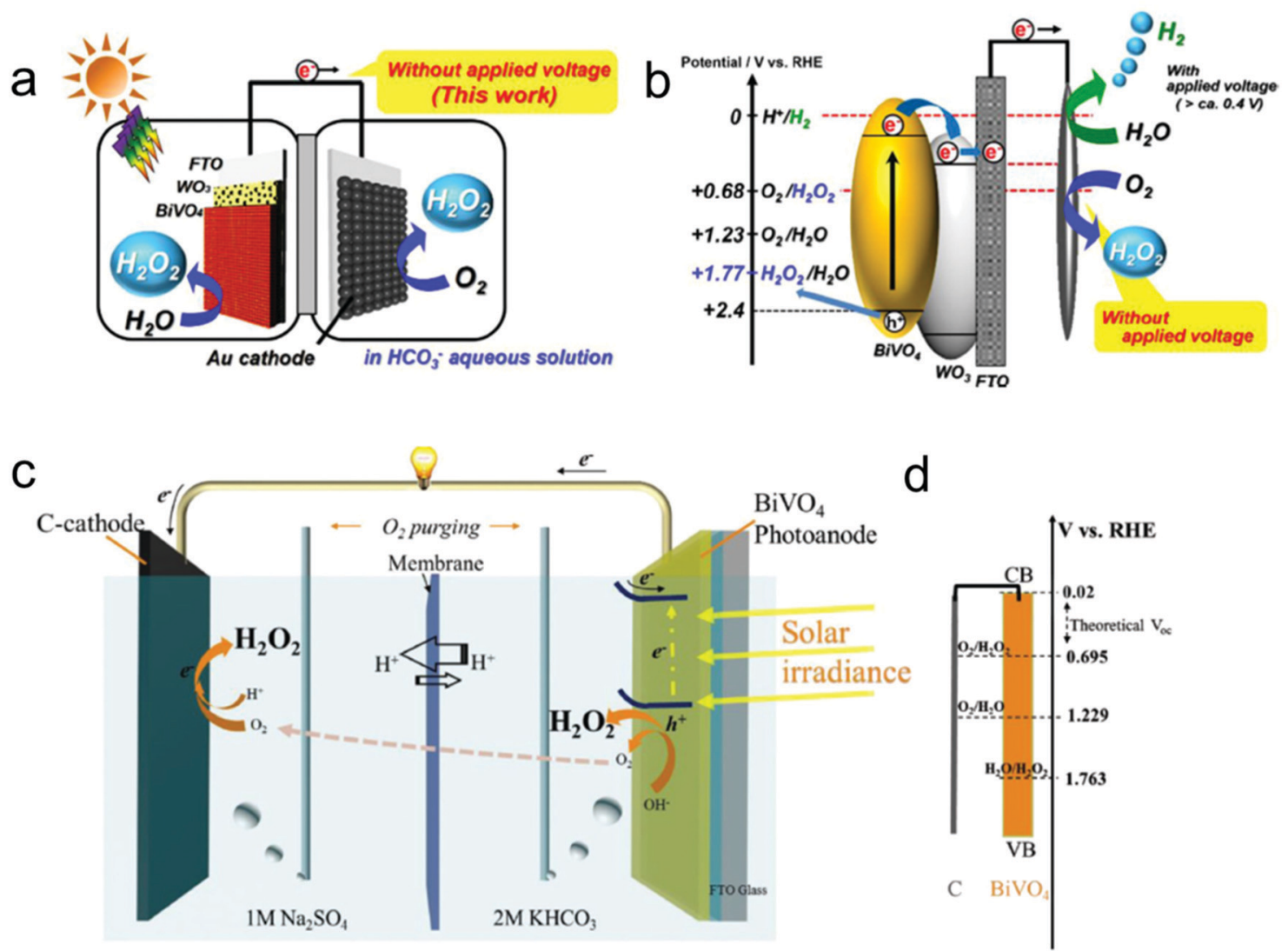

Fig. 11 (a) Diagram of the photoelectrode system for producing only $\mathrm{H}_{2} \mathrm{O}_{2}$ by using a two-electron oxidation system of $\mathrm{H}_{2} \mathrm{O}$ on a $\mathrm{WO}_{3} / \mathrm{BiVO}_{4}$ photoanode under solar light irradiation; (b) energy diagram of the photoelectrode systems; (c) schematic illustration of the design of a light-driven fuel cell with spontaneous $\mathrm{H}_{2} \mathrm{O}_{2}$ generation; and (d) the band diagram of the system. The conduction band (CB) and valence band (VB) edge positions of $\mathrm{BiVO}_{4}$ straddle the redox potentials of $\mathrm{O}_{2} / \mathrm{H}_{2} \mathrm{O}_{2}$ and $\mathrm{H}_{2} \mathrm{O} / \mathrm{H}_{2} \mathrm{O}_{2}$, suggesting the possibility of unassisted $\mathrm{H}_{2} \mathrm{O}_{2}$ production. The theoretical $V_{\text {oc }}$ for the light-driven fuel cell is $0.693 \mathrm{~V}$, estimated from the $\mathrm{CB}$ of $\mathrm{BiVO}_{4}$ and the $\mathrm{O}_{2} / \mathrm{H}_{2} \mathrm{O}_{2}$ redox potential. (a and b) Reprinted with permission. ${ }^{183} \mathrm{Copyright} 2017$ Wiley-VCH. (c and d) Reprinted with permission. ${ }^{184}$ Copyright 2018 Wiley-VCH.

the growing $\mathrm{H}_{2} \mathrm{O}_{2}$ demand and market, on one side, and the severe unsustainability of today's industrial production methods, on the other. Future $\mathrm{H}_{2} \mathrm{O}_{2}$ production pathways involving either electrochemical or photochemical approaches are currently considered most promising and sustainable, because only water, $\mathrm{O}_{2}$, solar energy or electricity from renewable power sources are involved during the entire process. The key challenge lies in the development of new scalable catalysts with low-cost, high efficiency and excellent electrochemical stability. In the past few years, various catalysts have been widely studied from the viewpoint of both electrochemical and photochemical $\mathrm{H}_{2} \mathrm{O}_{2}$ production, including ORR electrocatalysts such as noble-metal-based materials, transition-metalbased materials, and metal-free carbon-based materials, and semiconductor photocatalysts such as metal oxides, metalorganic complexes, and metal-free graphitic carbon nitride. Recent advances have been summarized herein. Importantly, upon comparing various ORR electrocatalysts and semiconductor photocatalysts, it becomes obvious that most strategies that have been explored to improve the catalyst activity and selectivity for $\mathrm{H}_{2} \mathrm{O}_{2}$ production largely follow two aspects, that is, geometric structural engineering and electronic structure engineering.
Geometric structure engineering of catalysts can be achieved through accurately controlling the morphology of both ORR electrocatalysts and semiconductor photocatalysts. Electronic structure engineering of ORR electrocatalysts, on the other hand, can be achieved through surface passivation or alloying with inactive elements, single-atom dispersion, and surface heteroatom doping, whereas for semiconductor photocatalysts, electronic structure engineering can be achieved through selfmodification by the introduction of carbon or nitrogen vacancies and heteroatom doping, chemical modification with electron-deficient or $\pi$-conjugated organic monomers and POMs, hybridization with other materials such as noble metal and carbon materials, and surface passivation by anion and cations. Besides, the simultaneous generation of $\mathrm{H}_{2} \mathrm{O}_{2}$ and electricity can also be achieved by the combination of semiconductor photocatalysts as photoanodes with ORR electrocatalysts as cathodes in photoelectrochemical systems.

Generally, there are three different reaction intermediates during the ORR and WOR processes for $\mathrm{H}_{2} \mathrm{O}_{2}$ production, including $\mathrm{HOO}^{*}, \mathrm{O}^{*}$, and $\mathrm{HO}^{*}$. According to Sabatier's principle, the optimal catalyst for $\mathrm{H}_{2} \mathrm{O}_{2}$ production should possess balanced binding of $\mathrm{HOO}^{*}$ on the surface of the catalyst during the ORR 
process, whereas balanced binding of $\mathrm{HO}^{*}$ during the WOR process. In reported studies, most of them mainly focused on tuning the binding of the reaction intermediates through coating a carbon layer on the surface of catalysts, forming single metal atoms dispersed on the support, or regulating the composition of the catalyst like the formation of alloys comprising reactive metals with inactive metals, making the overall reaction pathway favorable for the two-electron pathway. In addition, optimizing the morphological structure of catalysts has been reported as an efficient method to promote $\mathrm{H}_{2} \mathrm{O}_{2}$ production. For instance, the mass transport within a mesoporous structure favored the fast release of the produced $\mathrm{H}_{2} \mathrm{O}_{2}$ from the surface of the catalyst, thus avoiding the subsequent reduction of $\mathrm{H}_{2} \mathrm{O}_{2}$. Besides, for photocatalytic systems, the experimental conditions have a certain effect on the reaction intermediates during the $\mathrm{H}_{2} \mathrm{O}_{2}$ production process. For instance, using benzylic alcohols as electron donors was reported to result in the formation of new reaction intermediates, coordinated peroxo species, which facilitated $\mathrm{H}_{2} \mathrm{O}_{2}$ production.

Even though there are some significant advances in the development of both electrocatalytic and photocatalytic $\mathrm{H}_{2} \mathrm{O}_{2}$ production over various nanostructured heterogeneous catalysts, there remains a grand challenge to further improve their performances prior to commercialization becoming industrially viable and economical. Future work in this area should focus on the following aspects.

\subsection{Exploiting further improved catalytic materials}

Seeking materials with new compositions and structures is still at the heart of research work on electrocatalytic and photocatalytic $\mathrm{H}_{2} \mathrm{O}_{2}$ production. To date, the developed noble-metalbased materials are considered to be most efficient ORR electrocatalysts for $\mathrm{H}_{2} \mathrm{O}_{2}$ production, but their inherent disadvantages of high cost and scarcity significantly hamper their practical industrial application. In view of cost reduction, it is thus urgently needed that ORR electrocatalysts with low-cost and high efficiency are developed. Recently, $\mathrm{H}_{2} \mathrm{O}_{2}$ production by two-electron water oxidation over metal oxides has also shown great potential application in the field of water electrolysis, capable of the simultaneous generation of two important valuable products of $\mathrm{H}_{2} \mathrm{O}_{2}$ and $\mathrm{H}_{2}$ in a single electrochemical system using water as the only raw material. ${ }^{109,110,190}$ Nevertheless, very few kinds of metal oxides were explored, such as $\mathrm{ZnO}, \mathrm{WO}_{3}, \mathrm{SnO}_{2}, \mathrm{BiVO}_{4}$, and $\mathrm{TiO}_{2}$, and thus considerable efforts need to be made for the development of other metal oxides and beyond. For photocatalytic $\mathrm{H}_{2} \mathrm{O}_{2}$ production, considering that UV light only accounts for $\mathrm{ca}$. $4 \%$ and also induces $\mathrm{H}_{2} \mathrm{O}_{2}$ decomposition, it is thus essential to design and develop visible-light-driven photocatalysts with highly selective promotion of the two-electron ORR to produce $\mathrm{H}_{2} \mathrm{O}_{2}$ and efficient suppression of subsequent decomposition of the produced $\mathrm{H}_{2} \mathrm{O}_{2}$, thus enhancing the SCC efficiency. Nevertheless, the reported visible-light-driven photocatalysts such as $\mathrm{BiVO}_{4}$ and g- $\mathrm{C}_{3} \mathrm{~N}_{4}$ still have some critical issues including sluggish kinetics of water oxidation and unsatisfactory stability. In addition, careful observation demonstrates that the only difference between photocatalytic $\mathrm{H}_{2} \mathrm{O}_{2}$ production and photocatalytic water splitting lies in the surface redox reaction process. This point provides a possibility for the integration of the existing photocatalysts for water splitting with two-electron ORR and water oxidation electrocatalysts as co-catalysts to achieve highly efficient $\mathrm{H}_{2} \mathrm{O}_{2}$ production.

\subsection{Mechanistic investigations}

The introduction of porous structure and heteroatom doping has been reported to play an important role in improving the capability of carbon-based materials for electrochemical $\mathrm{H}_{2} \mathrm{O}_{2}$ production through the two-electron ORR. However, the precise role of the pore size and heteroatom doping species is still unclear and even conflicting. Similarly, the introduction of metal catalytically active sites into nitrogen-doped carbon materials can further improve the catalytic performances through the formation of metal-coordinated metal- $\mathrm{N}_{x}-\mathrm{C}$ moieties, but there have also been conflicting opinions on which coordination number is more favorable for the two-electron ORR for $\mathrm{H}_{2} \mathrm{O}_{2}$ production. For photocatalytic $\mathrm{H}_{2} \mathrm{O}_{2}$ production, most studies demonstrated the negative effect of the one-electron ORR on the efficiency of the ORR and $\mathrm{H}_{2} \mathrm{O}_{2}$ production, and thus various methods have been developed to suppress the one-electron ORR by the positive shift of the $\mathrm{CB}$ edge within semiconductor photocatalysts. Nevertheless, recent research also reported the negative shift of the $\mathrm{CB}$ edge of $\mathrm{g}-\mathrm{C}_{3} \mathrm{~N}_{4}$-based catalysts to enhance the one-electron $\mathrm{ORR}$ for ${ }^{\bullet} \mathrm{OOH}$ formation and thus promote the sequential two-step one-electron ORR for $\mathrm{H}_{2} \mathrm{O}_{2}$ production. Besides, the type of electron donor used has been found to play distinct roles in influencing the ORR reaction pathways in photocatalytic systems, but the detailed reason is still unknown and thus requires further study. All in all, more studies are needed to understand the nature of active sites and the reaction pathways, and how they contribute to the high catalytic performances for $\mathrm{H}_{2} \mathrm{O}_{2}$ production, which provides guidance for the design of novel catalytic systems for electrochemical and photochemical $\mathrm{H}_{2} \mathrm{O}_{2}$ production.

\subsection{Scalable photo-/electro-chemical interfaces and devices}

Most of the recently reported research work mainly evaluated the electrochemical performances of ORR electrocatalysts for $\mathrm{H}_{2} \mathrm{O}_{2}$ selectivity by the RRDE technique, whereas only a few studies about the practical $\mathrm{H}_{2} \mathrm{O}_{2}$ productivity in home-made two-compartment H-cells and flow cells were reported. Nevertheless, it should be highlighted that flow cells may be more relevant to a commercial scale $\mathrm{H}_{2} \mathrm{O}_{2}$ production system compared to $\mathrm{H}$-cells, providing a key stepping stone for the translation of fundamental lab discoveries into practice. In addition, the electrochemical systems discussed above generally produce a mixture of $\mathrm{H}_{2} \mathrm{O}_{2}$ and solutes in traditional liquid electrolytes, thus requiring extra separation processes for the purification of the produced $\mathrm{H}_{2} \mathrm{O}_{2}$ solutions. Recently, Wang's group produced a new strategy to achieve the direct electrochemical production of pure $\mathrm{H}_{2} \mathrm{O}_{2}$ solutions by using a porous solid electrolyte, and various concentrations of pure $\mathrm{H}_{2} \mathrm{O}_{2}$ solutions could be easily achieved by the change of the water flow rate. ${ }^{1}$ Based on this point, we expect more widespread use of solid electrolytes in PEC systems for simultaneous generation of $\mathrm{H}_{2} \mathrm{O}_{2}$ and electricity. 
Anyway, the research based on such a thought is still in its infancy, and more work is needed.

\section{Conflicts of interest}

There are no conflicts to declare.

\section{Acknowledgements}

P. S. and Y. S. acknowledge financial support from FCH Joint Undertaking (CRESCENDO project, Grant Agreement No. 779366) and the German Ministry of Economics and Energy (BMWi) through project "ChemEFlex" (FKN 0350013A). L. H. gratefully acknowledges financial support from Fundamental Research Funds for the Central Universities (No. 531118010232) and Huxiang High-Level Talent Gathering Project of Hunan Province (No. 2019RS1012).

\section{References}

1 C. Xia, Y. Xia, P. Zhu, L. Fan and H. Wang, Science, 2019, 366, 226-231.

2 S. Siahrostami, A. Verdaguer-Casadevall, M. Karamad, D. Deiana, P. Malacrida, B. Wickman, M. EscuderoEscribano, E. A. Paoli, R. Frydendal, T. W. Hansen, I. Chorkendorff, I. E. Stephens and J. Rossmeisl, Nat. Mater., 2013, 12, 1137-1143.

3 Z. Lu, G. Chen, S. Siahrostami, Z. Chen, K. Liu, J. Xie, L. Liao, T. Wu, D. Lin, Y. Liu, T. F. Jaramillo, J. K. Nørskov and Y. Cui, Nat. Catal., 2018, 1, 156-162.

4 J. M. Campos-Martin, G. Blanco-Brieva and J. L. Fierro, Angew. Chem., Int. Ed., 2006, 45, 6962-6984.

5 K. Mase, M. Yoneda, Y. Yamada and S. Fukuzumi, Nat. Commun., 2016, 7, 11470.

6 L. Han, S. Guo, P. Wang and S. Dong, Adv. Energy Mater., 2015, 5, 1400424.

7 S. A. Mousavi Shaegh, N.-T. Nguyen, S. M. Mousavi Ehteshami and S. H. Chan, Energy Environ. Sci., 2012, 5, 8225.

8 J. K. Edwards, J. Pritchard, L. Lu, M. Piccinini, G. Shaw, A. F. Carley, D. J. Morgan, C. J. Kiely and G. J. Hutchings, Angew. Chem., Int. Ed., 2014, 53, 2381-2384.

9 S. Shibata, T. Suenobu and S. Fukuzumi, Angew. Chem., Int. Ed., 2013, 52, 12327-12331.

10 R. Arrigo, M. E. Schuster, S. Abate, G. Giorgianni, G. Centi, S. Perathoner, S. Wrabetz, V. Pfeifer, M. Antonietti and R. Schlögl, ACS Catal., 2016, 6, 6959-6966.

11 V. Paunovic, J. C. Schouten and T. A. Nijhuis, Appl. Catal., A, 2015, 505, 249-259.

12 I. Yamanaka, Y. Satake, P. Pantira, D. Hiraki and H. Ogihara, ChemistrySelect, 2017, 2, 464-468.

13 S. Yang, A. Verdaguer-Casadevall, L. Arnarson, L. Silvioli, V. Čolić, R. Frydendal, J. Rossmeisl, I. Chorkendorff and I. E. L. Stephens, ACS Catal., 2018, 8, 4064-4081.

14 Y. Liu, X. Quan, X. Fan, H. Wang and S. Chen, Angew. Chem., Int. Ed., 2015, 54, 6837-6841.
15 I. Yamanaka and T. Murayama, Angew. Chem., Int. Ed., 2008, 47, 1900-1902.

16 T. P. Fellinger, F. Hasche, P. Strasser and M. Antonietti, J. Am. Chem. Soc., 2012, 134, 4072-4075.

17 J. S. Jirkovsky, I. Panas, E. Ahlberg, M. Halasa, S. Romani and D. J. Schiffrin, J. Am. Chem. Soc., 2011, 133, 19432-19441.

18 Y. Sun, L. Silvioli, N. R. Sahraie, W. Ju, J. Li, A. Zitolo, S. Li, A. Bagger, L. Arnarson, X. Wang, T. Moeller, D. Bernsmeier, J. Rossmeisl, F. Jaouen and P. Strasser, J. Am. Chem. Soc., 2019, 141, 12372-12381.

19 W. Ju, A. Bagger, G. P. Hao, A. S. Varela, I. Sinev, V. Bon, B. Roldan Cuenya, S. Kaskel, J. Rossmeisl and P. Strasser, Nat. Commun., 2017, 8, 944.

20 Y. Kofuji, Y. Isobe, Y. Shiraishi, H. Sakamoto, S. Tanaka, S. Ichikawa and T. Hirai, J. Am. Chem. Soc., 2016, 138, 10019-10025.

21 Z. Wei, M. Liu, Z. Zhang, W. Yao, H. Tan and Y. Zhu, Energy Environ. Sci., 2018, 11, 2581-2589.

22 J. Song and S. Cho, APL Mater., 2020, 8, 050701.

23 Y. Nie, L. Li and Z. Wei, Chem. Soc. Rev., 2015, 44, 2168-2201.

24 P. Strasser, M. Gliech, S. Kuehl and T. Moeller, Chem. Soc. Rev., 2018, 47, 715-735.

25 D.-W. Wang and D. Su, Energy Environ. Sci., 2014, 7, 576.

26 R. Chattot, O. Le Bacq, V. Beermann, S. Kuhl, J. Herranz, S. Henning, L. Kuhn, T. Asset, L. Guetaz, G. Renou, J. Drnec, P. Bordet, A. Pasturel, A. Eychmuller, T. J. Schmidt, P. Strasser, L. Dubau and F. Maillard, Nat. Mater., 2018, 17, 827-833.

27 T. Najam, S. S. A. Shah, W. Ding, J. Jiang, L. Jia, W. Yao, L. Li and Z. Wei, Angew. Chem., Int. Ed., 2018, 57, 15101-15106.

28 I. Yamanaka, T. Onizawa, S. Takenaka and K. Otsuka, Angew. Chem., Int. Ed., 2003, 42, 3653-3655.

29 I. Yamanaka, S. Tazawa, T. Murayama, R. Ichihashi and N. Hanaizumi, ChemSusChem, 2008, 1, 988-992.

30 J.-y. Chen, L. Zhao, N. Li and H. Liu, J. Power Sources, 2015, 287, 291-296.

31 D. Ki, S. C. Popat, B. E. Rittmann and C. I. Torres, Environ. Sci. Technol., 2017, 51, 6139-6145.

32 https://www.hpnow.eu/\#.

33 S. Siahrostami, G. L. Li, V. Viswanathan and J. K. Norskov, J. Phys. Chem. Lett., 2017, 8, 1157-1160.

34 L. Han, S. Dong and E. Wang, Adv. Mater., 2016, 28, 9266-9291.

35 A. Torres-Pinto, M. J. Sampaio, C. G. Silva, J. L. Faria and A. M. T. Silva, Appl. Catal., B, 2019, 252, 128-137.

36 J. Lei, B. Chen, W. Lv, L. Zhou, L. Wang, Y. Liu and J. Zhang, ACS Sustainable Chem. Eng., 2019, 7, 16467-16473.

37 H. Hirakawa, S. Shiota, Y. Shiraishi, H. Sakamoto, S. Ichikawa and T. Hirai, ACS Catal., 2016, 6, 4976-4982.

38 G.-h. Moon, M. Fujitsuka, S. Kim, T. Majima, X. Wang and W. Choi, ACS Catal., 2017, 7, 2886-2895.

39 Y. Kofuji, S. Ohkita, Y. Shiraishi, H. Sakamoto, S. Ichikawa, S. Tanaka and T. Hirai, ACS Sustainable Chem. Eng., 2017, 5, 6478-6485. 
40 K. Fuku and K. Sayama, Chem. Commun., 2016, 52, 5406-5409.

41 M. Traube, Ber. Dtsch. Chem. Ges., 1887, 2, 1041-1050.

42 E. Berl, J. Electrochem., 1939, 76, 359.

43 R. M. Reis, A. A. G. F. Beati, R. S. Rocha, M. H. M. T. Assumpção, M. C. Santos, R. Bertazzoli and M. R. V. Lanza, Ind. Eng. Chem. Res., 2011, 51, 649-654.

44 J. F. Pérez, A. Galia, M. A. Rodrigo, J. Llanos, S. Sabatino, C. Sáez, B. Schiavo and O. Scialdone, Electrochim. Acta, 2017, 248, 169-177.

45 M. N. Young, M. J. Links, S. C. Popat, B. E. Rittmann and C. I. Torres, ChemSusChem, 2016, 9, 3345-3352.

46 E. Baur and C. Neuweiler, Helv. Chim. Acta, 1927, 10, 901-907.

47 V. Maurino, C. Minero, G. Mariella and E. Pelizzetti, Chem. Commun., 2005, 2627-2629.

48 G.-h. Moon, W. Kim, A. D. Bokare, N.-e. Sung and W. Choi, Energy Environ. Sci., 2014, 7, 4023-4028.

49 A. Bonakdarpour, T. R. Dahn, R. T. Atanasoski, M. K. Debe and J. R. Dahn, Electrochem. Solid-State Lett., 2008, 11, B208.

50 V. Viswanathan, H. A. Hansen, J. Rossmeisl and J. K. Norskov, J. Phys. Chem. Lett., 2012, 3, 2948-2951.

51 A. Verdaguer-Casadevall, D. Deiana, M. Karamad, S. Siahrostami, P. Malacrida, T. W. Hansen, J. Rossmeisl, I. Chorkendorff and I. E. Stephens, Nano Lett., 2014, 14, 1603-1608.

52 U. A. Paulus, T. J. Schmidt, H. A. Gasteiger and R. J. Behm, J. Electroanal. Chem., 2001, 495, 134-145.

53 D. R. Lawson, J. Electrochem. Soc., 1988, 135, 2247.

54 G. Yang, W. Choi, X. Pu and C. Yu, Energy Environ. Sci., 2015, 8, 1799-1807.

55 I. Yamanaka, T. Hashimoto, R. Ichihashi and K. Otsuka, Electrochim. Acta, 2008, 53, 4824-4832.

56 R. B. Valim, R. M. Reis, P. S. Castro, A. S. Lima, R. S. Rocha, M. Bertotti and M. R. V. Lanza, Carbon, 2013, 61, 236-244.

57 W. R. P. Barros, R. M. Reis, R. S. Rocha and M. R. V. Lanza, Electrochim. Acta, 2013, 104, 12-18.

58 J. Choi, S. H. Hwang, J. Jang and J. Yoon, Electrochem. Commun., 2013, 30, 95-98.

59 D. M. Weekes, D. A. Salvatore, A. Reyes, A. Huang and C. P. Berlinguette, Acc. Chem. Res., 2018, 51, 910-918.

60 M. Teranishi, S. Naya and H. Tada, J. Am. Chem. Soc., 2010, 132, 7850-7851.

61 R. Shen, W. Chen, Q. Peng, S. Lu, L. Zheng, X. Cao, Y. Wang, W. Zhu, J. Zhang, Z. Zhuang, C. Chen, D. Wang and Y. Li, Chemistry, 2019, 5, 2099-2110.

62 Z. Chen, S. Chen, S. Siahrostami, P. Chakthranont, C. Hahn, D. Nordlund, S. Dimosthenis, J. K. Nørskov, Z. Bao and T. F. Jaramillo, React. Chem. Eng., 2017, 2, 239-245.

63 Y. Sun, I. Sinev, W. Ju, A. Bergmann, S. Dresp, S. Kühl, C. Spöri, H. Schmies, H. Wang, D. Bernsmeier, B. Paul, R. Schmack, R. Kraehnert, B. Roldan Cuenya and P. Strasser, ACS Catal., 2018, 8, 2844-2856.

64 S. Y. Park, H. Abroshan, X. Shi, H. S. Jung, S. Siahrostami and X. Zheng, ACS Energy Lett., 2018, 4, 352-357.
65 J. H. Baek, T. M. Gill, H. Abroshan, S. Park, X. Shi, J. Nørskov, H. S. Jung, S. Siahrostami and X. Zheng, ACS Energy Lett., 2019, 4, 720-728.

66 D. Tsukamoto, A. Shiro, Y. Shiraishi, Y. Sugano, S. Ichikawa, S. Tanaka and T. Hirai, ACS Catal., 2012, 2, 599-603.

67 Y. Shiraishi, Y. Kofuji, H. Sakamoto, S. Tanaka, S. Ichikawa and T. Hirai, ACS Catal., 2015, 5, 3058-3066.

68 Y. Miyase, S. Takasugi, S. Iguchi, Y. Miseki, T. Gunji, K. Sasaki, E. Fujita and K. Sayama, Sustainable Energy Fuels, 2018, 2, 1621-1629.

69 H. Joo, Korean J. Chem. Eng., 2006, 23, 931-934.

70 Y. Kofuji, S. Ohkita, Y. Shiraishi, H. Sakamoto, S. Tanaka, S. Ichikawa and T. Hirai, ACS Catal., 2016, 6, 7021-7029.

71 C. H. Choi, H. C. Kwon, S. Yook, H. Shin, H. Kim and M. Choi, J. Phys. Chem. C, 2014, 118, 30063-30070.

72 A. Mahata and B. Pathak, Nanoscale, 2017, 9, 9537-9547.

73 A. von Weber, E. T. Baxter, H. S. White and S. L. Anderson, J. Phys. Chem. C, 2015, 119, 11160-11170.

74 K. Asakura, H. Nagahiro, N. Ichikuni and Y. Iwasawa, Appl. Catal., A, 1999, 188, 313-324.

75 B. Qiao, A. Wang, X. Yang, L. F. Allard, Z. Jiang, Y. Cui, J. Liu, J. Li and T. Zhang, Nat. Chem., 2011, 3, 634-641.

76 H. Wei, X. Liu, A. Wang, L. Zhang, B. Qiao, X. Yang, Y. Huang, S. Miao, J. Liu and T. Zhang, Nat. Commun., 2014, 5, 5634.

77 J. Deng, H. Li, J. Xiao, Y. Tu, D. Deng, H. Yang, H. Tian, J. Li, P. Ren and X. Bao, Energy Environ. Sci., 2015, 8, 1594-1601.

78 Y. H. Li, J. Xing, X. H. Yang and H. G. Yang, Chem. - Eur. J., 2014, 20, 12377-12380.

79 S. Yang, J. Kim, Y. J. Tak, A. Soon and H. Lee, Angew. Chem., Int. Ed., 2016, 55, 2058-2062.

80 S. Yang, Y. J. Tak, J. Kim, A. Soon and H. Lee, ACS Catal., 2017, 7, 1301-1307.

81 C. H. Choi, M. Kim, H. C. Kwon, S. J. Cho, S. Yun, H. T. Kim, K. J. Mayrhofer, H. Kim and M. Choi, Nat. Commun., 2016, 7, 10922.

82 Z. Zheng, Y. H. Ng, D. W. Wang and R. Amal, Adv. Mater., 2016, 28, 9949-9955.

83 A. Bonakdarpour, M. Lefevre, R. Yang, F. Jaouen, T. Dahn, J.-P. Dodelet and J. R. Dahn, Electrochem. Solid-State Lett., 2008, 11, B105.

84 A. Bonakdarpour, C. Delacote, R. Yang, A. Wieckowski and J. R. Dahn, Electrochem. Commun., 2008, 10, 611-615.

85 N. M. Wilson, P. Priyadarshini, S. Kunz and D. W. Flaherty, J. Catal., 2018, 357, 163-175.

86 F. V. E. dos Reis, V. S. Antonin, P. Hammer, M. C. Santos and P. H. C. Camargo, J. Catal., 2015, 326, 100-106.

87 S. Siahrostami, M. E. Bjorketun, P. Strasser, J. Greeley and J. Rossmeisl, Phys. Chem. Chem. Phys., 2013, 15, 9326-9334.

88 I. Yamanaka, S. Tazawa, T. Murayama, T. Iwasaki and S. Takenaka, ChemSusChem, 2010, 3, 59-62.

89 B. Q. Li, C. X. Zhao, J. N. Liu and Q. Zhang, Adv. Mater., 2019, 31, e1808173.

90 I. Yamanaka, R. Ichihashi, T. Iwasaki, N. Nishimura, T. Murayama, W. Ueda and S. Takenaka, Electrochim. Acta, 2013, 108, 321-329. 
91 E. Jung, H. Shin, B. H. Lee, V. Efremov, S. Lee, H. S. Lee, J. Kim, W. Hooch Antink, S. Park, K. S. Lee, S. P. Cho, J. S. Yoo, Y. E. Sung and T. Hyeon, Nat. Mater., 2020, 19, 436-442.

92 K. Jiang, S. Back, A. J. Akey, C. Xia, Y. Hu, W. Liang, D. Schaak, E. Stavitski, J. K. Norskov, S. Siahrostami and H. Wang, Nat. Commun., 2019, 10, 3997.

93 J. P. Paraknowitsch and A. Thomas, Energy Environ. Sci., 2013, 6, 2839.

94 J. Park, Y. Nabae, T. Hayakawa and M.-A. Kakimoto, ACS Catal., 2014, 4, 3749-3754.

95 F. Yu, M. Zhou, L. Zhou and R. Peng, Environ. Sci. Technol. Lett., 2014, 1, 320-324.

96 S. Chen, Z. Chen, S. Siahrostami, T. R. Kim, D. Nordlund, D. Sokaras, S. Nowak, J. W. F. To, D. Higgins, R. Sinclair, J. K. Nørskov, T. F. Jaramillo and Z. Bao, ACS Sustainable Chem. Eng., 2017, 6, 311-317.

97 Y.-H. Lee, F. Li, K.-H. Chang, C.-C. Hu and T. Ohsaka, Appl. Catal., B, 2012, 126, 208-214.

98 M. H. M. T. Assumpção, R. F. B. De Souza, D. C. Rascio, J. C. M. Silva, M. L. Calegaro, I. Gaubeur, T. R. L. C. Paixão, P. Hammer, M. R. V. Lanza and M. C. Santos, Carbon, 2011, 49, 2842-2851.

99 A. Moraes, M. H. M. T. Assumpção, F. C. Simões, V. S. Antonin, M. R. V. Lanza, P. Hammer and M. C. Santos, Electrocatalysis, 2015, 7, 60-69.

100 K. Gong, F. Du, Z. Xia, M. Durstock and L. Dai, Science, 2009, 323, 760-764.

101 D. Guo, R. Shibuya, C. Akiba, S. Saji, T. Kondo and J. Nakamura, Science, 2016, 351, 361-365.

102 Y. Yang, F. He, Y. Shen, X. Chen, H. Mei, S. Liu and Y. Zhang, Chem. Commun., 2017, 53, 9994-9997.

103 T. Xing, Y. Zheng, L. H. Li, B. C. Cowie, D. Gunzelmann, S. Z. Qiao, S. Huang and Y. Chen, ACS Nano, 2014, 8, 6856-6862.

104 L. Han, Y. Sun, S. Li, C. Cheng, C. E. Halbig, P. Feicht, J. L. Hübner, P. Strasser and S. Eigler, ACS Catal., 2019, 9, 1283-1288.

105 R. A. Sidik, A. B. Anderson, N. P. Subramanian, S. P. Kumaraguru and B. N. Popov, J. Phys. Chem. B, 2006, 110, 1787-1793.

106 D. Iglesias, A. Giuliani, M. Melchionna, S. Marchesan, A. Criado, L. Nasi, M. Bevilacqua, C. Tavagnacco, F. Vizza, M. Prato and P. Fornasiero, Chemistry, 2018, 4, 106-123.

107 Y. Sun, S. Li, Z. Jovanov, D. Bernsmeier, H. Wang, B. Paul, X. Wang, S. Kuehl and P. Strasser, ChemSusChem, 2018, 11, 3388-3395.

108 K. Zhao, Y. Su, X. Quan, Y. Liu, S. Chen and H. Yu, J. Catal., 2018, 357, 118-126.

109 X. Shi, S. Siahrostami, G. L. Li, Y. Zhang, P. Chakthranont, F. Studt, T. F. Jaramillo, X. Zheng and J. K. Norskov, Nat. Commun., 2017, 8, 701.

110 S. R. Kelly, X. Shi, S. Back, L. Vallez, S. Y. Park, S. Siahrostami, X. Zheng and J. K. Nørskov, ACS Catal., 2019, 9, 4593-4599.
111 A. Nadar, S. S. Gupta, Y. Kar, S. Shetty, A. P. van Bavel and D. Khushalani, J. Phys. Chem. C, 2020, 124, 4152-4161.

112 V. Viswanathan, H. A. Hansen and J. K. Norskov, J. Phys. Chem. Lett., 2015, 6, 4224-4228.

113 A. Fujishima and K. Honda, Nature, 1972, 238, 37-38.

$114 \mathrm{~J}$. Wu, Y. Huang, W. Ye and Y. Li, Adv. Sci., 2017, 4, 1700194.

115 T. Hisatomi, J. Kubota and K. Domen, Chem. Soc. Rev., 2014, 43, 7520-7535.

116 Y. Shiraishi, S. Kanazawa, D. Tsukamoto, A. Shiro, Y. Sugano and T. Hirai, ACS Catal., 2013, 3, 2222-2227.

117 M. Teranishi, R. Hoshino, S. Naya and H. Tada, Angew. Chem., Int. Ed., 2016, 55, 12773-12777.

118 L. Zheng, H. Su, J. Zhang, L. S. Walekar, H. Vafaei Molamahmood, B. Zhou, M. Long and Y. H. Hu, Appl. Catal., B, 2018, 239, 475-484.

119 V. Maurino, C. Minero, E. Pelizzetti, G. Mariella, A. Arbezzano and F. Rubertelli, Res. Chem. Intermed., 2007, 33, 319-332.

120 C. Chu, D. Huang, Q. Zhu, E. Stavitski, J. A. Spies, Z. Pan, J. Mao, H. L. Xin, C. A. Schmuttenmaer, S. Hu and J.-H. Kim, ACS Catal., 2018, 9, 626-631.

121 R. Ma, L. Wang, H. Wang, Z. Liu, M. Xing, L. Zhu, X. Meng and F.-S. Xiao, Appl. Catal., B, 2019, 244, 594-603.

122 T. Baran, S. Wojtyła, A. Minguzzi, S. Rondinini and A. Vertova, Appl. Catal., B, 2019, 244, 303-312.

123 Y. Isaka, Y. Kondo, Y. Kawase, Y. Kuwahara, K. Mori and H. Yamashita, Chem. Commun., 2018, 54, 9270-9273.

124 Y. Isaka, Y. Kawase, Y. Kuwahara, K. Mori and H. Yamashita, Angew. Chem., Int. Ed., 2019, 58, 5402-5406.

125 H. Zhuang, L. Yang, J. Xu, F. Li, Z. Zhang, H. Lin, J. Long and X. Wang, Sci. Rep., 2015, 5, 16947.

$126 \mathrm{~J} . \mathrm{Xu}, \mathrm{Z}$. Chen, H. Zhang, G. Lin, H. Lin, X. Wang and J. Long, Sci. Bull., 2017, 62, 610-618.

127 Y. Shiraishi, S. Kanazawa, Y. Sugano, D. Tsukamoto, H. Sakamoto, S. Ichikawa and T. Hirai, ACS Catal., 2014, 4, 774-780.

128 S. Li, G. Dong, R. Hailili, L. Yang, Y. Li, F. Wang, Y. Zeng and C. Wang, Appl. Catal., B, 2016, 190, 26-35.

129 R. Wang, X. Zhang, F. Li, D. Cao, M. Pu, D. Han, J. Yang and X. Xiang, J. Energy Chem., 2018, 27, 343-350.

130 X. Qu, S. Hu, P. Li, Z. Li, H. Wang, H. Ma and W. Li, Diamond Relat. Mater., 2018, 86, 159-166.

131 L. Shi, L. Yang, W. Zhou, Y. Liu, L. Yin, X. Hai, H. Song and J. Ye, Small, 2018, 14.

132 Z. Zhu, H. Pan, M. Murugananthan, J. Gong and Y. Zhang, Appl. Catal., B, 2018, 232, 19-25.

133 S. Kim, G.-H. Moon, H. Kim, Y. Mun, P. Zhang, J. Lee and W. Choi, J. Catal., 2018, 357, 51-58.

134 J. Tian, T. Wu, D. Wang, Y. Pei, M. Qiao and B. Zong, Catal. Today, 2019, 330, 171-178.

135 Y. Shiraishi, S. Kanazawa, Y. Kofuji, H. Sakamoto, S. Ichikawa, S. Tanaka and T. Hirai, Angew. Chem., Int. Ed., 2014, 53, 13454-13459.

136 Y. Kofuji, Y. Isobe, Y. Shiraishi, H. Sakamoto, S. Ichikawa, S. Tanaka and T. Hirai, ChemCatChem, 2018, 10, 2070-2077. 
137 L. Yang, G. Dong, D. L. Jacobs, Y. Wang, L. Zang and C. Wang, J. Catal., 2017, 352, 274-281.

138 S. Zhao, X. Zhao, S. Ouyang and Y. Zhu, Catal. Sci. Technol., 2018, 8, 1686-1695.

139 S. Zhao, X. Zhao, H. Zhang, J. Li and Y. Zhu, Nano Energy, 2017, 35, 405-414.

140 S. Zhao and X. Zhao, J. Catal., 2018, 366, 98-106.

141 S. Zhao and X. Zhao, Appl. Catal., B, 2019, 250, 408-418.

142 R. Wang, K. Pan, D. Han, J. Jiang, C. Xiang, Z. Huang, L. Zhang and X. Xiang, ChemSusChem, 2016, 9, 2470-2479.

143 S. Zhao, T. Guo, X. Li, T. Xu, B. Yang and X. Zhao, Appl. Catal., B, 2018, 224, 725-732.

144 X. Chang, J. Yang, D. Han, B. Zhang, X. Xiang and J. He, Catalysts, 2018, 8, 147.

145 G. Zuo, S. Liu, L. Wang, H. Song, P. Zong, W. Hou, B. Li, Z. Guo, X. Meng, Y. Du, T. Wang and V. A. L. Roy, Catal. Commun., 2019, 123, 69-72.

146 Y. Peng, L. Wang, Y. Liu, H. Chen, J. Lei and J. Zhang, Eur. J. Inorg. Chem., 2017, 4797-4802.

147 S. Gogoi and N. Karak, Nano-Micro Lett., 2017, 9, 40.

148 B. Weng, J. Wu, N. Zhang and Y. J. Xu, Langmuir, 2014, 30, 5574-5584.

149 C. Wang, M. Long, B. Tan, L. Zheng, J. Cai and J. Fu, Electrochim. Acta, 2017, 250, 108-116.

150 R. Cai, Y. Kubota and A. Fujishima, J. Catal., 2003, 219, 214-218.

151 H. Furukawa, K. E. Cordova, M. O’Keeffe and O. M. Yaghi, Science, 2013, 341, 1230444.

152 J. Della Rocca, D. Liu and W. Lin, Acc. Chem. Res., 2011, 44, 957-968.

153 L. E. Kreno, K. Leong, O. K. Farha, M. Allendorf, R. P. Van Duyne and J. T. Hupp, Chem. Rev., 2012, 112, 1105-1125.

154 J. Lee, O. K. Farha, J. Roberts, K. A. Scheidt, S. T. Nguyen and J. T. Hupp, Chem. Soc. Rev., 2009, 38, 1450-1459.

155 L. Han, X. Y. Yu and X. W. Lou, Adv. Mater., 2016, 28, 4601-4605.

156 M. Wen, K. Mori, Y. Kuwahara and H. Yamashita, ACS Energy Lett., 2016, 2, 1-7.

157 Y. Fu, D. Sun, Y. Chen, R. Huang, Z. Ding, X. Fu and Z. Li, Angew. Chem., Int. Ed., 2012, 51, 3364-3367.

158 M. Wen, K. Mori, T. Kamegawa and H. Yamashita, Chem. Commun., 2014, 50, 11645-11648.

159 Y. Kuwahara, H. Kango and H. Yamashita, ACS Sustainable Chem. Eng., 2016, 5, 1141-1152.

160 J. Collén, M. J. Del Rio, G. García-Reina and M. Pedersén, Planta, 1995, 196, 225-230.

161 X. Wang, K. Maeda, A. Thomas, K. Takanabe, G. Xin, J. M. Carlsson, K. Domen and M. Antonietti, Nat. Mater., 2009, 8, 76-80.

162 J. Liu, Y. Liu, N. Liu, Y. Han, X. Zhang, H. Huang, Y. Lifshitz, S. T. Lee, J. Zhong and Z. Kang, Science, 2015, 347, 970-974.

163 K. Schwinghammer, M. B. Mesch, V. Duppel, C. Ziegler, J. Senker and B. V. Lotsch, J. Am. Chem. Soc., 2014, 136, 1730-1733.

164 D. Zheng, X. N. Cao and X. Wang, Angew. Chem., Int. Ed., 2016, 55, 11512-11516.
165 Y. Wang, X. Wang and M. Antonietti, Angew. Chem., Int. Ed., 2012, 51, 68-89.

166 Y. He, L. Zhang, B. Teng and M. Fan, Environ. Sci. Technol., 2015, 49, 649-656.

167 P. Niu, Y. Yang, J. C. Yu, G. Liu and H. M. Cheng, Chem. Commun., 2014, 50, 10837-10840.

168 S. Cao, J. Low, J. Yu and M. Jaroniec, Adv. Mater., 2015, 27, 2150-2176.

169 H. Zhang, L. Zhao, F. Geng, L.-H. Guo, B. Wan and Y. Yang, Appl. Catal., B, 2016, 180, 656-662.

170 J. Sun and Y. Wu, Angew. Chem., Int. Ed., 2020, 59, 10904-10908.

171 J. Sun, Y. Yu, A. E. Curtze, X. Liang and Y. Wu, Chem. Sci., 2019, 10, 5519-5527.

172 K. Mase, M. Yoneda, Y. Yamada and S. Fukuzumi, ACS Energy Lett., 2016, 1, 913-919.

173 N. U. Day and C. C. Wamser, J. Phys. Chem. C, 2017, 121, 11076-11082.

174 M. Gryszel, A. Markov, M. Vagin and E. D. Głowacki, J. Mater. Chem. A, 2018, 6, 24709-24716.

175 X. Zong, H. Chen, B. Seger, T. Pedersen, M. S. Dargusch, E. W. McFarland, C. Li and L. Wang, Energy Environ. Sci., 2014, 7, 3347-3351.

176 G. S. Calabrese and M. S. Wrighton, J. Electrochem. Soc., 1981, 128, 1014-1018.

177 G. S. Calabrese, R. M. Buchanan and M. S. Wrighton, J. Am. Chem. Soc., 1983, 105, 5594-5600.

178 O. Jung, M. L. Pegis, Z. Wang, G. Banerjee, C. T. Nemes, W. L. Hoffeditz, J. T. Hupp, C. A. Schmuttenmaer, G. W. Brudvig and J. M. Mayer, J. Am. Chem. Soc., 2018, 140, 4079-4084.

179 W. Fan, B. Zhang, X. Wang, W. Ma, D. Li, Z. Wang, M. Dupuis, J. Shi, S. Liao and C. Li, Energy Environ. Sci., 2020, 13, 238-245.

180 A. S. Konev, M. Y. Kayumov, M. P. Karushev, Y. V. Novoselova, D. A. Lukyanov, E. V. Alekseeva and O. V. Levin, ChemElectroChem, 2018, 5, 3138-3142.

181 I. Papagiannis, E. Doukas, A. Kalarakis, G. Avgouropoulos and P. Lianos, Catalysts, 2019, 9, 243.

182 F. Ye, T. Wang, X. Quan, H. Yu and S. Chen, Chem. Eng. J., 2020, 389, 123427.

183 K. Fuku, Y. Miyase, Y. Miseki, T. Funaki, T. Gunji and K. Sayama, Chem. - Asian J., 2017, 12, 1111-1119.

184 X. Shi, Y. Zhang, S. Siahrostami and X. Zheng, Adv. Energy Mater., 2018, 8, 1801158.

185 K. Fuku, Y. Miyase, Y. Miseki, T. Gunji and K. Sayama, RSC Adv., 2017, 7, 47619-47623.

186 J. Zhang, X. Chang, Z. Luo, T. Wang and J. Gong, Chem. Commun., 2018, 54, 7026-7029.

187 Y. Miyase, S. Takasugi, S. Iguchi, Y. Miseki, T. Gunji, K. Sasaki, E. Fujita and K. Sayama, Sustainable Energy Fuels, 2018, 2, 1621-1629.

188 T. Baran, S. Wojtyła, A. Vertova, A. Minguzzi and S. Rondinini, J. Electroanal. Chem., 2018, 808, 395-402.

189 T. H. Jeon, H. Kim, H.-I. Kim and W. Choi, Energy Environ. Sci., 2020, 13, 1730-1742.

190 K. Fuku, Y. Miyase, Y. Miseki, T. Gunji and K. Sayama, ChemistrySelect, 2016, 1, 5721-5726. 